\title{
The Scourge of Aflatoxins in Kenya: A 60-Year Review (1960 to 2020)
}

\author{
Timothy Omara ${ }^{(D,},{ }^{1,2,3}$ Ambrose K Kiprop ${ }^{(D,},{ }^{1,2}$ Phanice Wangila, ${ }^{4}$ Alex Paul Wacoo ${ }^{1 D},{ }^{5}$ \\ Sarah Kagoya $\left(\mathbb{D},{ }^{6}\right.$ Papias Nteziyaremye $\mathbb{D}^{1,2}$ Mark Peter Odero ${ }^{10},{ }^{1,2}$ \\ Caroline Kiwanuka Nakiguli $\mathbb{D}^{1,2,7}$ and Samuel Baker Obakiro $\mathbb{D}^{1,2,8}$
}

${ }^{1}$ Department of Chemistry and Biochemistry, School of Sciences and Aerospace Studies, Moi University, Uasin Gishu County, P.O. Box 3900, Eldoret, Kenya

${ }^{2}$ Africa Center of Excellence II in Phytochemicals, Textiles and Renewable Energy (ACE II PTRE), Moi University, Uasin Gishu County, P.O. Box 3900, Eldoret, Kenya

${ }^{3}$ Department of Quality Control and Quality Assurance, Product Development Directory, AgroWays Uganda Limited, Plot 34-60, Kyabazinga Way, P.O. Box 1924, Jinja, Uganda

${ }^{4}$ Department of Physical Sciences, University of Kabianga, P.O. Box 2030, Kericho, Kenya

${ }^{5}$ Department of Medical Biochemistry, School of Biomedical Sciences, College of Health Sciences, Makerere University, P. O. Box 7026, Kampala, Uganda

${ }^{6}$ Department of Quality Control and Quality Assurance, Sweets and Confectionaries Section, Kakira Sugar Limited, P.O. Box 121, Jinja, Uganda

${ }^{7}$ Chemistry Department, Faculty of Science, Mbarara University of Science and Technology, P.O. Box 1410, Mbarara, Uganda

${ }^{8}$ Department of Pharmacology and Therapeutics, Faculty of Health Sciences, Busitema University, P.O. Box 1460, Mbale, Uganda

Correspondence should be addressed to Timothy Omara; prof.timo2018@gmail.com

Received 30 May 2020; Revised 4 September 2020; Accepted 3 February 2021; Published 18 February 2021

Academic Editor: Luis Patarata

Copyright (C) 2021 Timothy Omara et al. This is an open access article distributed under the Creative Commons Attribution License, which permits unrestricted use, distribution, and reproduction in any medium, provided the original work is properly cited.

\begin{abstract}
Aflatoxins are endemic in Kenya. The 2004 outbreak of acute aflatoxicosis in the country was one of the unprecedented epidemics of human aflatoxin poisoning recorded in mycotoxin history. In this study, an elaborate review was performed to synthesize Kenya's major findings in relation to aflatoxins, their prevalence, detection, quantification, exposure assessment, prevention, and management in various matrices. Data retrieved indicate that the toxins are primarily biosynthesized by Aspergillus flavus and A. parasiticus, with the eastern part of the country reportedly more aflatoxin-prone. Aflatoxins have been reported in maize and maize products (Busaa, chan'gaa, githeri, irio, muthokoi, uji, and ugali), peanuts and its products, rice, cassava, sorghum, millet, yams, beers, dried fish, animal feeds, dairy and herbal products, and sometimes in tandem with other mycotoxins. The highest total aflatoxin concentration of $58,000 \mu \mathrm{g} / \mathrm{kg}$ has been reported in maize. At least 500 acute human illnesses and 200 deaths due to aflatoxins have been reported. The causes and prevalence of aflatoxins have been grossly ascribed to poor agronomic practices, low education levels, and inadequate statutory regulation and sensitization. Low diet diversity has aggravated exposure to aflatoxins in Kenya because maize as a dietetic staple is aflatoxin-prone. Detection and surveillance are only barely adequate, though some exposure assessments have been conducted. There is a need to widen diet diversity as a measure of reducing exposure due to consumption of aflatoxin-contaminated foods.
\end{abstract}

\section{Introduction}

Mycotoxins constitute a family of secondary metabolites biosynthesized by fungi from genera Penicillium, Aspergillus, and Fusarium [1]. They contaminate various agricultural commodities prior to or after harvest [2]. Deoxynivalenol (DON), aflatoxins (AFs), ochratoxins, zearalenone (ZEA), T-2 toxins, and fumonisins (FUMs) are some of the 
mycotoxins of toxicological priority in foods $[3,4]$. In developing countries, AFs and FUMs pose the greatest threat $[4,5]$. At least 4 billion people in Third World countries are recurrently exposed to AFs [6], and the statutory standards for AFs in foods negatively impact the economic growth of such nations [7-9].

Aflatoxins are a group of mycotoxins produced by at least 20 fungal strains of Aspergillus section Flavi, Nidulantes, and Ochraceorosei $[10,11]$. Their discovery and recognition are traced back to 1960 in which Turkey "X" disease was reported in England with several poults lost to the toxins after feeding on a contaminated peanut ration $[12,13]$. AFs were eventually recovered in East Africa (Kenya and Uganda) in peanut rations that caused substantial losses in ducklings $[14,15]$. AFs are chemically polysubstituted coumarins with very similar chemical structures [16]. About 20 different types have been reported, and aflatoxin $B_{1}\left(A_{F} B_{1}\right)$, aflatoxin $G_{1}\left(A F G_{1}\right)$, aflatoxin $\mathrm{M}_{1}\left(\mathrm{AFM}_{1}\right)$, aflatoxin $\mathrm{B}_{2}\left(\mathrm{AFB}_{2}\right)$, and aflatoxin $\mathrm{G}_{2}\left(\mathrm{AFG}_{2}\right)$ are of demonstrated toxicological importance [17]. The B-type AFs are pentanone derivatives that show strong blue fluorescence under UV light. On the other hand, the G-series AFs are six-membered lactones that fluoresce yellow-green under UV light and thus the $\mathrm{B}$ and $\mathrm{G}$ nomenclature $[2,18]$. Aflatoxin $\mathrm{G}_{2}$ and $\mathrm{B}_{2}$ are congeners of $G_{1}$ and $B_{1}$ which lack the 8,9-double bond in the furan ring and therefore usually only encountered in tandem with the latter [19]. Aflatoxins $M_{1}$ and $M_{2}$ are metabolic derivatives of $B_{1}$ and $B_{2}$ that exhibit blue-violet fluorescence and are usually detected in urine and milk of animals served $\mathrm{AFB}_{1}$-contaminated rations $[20,21]$.

Aflatoxins are mutagenic, genotoxic, immunosuppressive, carcinogenic, and teratogenic [17] in the order $\mathrm{AFG}_{2}<\mathrm{AFB}_{2}<\mathrm{AFG}_{1}<\mathrm{AFM}_{1}<\mathrm{AFB}_{1}$ [22-24] (Figure 1). This order reflects the role of epoxidation of the 8,9double bond and the unique potency of cyclopentenone ring in B-type AFs [25]. The mutagenic and carcinogenic effects of $\mathrm{AFB}_{1}$ and other $\mathrm{AFs}$ possessing double bonds between $\mathrm{C}_{8}$ and $\mathrm{C}_{9}$ in the furan ring have been ascribed to their hepatic bioactivation to the intermediate metabolite $\left(\mathrm{AFB}_{1}-8,9\right.$-epoxide) [26-30]. The reaction is catalyzed by polymorphic cytochrome $\mathrm{P} 450$ enzymes $[28,31]$. $\mathrm{AFB}_{1}{ }^{-}$ 8,9 -epoxide is an unstable mutagen [32] that covalently interacts with nucleophilic sites of cellular macromolecules such as nucleic acids (principally DNA and RNA), inducing irreversible signaling and genetic, metabolic, and cell configuration dysregulations [26, 33-36]. Details of how AFs induce mutagenicity and carcinogenicity have been discussed in sufficient details in previous studies $[28,37]$.

Mutegi et al. [38] published a review on the prevalence and strategies for mitigation of AFs in Kenya from 1960 to 2018. Since then, more than 15 studies on AFs have been undertaken in Kenya. The current review digests the scourge of AFs in Kenya from 1960 to the present, highlighting the progresses in the occurrence, detection, quantification, and exposure assessment. Prevention and control measures as well as evidence-based management strategies are discussed.

\section{Occurrence of Aflatoxins in Kenya}

2.1. Causative Fungi and Prevalence of Aflatoxins. Aflatoxins in Kenya are predominantly produced by $A s-$ pergillus parasiticus and A. flavus [39-49]. The latter is a universal fungus known to produce $\mathrm{AFB}_{1}$ and $\mathrm{AFB}_{2}$ along with aspergillic, cyclopiazonic, and kojic acids [50]. A. parasiticus produces both $\mathrm{B}$ and $\mathrm{G}$ AFs plus kojic and aspergillic acids [50-52]. A. niger, A. terreus, and $A$. versicolor were reported in soils and mill dust in Eastern Kenya [40]. Further, the occurrence of A. alliaceus, A. tamarii, and A. caelatus in Kenya has been echoed $[44,53,54]$. A genetic profiling study reported that A. minisclerotigenes in Eastern Kenya exhibited a higher AF biosynthesis potential than A. flavus [42]. Though both the L- and S-strain morphologies of Aspergillus section Flavi have been reported, probing aetiological studies revealed that aflatoxicoses associated with maize consumption in Kenya have been due to a novel S-morphology fungus previously implicated for the 2004-2006 aflatoxicosis outbreaks $[39,55,56]$. Overall, A. flavus is considered the primary producer of AFs in agricultural commodities with an optimal growth temperature of $25^{\circ} \mathrm{C}$ and a minimum water activity of 0.75 . AF biosynthesis, however, starts at $10-12^{\circ} \mathrm{C}[57]$.

Kenya possesses an erratic tropical climate characterized by periodic droughts, high humidity, and high temperatures preceding harvests [58]. The climate is tropical along the coast, temperate inland, and arid in the north and northeast. The country has distinct seasons: March to June with long rains and October to December with intermittent rains. It has four marked climatic zones, further partitioned into agroecological zones contingent on the rain and temperature conditions suitable for the staple crops. The Central Highlands and the Rift Valley are blessed with fertile soils, rainfall of up to $3000 \mathrm{~mm}$ per annum, and temperatures of $21^{\circ} \mathrm{C}$ to $26^{\circ} \mathrm{C}$. On the other hand, the western part of the country is hot and remains wet throughout. Rain received is more than $1000 \mathrm{~mm}$ per annum with temperatures of $27^{\circ} \mathrm{C}$ to $29^{\circ} \mathrm{C}$. North and eastern parts are relatively hot with annual rains lower than $510 \mathrm{~mm}$ and temperatures which occasionally reach $39^{\circ} \mathrm{C}$ in some areas [58].

Poor grain conditioning before storage, use of propylene storage bags, drying of grain on bare grounds, insect infestation, poor storage structures (stores with leaking roofs), poor transportation, and handling of produce as well as chronic poverty have been incriminated for the aflatoxigenic contamination of Kenyan foods [3, 59-68]. Contamination has also been due to the cultivation of maize in ecologically predisposed regions of the country [69-73]. Biophysical factors (including soil, plant genetic constitution and susceptibility, and fungal community), low education levels, inadequate sensitization, and gender have also favoured the spread of AFs in Kenya $[60,67,74-76]$. On toxicological studies, $\mathrm{AFB}_{1}$ is by far the most studied AF in Kenya, followed by $\mathrm{AFM}_{1}$ [38]. Thus, most studies reported on the levels of $\mathrm{AFB}_{1}, \mathrm{AFM}_{1}$, or total AFs. It is worth noting that because of the aflatoxicoses that dawned several times on the country, a number of 


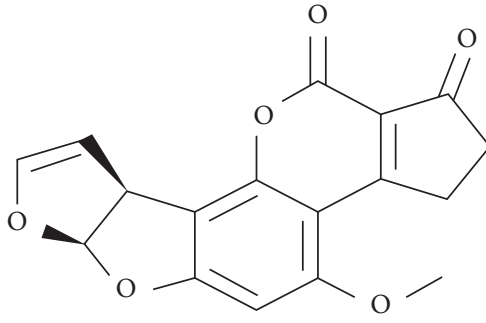

(a)

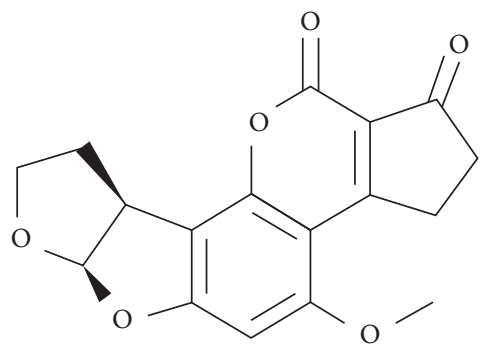

(d)

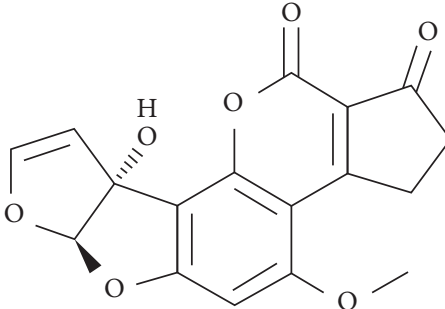

(b)<smiles>COc1cc2c(c3oc(=O)c4c(c13)CCOC4=O)C1C=COC1O2</smiles>

(c)

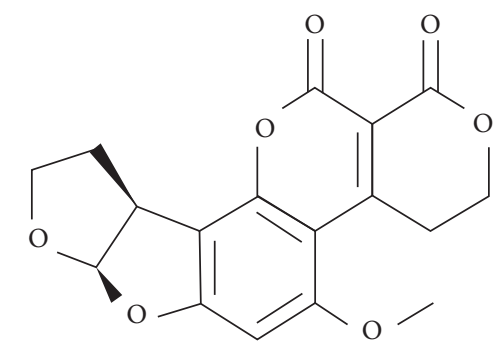

(e)

Figure 1: Structure of major AFs of toxicological concern: (a) $\mathrm{AFB}_{1}$; (b) $\mathrm{AFM}_{1}$; (c) $\mathrm{AFG}_{1}$; (d) $\mathrm{AFB}_{2}$; (e) $\mathrm{AFG}_{2}$.

investigations have been undertaken, with often alarming AF levels reported [38, 63, 70, 77-79].

2.2. Commodities Contaminated. Aflatoxins in Kenya have been reported to contaminate staple foods such as maize (Zea mays L.) and its products (Busaa, chan'gaa, githeri, irio, muthokoi, uji, and ugali) $[8,40,41,45,54,63,66,77,80]$, sorghum (Sorghum bicolor L.) [66, 76, 80], millet (Eleusine coracana) $[76,81]$, pigeon peas and their local products $[80,82,83]$, peanuts and its products $[53,61,62,80,84]$, cassava, rice, and dried silverfish (Rastrineobola argentea, locally called omena) [80, 85], animal feeds $[73,86]$, dairy products (milk, yoghurt, and Lala) [57, 66, 87-90], and herbal products [91]. Research on AFs in Kenya has concentrated mostly on maize, peanuts, animal feeds, and dairy products, particularly milk [92]. Despite their ubiquitous presence in foods, food processing techniques cannot completely destroy AFs in precontaminated foodstuffs owing to their heat-proof nature [93].

2.2.1. Cereals and Cereal-Based Products. Maize, millet, and sorghum are Kenyan staples for specific regions. Maize is the main dietary staple $[94,95]$. Subsistence farmers stock maize under various suboptimal conditions for more than 3 months prior to use or sale [96]. Maize is often for home consumption as flour or used for making irio and githeri (a traditional dish of maize mixed with legumes or pulses such as beans, pigeon peas, and cowpeas, usually cooked whole), though some may be sold [8]. Approximately $60 \%$ of the maize are processed for consumption using hammer mills [40,97]. It was previously echoed that maize consumption is the primary route through which Africans have been chronically exposed to AFs [98-100]. On the other hand, sorghum and millet are grown primarily in the semiarid regions of the country and are consumed mainly as flours used for the preparation of thick porridge (ugali) and thin porridge (uji). Uji is an ingredient of infant weaning foods and diet for children [9].

In Kenya, maize meal consumption is estimated at $400 \mathrm{~g} /$ person/day with an average total AF content of $0.132 \mu \mathrm{g} / \mathrm{kg}$ and has been incriminated for all aflatoxicoses recorded $[71,101]$. In one of the pioneering studies, Kenji et al. [81] reported very high total AFs of $1,120 \mu \mathrm{g} / \mathrm{kg}$ in malted maize with an $86 \%$ incidence of $\mathrm{AFB}_{1} . \mathrm{AFB}_{1}$ ranged from 0 to $260 \mu \mathrm{g} / \mathrm{kg}$ in malted millet from Thika market (Kenya) though no $\mathrm{AFB}_{2}$ and $\mathrm{AFG}_{1}$ were detected. On the other hand, maize flour had $\mathrm{AFB}_{1}$ ranging from 0 to $160 \mu \mathrm{g} / \mathrm{kg}$ (from Nairobi) and traces (from Thika) with undetectable $\mathrm{AFB}_{2}$. In another study, $68 \%$ of a maize-based traditional brew (Busaa) in the slums of Nairobi was declared to contain AFs in concentrations above $5 \mu \mathrm{g} / \mathrm{kg}, 17 \%$ of which were above $50 \mu \mathrm{g} / \mathrm{kg}$ [102]. Likewise, the magnitude of AF contamination of 480 maize grains, maize flour, and dehulled dry maize-muthokoi (362 random environmental samples, 26 cases, and 92 controls) samples from Makueni, Kitui, Machakos, and Thika districts was assessed [103]. It was reported that $46.4 \%$ of the environmental samples, $15 \%$ of cases, and $29.3 \%$ of controls were within the then threshold of $20 \mu \mathrm{g} / \mathrm{kg}$, implying that $54.6 \%$ of the samples could not be used for human consumption. Further, $6.9 \%$ of the environmental samples, $57.7 \%$ of cases, and $21.7 \%$ of controls had AF concentrations above $1000 \mu \mathrm{g} / \mathrm{kg}$. The overall AF contamination of the samples ranged from 0 to $58,000 \mu \mathrm{g} / \mathrm{kg}$ [103]. Further, Sirma et al. [76] recorded total AFs of $0.17-5.3 \mu \mathrm{g} / \mathrm{kg}$ from $67 \%$ of maize from the Rift Valley region. About $92 \%$ of millet and $50 \%$ of sorghum samples collected in the study were positive for AFs in the ranges of $0.14-6.4 \mu \mathrm{g} / \mathrm{kg}$ and $0.21-210.1 \mu \mathrm{g} / \mathrm{kg}$, respectively.

Later, Muthomi et al. [40] reported that samples of whole maize, mill dust, and semiprocessed maize in Machakos, 
Eastern Kenya, had more than $20 \mu \mathrm{g} / \mathrm{kg} \mathrm{AFB}_{1}$ threshold allowed by then in Kenya. The highest AFB $_{1}$ level $(160 \mu \mathrm{g} / \mathrm{kg})$ was recorded in whole grains. The dust registered the highest AF content, probably due to dehulling operations and the continuous availability of maize products which are potential substrates for A. flavus proliferation. As expected, semiprocessed grains had the lowest contamination levels and this was speculated to be so due to dehulling of the grains as reported elsewhere [104].

Similarly, a random study appraising market maize contamination as well as the relationship between market maize AFs and aflatoxicosis outbreak was conducted [71]. A total of 65 markets were surveyed, 243 maize vendors were interviewed, and 350 maize and maize products samples were drawn from the most affected districts as per the previous history of aflatoxicoses. About $55 \%$ of the samples had AFs in levels above the then advisory threshold of $20 \mu \mathrm{g} /$ $\mathrm{kg}, 35 \%$ had levels $>100 \mu \mathrm{g} / \mathrm{kg}$, and $7 \%$ had levels $>1,000 \mu \mathrm{g} /$ $\mathrm{kg}$ (Table 1). Makueni district which had the highest number of aflatoxicosis case-patients had evidently higher market maize AF concentrations than Thika district (which had the fewest case-patients) with a geometric mean of $52.91 \mu \mathrm{g} / \mathrm{kg}$ versus $7.52 \mu \mathrm{g} / \mathrm{kg}$. In addition, maize from local farms in the affected areas was more likely to have AFs in concentrations $>20 \mu \mathrm{g} / \mathrm{kg}$ vis-à-vis those from other regions or countries. Because it was understood that contaminated homegrown maize in the affected areas infiltrated the distribution system, wild AF contamination of market maize was inevitable, and the contaminated market maize bought after homegrown maize supplies were exhausted was cited as the reason for persistent exposure to AFs. The authors stressed that efforts to meaningfully evade $\mathrm{AF}$ exposure during an aflatoxicosis epidemic should take into account the role of the market chain [71].

Probst et al. [55] reported that, in Eastern province (Kitui and Mukueni), Coast (Makueni, Kwale, Kilifi, Tana River, and Taita Taveta), and Rift Valley (Marakwet, Keiiyo II, Kajiado, Baringo, Nakuru, and Laikipia), total AFs in maize ranged from 219.6 to $426.3 \mu \mathrm{g} / \mathrm{kg}, 0.1-120.4 \mu \mathrm{g} / \mathrm{kg}$, and below detection limit (BDL) to $13.4 \mu \mathrm{g} / \mathrm{kg}$, respectively. Indeed, the Aflacontrol Project [105] also reconfirmed this observation. Maize grains sampled between January 2010 and May 2010 from fields (preharvest), stores (postharvest), and wholesalers, retailers, and open-air vendors were declared to be contaminated with AFs. The highest level of AFs in preharvest maize $(n=281)$ was $1,455 \mu \mathrm{g} / \mathrm{kg}$ from Mbooni East (Eastern Kenya). No appreciable differences were noted between samples from Western and Eastern Kenya. For example, samples from Homa Bay and Rongo had $37 \mu \mathrm{g} / \mathrm{kg}$ and $54 \mu \mathrm{g} /$ $\mathrm{kg}$ of total AFs vis-à-vis $21 \mu \mathrm{g} / \mathrm{kg}$ reported in Makueni, $25 \mu \mathrm{g} /$ $\mathrm{kg}$ reported in Mbeere North, and $44 \mu \mathrm{g} / \mathrm{kg}$ reported in Mbooni East. Matter-of-factly, more samples from the Western sites were unfit for human consumption (had total AFs $>10 \mu \mathrm{g} / \mathrm{kg}$ ) than those from the eastern sites. For 241 postharvest samples, $38 \%$ from the eastern region had AF levels above $10 \mu \mathrm{g} / \mathrm{kg}$. The plague was most acute in Makueni where $87 \%$ of samples were unfit for human consumption and the maximum AF level was $1,777 \mu \mathrm{g} / \mathrm{kg}$. In Mbooni East and Mbeere North, the proportion of maize with levels above
$10 \mu \mathrm{g} / \mathrm{kg}$ was $29 \%$ and $7 \%$, respectively. In entirety, the proportion of maize unfit for human consumption was higher in the eastern sites than in the western sites, but there was considerable variation across the different areas sampled.

Another study reaffirmed the foregoing. For 306 maize samples collected from markets in Upper Eastern Kenya $(n=101)$, Lower Eastern Kenya $(n=87)$, Homa Bay/Rongo $(n=102)$, and Kisii Central $(n=21)$, majority (206) had AF levels below $10 \mu \mathrm{g} / \mathrm{kg}$. However, the eastern side had more samples with AFs $>10 \mu \mathrm{g} / \mathrm{kg}$, with a maximum of $1,633 \mu \mathrm{g} / \mathrm{kg}$ recorded. In another concerted study, Collins et al. [106] reported that maize from Homa Bay and Rongo had mean AF levels of $37.0 \mu \mathrm{g} / \mathrm{kg}$ and $54.0 \mu \mathrm{g} / \mathrm{kg}$ compared to $21.0 \mu \mathrm{g} /$ $\mathrm{kg}, 25.0 \mu \mathrm{g} / \mathrm{kg}$, and $44.0 \mu \mathrm{g} / \mathrm{kg}$ in Makueni, Mbeere North, and Mbooni East, respectively.

In consonance with the aforementioned, Muthomi et al. [107] evaluated the distribution and contamination levels of Aspergillus species (spp) and $\mathrm{AFB}_{1}$ in soil, maize, and maizebased products. Maize grain $(n=256)$, semiprocessed grain $(n=56)$, flour $(n=52)$, hammer mill dust $(n=11)$, and soils $(n=117)$ had A. flavus in all the samples, though the fungi were prevalent in the grain. $\mathrm{AFB}_{1}$ was undetected in samples from the humid regions but was present in concentrations in excess of $10 \mu \mathrm{g} / \mathrm{kg}$ in $20 \%$ of the samples, with maxima of $136 \mu \mathrm{g} / \mathrm{kg}$ for semiprocessed maize, $77 \mu \mathrm{g} / \mathrm{kg}$ for whole grain, and $41 \mu \mathrm{g} / \mathrm{kg}$ for flour in open bags. Incidental high temperature and periodic droughts prevalent in the semiarid regions were incriminated for the higher levels of $A$. flavus and $\mathrm{AFB}_{1}$ recorded. A study report recapitulated in $[16,108]$ indicated that Kenyan maize was the most contaminated in East Africa with a mean of $131.7 \mu \mathrm{g} / \mathrm{kg}$ (Table 2).

A total of 54 processed and unprocessed (brands A and B) cattle feed from agricultural and veterinary stores and 96 human foods (unprocessed and processed maize, polished and unpolished rice, peanut seeds, and flour) samples collected from open market traders in Nairobi County were analyzed [86]. The awareness of the traders on AFs and the associated health effects were assessed using questionnaires. Total AF concentrations recorded were $120.9 \pm 27.2 \mu \mathrm{g} / \mathrm{kg}$ (processed feed), $77.6 \pm 16.0 \mu \mathrm{g} / \mathrm{kg}$ (brand A), $48.6 \pm 12.0 \mu \mathrm{g} /$ $\mathrm{kg}$ (brand B), $49.7 \pm 14.7 \mu \mathrm{g} / \mathrm{kg}$ (unprocessed maize), $101.20 \pm 21.30 \mu \mathrm{g} / \mathrm{kg}$ (maize flour), $38.2 \pm 10.5 \mu \mathrm{g} / \mathrm{kg}$ (unpolished rice), $63.9 \pm 14.5 \mu \mathrm{g} / \mathrm{kg}$ (polished rice), $54.6 \pm 14.8 \mu \mathrm{g} / \mathrm{kg}$ (peanut seeds), and $120.9 \pm 27.2 \mu \mathrm{g} / \mathrm{kg}$ (peanut flour). Higher AF levels were reported in processed foods (mean: $95.0 \pm 12.7 \mu \mathrm{g} / \mathrm{kg}$ ) than in nonprocessed foods (mean: $47.5 \pm 7.6 \mu \mathrm{g} / \mathrm{kg}$ ), and this implied that some food processing techniques used predisposed the foods to aflatoxigenic contamination. Roughly $56.6 \%$ of the traders were aware of AF contamination; cattle feed traders were more conversant with AFs (40\%) than human food traders (17\%). A very small portion of food traders (3.7\%) and feed traders (8\%) were aware of the health effects of AFs in humans and animals, respectively. Because the mean AF levels in both feeds and foods were above statutory limits, the author recommended the need for creating traders' awareness on $\mathrm{AFs}$, their effects, and practices that favour AF proliferation.

Aflatoxin exposure via intake of maize and its products was evaluated through analysis of 20 samples each of maize 
TABLE 1: Distribution of AFs in maize products from some Kenyan districts following the 2004 aflatoxicosis.

\begin{tabular}{|c|c|c|c|c|c|}
\hline \multirow{2}{*}{ District } & \multirow{2}{*}{ Number of samples ${ }^{\mathrm{a}}$} & \multicolumn{4}{|c|}{ Total aflatoxin concentration $^{\mathrm{b}}$} \\
\hline & & $\leq 20 \mu \mathrm{g} / \mathrm{kg}(\%)$ & $21-99 \mu \mathrm{g} / \mathrm{kg}(\%)$ & $100-1,000 \mu \mathrm{g} / \mathrm{kg}(\%)$ & $>1,000 \mu \mathrm{g} / \mathrm{kg}(\%)$ \\
\hline Makueni & 91 & $32(35)$ & $12(13)$ & $36(40)$ & $11(12)$ \\
\hline Kitui & 73 & $28(38)$ & $15(21)$ & $23(32)$ & $7(10)$ \\
\hline Machakos & 102 & $50(49)$ & $26(25)$ & $23(23)$ & $3(3)$ \\
\hline Thika & 76 & $50(66)$ & $13(17)$ & $10(13)$ & $3(4)$ \\
\hline Total & 342 & $160(47)$ & $66(19)$ & $92(27)$ & $24(7)$ \\
\hline
\end{tabular}

Excerpted from Lewis et al. [71]. Values shown were for samples with AFs and the percentage of total samples within the district. ${ }^{a}$ Number of samples analyzed for AFs, did not include samples that were collected but not analyzed. ${ }^{\mathrm{b}}$ Acceptable upper limit for AFs in grains by then was $20 \mu \mathrm{g} / \mathrm{kg}$.

TABle 2: AFs contamination of foods in Eastern Africa.

\begin{tabular}{lccc}
\hline Food & Country & Per capita intake $(\mathrm{g} /$ person/day) & Average AF level $(\mu \mathrm{g} / \mathrm{kg})$ \\
\hline \multirow{3}{*}{ Maize } & Kenya & 405 & $\mathbf{1 3 1 . 7}$ \\
& Tanzania & 69 & $\mathbf{4 9 . 7}$ \\
& Uganda & 400 & $\mathbf{9 . 7}$ \\
\hline \multirow{3}{*}{ Groundnuts (peanuts) } & Uganda & & $\mathbf{2 5 . 1}$ \\
& Tanzania & 65 & $\mathbf{1 5 . 0}$ \\
\hline \multirow{2}{*}{ Cassava chips } & Burundi & & $\mathbf{1 2 . 5}$ \\
Sorghum & Uganda & 214 & 0.5 \\
\hline \multirow{3}{*}{ Milk } & Tanzania & 40 & 0.9 \\
& Tanzania & $750 \mathrm{ml}$ & 3.0 \\
\hline
\end{tabular}

Values in bold indicate exceedance of East African thresholds.

kernels, muthokoi, and githeri haphazardly drawn from households in the eastern district of Kibwezi of Makueni County [109]. Uncertainty and variability in dietary exposure were modelled quantitatively. AFs were recorded in $45 \%$ of maize (range: $18-480 \mu \mathrm{g} / \mathrm{kg}$ ), $20 \%$ of muthokoi (range: $12-123 \mu \mathrm{g} / \mathrm{kg}$ ), and $35 \%$ of githeri (range: 6-30 $\mu \mathrm{g}$ / $\mathrm{kg}$ ). The mean dietary exposure to AFs in maize kernels, muthokoi, and githeri, respectively, was $292 \pm 1567,27 \pm 154$, and $59 \pm 62 \mathrm{ng} / \mathrm{kg}$ bw/day. The amount and frequency of consumption of the foods were cited as the requisite factors for dietary exposure to AFs. Moreover, some maize $(n=268)$, sorghum $(n=62)$, and millet grains $(n=39)$ from households and markets in villages of Nandi County were subjected to AF analysis [76]. Computed 67.7\% (72/106), $73.3 \%(44 / 60)$, and $65.7 \%(67 / 102)$ of maize from Laboret, Kilibwoni, and Chepkongony sublocations were contaminated with AFs (range: $0.17-5.3 \mu \mathrm{g} / \mathrm{kg}$ ); $92.9 \%$ (13/14), 100\% (9/9), and $87.5 \%$ (14/16) of millet from Laboret, Kilibwoni, and Chepkongony had AFs in the range of $0.14-6.4 \mu \mathrm{g} / \mathrm{kg}$. However, only $50 \%$ (9/18), 36.4\% (8/22), and $27.3 \%(6 / 22)$ of sorghum drawn from Laboret, Kilibwoni, and Chepkongony, respectively, had AFs above $10 \mu \mathrm{g} / \mathrm{kg}$ (range: $0.15-210.1 \mu \mathrm{g} / \mathrm{kg}$ ).

To check for chronic inadvertent exposure to AFs, maize $(n=75)$ and maize flour $(n=27)$ from different parts of Kenya were collected and analyzed [95]. Striking differences in the AF levels of maize grain between the regions and stores from which samples were drawn were reported. Eastern Kenya had the highest contaminated samples with a mean of $22.54 \pm 4.94 \mu \mathrm{g} / \mathrm{kg}$, while those from Nairobi had the lowest contamination $(7.92 \pm 1.57 \mu \mathrm{g} / \mathrm{kg})$. No appreciable differences were observed for total AFs in maize flours from the regions. AFs in maize flours were marginally above the European Union (EU) limit of $5 \mu \mathrm{g} / \mathrm{kg}$, and most of the samples had AFs lower than the statutory limit of $10 \mu \mathrm{g} / \mathrm{kg}$. The authors attributed this to adherence to good manufacturing practices by the millers. The highest AF level in maize flours from Eastern Kenya was $6.98 \pm 0.53 \mu \mathrm{g} / \mathrm{kg}$ [95]. Recently, Obonyo and Salano [63] echoed that maize grain in Eastern Kenya from May harvest had lower AF levels with variation $\left(5.68 \pm 6.31 \mu \mathrm{g} / \mathrm{kg}, 100 \% \mathrm{AFB}_{1}\right)$ than those from October-December rains $(10.77 \pm 10.14 \mu \mathrm{g} / \mathrm{kg}$, $\left.72 \% \mathrm{AFB}_{1}\right)$. From the two seasons, the authors hinted that $16 \%$ and $44 \%$ of the samples had total AFs above the statutory limit of $10 \mu \mathrm{g} / \mathrm{kg}$. Another group [110] undertook a random study in three agroecological zones: Kitui (semihumid to semiarid), Nakuru (semihumid), and Kitale (subhumid to semihumid) to determine the prevalence and AFs in 130 stored maize samples and the aflatoxigenicity potential of $A$. flavus in stored maize. The authors put forward that aflatoxigenic contamination between the sampled sites was markedly distinct with the highest mean total AFs of $9.68 \mu \mathrm{g} / \mathrm{kg}$ reported in Kitale district. A. flavus was detected in 91 (70\%) samples and the colonies with exorbitant aflatoxigenicity stemmed from Nakuru County with a recorded mean total AF of $239.7 \mu \mathrm{g} / \mathrm{kg}$.

Recently, maize from smallholder farmers' fields in Eastern and Southwestern Kenya $(n=789)$ was analyzed for $\mathrm{AFB}_{1}$ [94]. The authors detected $\mathrm{AFB}_{1}$ (range: $0.01-9,091.8 \mu \mathrm{g} / \mathrm{kg}$; mean: $67.8 \mu \mathrm{g} / \mathrm{kg}$ ) in $274 / 416$ samples 
from Eastern Kenya. In the Southwest, the toxins were quantified in 233/373 samples (range: 0.98-722.2 $\mu \mathrm{g} / \mathrm{kg}$; mean: $22.3 \mu \mathrm{g} / \mathrm{kg})$. Of these, $153(55.8 \%)$ from Eastern and $102(43.8 \%)$ from Southwest had $\mathrm{AFB}_{1}$ surpassing the threshold of $5 \mu \mathrm{g} / \mathrm{kg}$. The probable daily intake (PDI) of $\mathrm{AFB}_{1}$ in the East was 0.07 to $60,612 \mathrm{ng} / \mathrm{kg}$ bw/day (mean $451.8 \mathrm{ng} / \mathrm{kgbw} /$ day), while for the Southwest, it varied from 6.53 to $4,814.7 \mathrm{ng} / \mathrm{kgbw} /$ day with a mean of $148.4 \mathrm{ng} / \mathrm{kgbw} /$ day. The mean PDI for the regions surpassed $\mathrm{AFB}_{1}$ tolerable daily intake and therefore poses health concerns. As such, it was advanced that control of preharvest AF contamination should be emphasized in the bid to reduce exposure to AFs through maize consumption [94].

The prevalence and levels of AFs in freshly harvested maize and freshly milled maize flour $(n=338)$ from households in Siaya and Makueni Counties were evaluated by Nabwire et al. [77]. All (100\%) of the samples had detectable AFs, which ranged from 2.14 to $411 \mu \mathrm{g} / \mathrm{kg}$. The geometric mean of total AFs in samples from Makueni and Siaya Counties was reported as $62.5 \mu \mathrm{g} / \mathrm{kg}$ and $52.8 \mu \mathrm{g} / \mathrm{kg}$, respectively. This revalidated the fact that AFs are prevalent in maize and its products in the area. Taken together, regional disparities in AF levels of Kenyan maize have been reported with the Eastern provinces registering the highest level of $58,000 \mu \mathrm{g} / \mathrm{kg}[70,103,109]$ vis-à-vis the other provinces that registered $4,500 \mu \mathrm{g} / \mathrm{kg}$ as the maximum $[72,78]$. Recently, the Kenya Bureau of Standards (KEBS) banned a number of maize flour products on the market because of high AF levels [8]. As per the current study, reluctancy to dehull maize has been recognized as a plausible explanation for the exorbitant AF concentrations recorded in Kenyan maize flour.

2.2.2. Peanuts (Arachis hypogaea L.) and Its Products. Peanuts (groundnuts) are the only affordable dietary protein source in Kenya [65]. It is grown predominantly in the western but sold and consumed countrywide [61, 111]. Peanut productivity has over the years declined due to unpredictable rainfall, lack of disease-resistant peanut varieties, poor agronomic practices, and poor institutional support accorded to farmers [112-114]. It is grown for local consumption but is also exported through the World Food Programme $[115,116]$. Peanut is rich in proteins, fats, carbohydrates, zinc, sodium, potassium, calcium, magnesium, iron, phosphorous, and vitamins $\mathrm{E}$ and $\mathrm{B}$ [117]. In tandem with maize, they are the major portions of the gruel used to make weaning foods in Kenya and these have been shown to be a route of AF exposure [118, 119]. Most of the peanut samples tested in the country had AF levels above recommended regulatory limits set by the KEBS [120]. Fortunately, its consumption is as low as $1.1 \mathrm{~g} /$ person/day [92].

In one of the earlier surveys [61], baseline data on AF levels as well as 384 and 385 peanut samples from Busia and Homa Bay districts of Western Kenya were collected and analyzed. Total AFs ranged from 0 to $2,688 \mu \mathrm{g} / \mathrm{kg}$ and 0 to $7,525 \mu \mathrm{g} / \mathrm{kg}$ in samples from Busia and Homa Bay, respectively. Out of all the samples drawn $(n=769), 87.01 \%$ contained $<4 \mu \mathrm{g} / \mathrm{kg}$ of AFs, $5.45 \%$ were in the range $\geq 4$ and $20 \mu \mathrm{g} / \mathrm{kg}$ while $7.54 \%$ surpassed the advisory threshold of $20 \mu \mathrm{g} / \mathrm{kg}$. There was a highly strong association between the districts and the analytical total AFs recorded, which was further corroborated by a significant correlation between total AF levels and agroecological zones. Logistic regression unveiled that peanuts from Busia were 2.6 times at risk of contamination vis-à-vis those from Homa Bay and that planting improved cultivars could lower the odds of contamination to half those for local landraces. In the continuity of the foregoing, the authors [44] reported that the total AF content of 436 peanut samples drawn from Busia and Homa Bay districts varied from BDL to $2,687.6 \mu \mathrm{g} / \mathrm{kg}$ and BDL to $1,838.3 \mu \mathrm{g} / \mathrm{kg}$ in about $32 \%$ of the samples with detectable AFs. Both the incidence and the number of colonies of A. flavus S-strain were significantly and positively correlated with the total AF content of the samples. Up to $99.3 \%$ of the samples containing $<10 \mu \mathrm{g} / \mathrm{kg}$ of total AFs did not have A. flavus S-strain. This corroborated a previous report which confirmed the presence of Aspergillus, Rhizopus, Fusarium, and Penicillium spp in peanuts with AF contents spanning beyond $100 \mu \mathrm{g} / \mathrm{kg}$ [84].

In another survey by Mutegi et al. [62], peanut and their products from supermarkets and informal markets were analyzed. The authors announced that raw podded peanuts had the lowest AF contamination, with $96 \%$ having levels of less than $4 \mu \mathrm{g} / \mathrm{kg}$ and only $4 \%$ having more than $10 \mu \mathrm{g} / \mathrm{kg}$. Irrespective of the provenance, $69 \%$ of the samples and $75 \%$ of spoilt nuts had total AFs exceeding $10 \mu \mathrm{g} / \mathrm{kg}$. Though most samples (59\%) had AF levels below $4 \mu \mathrm{g} / \mathrm{kg}$, only $4 \%$ of these were acceptable under the KEBS but could be rejected under EU regulations. Of these, $37 \%$ of the peanuts were found to be unfit for human consumption as per KEBS and EU regulatory limits. Further, the team [64] evaluated the effect of storage bags, temperature, and relative humidity on the quality and AF content of peanut kernels of Homa Bay local, Valencia red, ICGV-SM 12991, and ICGV-SM 99568 varieties stored for 6 months in jute, polypropylene, and polyethylene bags. Moisture content, physical damage, rancidity, and AF levels were determined before storage and after every 30 days during storage. Moisture content changed remarkably from 3.3 to $6.9 \%$ with samples stored in different bag types recording mean values of $5.1 \%$ (polypropylene), 5.2\% (polyethylene), and 5.3\% (jute). Physical damage (range: 0.1 to $9.8 \%$ ) was influenced by storage temperature and relative humidity and the type of storage used. Rancidity ranged from 0.8 to 5.3 and increased with storage duration from a mean of 1.5 before storage to a peak of 2.5 after 5 months of storage. There was a reported variation in total AFs (range: 0 to $47.8 \mu \mathrm{g} / \mathrm{kg}$ ) of nuts stored in polyethylene bags having $7.3 \%$ and $13.4 \%$ more contamination than those stashed in polypropylene and jute bags.

Accordingly, it was hypothesized that the processing of peanuts in the cottage industry could facilitate their contamination by AFs. As such, Ndung'u et al. [53] assessed the AF content of raw and roasted peanuts and peanut butter marketed in Nairobi and Nyanza Provinces of Kenya. Marketers and processors of these were also interviewed on 
the source of groundnuts and the incidence of Aspergillus section Flavi was determined. The authors stressed that the percentage of defective nuts among all unsorted nuts ranged from 0 to $26.3 \%$. The mean percent of defective nuts was higher for Nairobi (imported from Malawi) than for Nyanza (homegrown) samples. Total AFs in the samples ranged from 0 to $2,377.1 \mu \mathrm{g} / \mathrm{kg}$ with higher mean total levels in raw samples from Nairobi than from Nyanza (Table 3). The source of groundnuts and defective nuts was positively associated with AF levels. A. flavus (L- and S-strains), A. parasiticus, A. niger, A. tamari, A. alliaceus, A. caelatus, and Penicillium spp were isolated from the samples.

The prevalence and diversity of fungal spp and aflatoxigenic contamination of 228 marketed peanut samples (from 140 formal and 88 from informal markets) in Kericho and Eldoret towns of Kenya were established [115]. A. flavus (L- and S-strains), A. parasiticus, A. tamarii, A. caelatus, A. alliaceus (members of Aspergillus section Flavi), and A. niger as well as Penicillium, Mucor, Fusarium, and Rhizopus spp were encountered. Total AFs in the nut products were 0 to $2,345 \mu \mathrm{g} / \mathrm{kg}$ in raw, 0 to $382 \mu \mathrm{g} / \mathrm{kg}$ in roasted, and 0 to $201 \mu \mathrm{g} / \mathrm{kg}$ in roasted decoated peanuts. Altogether, AFs occurred in higher concentrations in samples from informal $($ mean $=97.1 \mu \mathrm{g} / \mathrm{kg})$ than from formal $($ mean $=55.5 \mu \mathrm{g} / \mathrm{kg}$ ) markets. Meanwhile, a positive and strong correlation was cited between AF levels and the major aflatoxigenic fungi in raw peanuts from formal markets of Eldoret. Further, AFs in raw nuts from informal markets in Kericho positively and strongly correlated with the population of A. flavus (both strains). In roasted coated peanuts sampled from Eldoret formal markets, AFs correlated positively and significantly with A. flavus S-strain.

Another investigation [121] which compared the oil content and total AF level of peanuts in Busia and Kisii Central districts reported that Valencia red, Uganda local, Homa Bay local, and Local red peanut varieties from Busia had lower levels of total AFs except the Local red variety which had the highest total AF of $267 \mu \mathrm{g} / \mathrm{kg}$ with the lowest average oil content of $42.7 \%$ (Table 4 ). Peanuts from Kisii Central had higher AF levels and low oil contents. Summed up, there was an increase in total AF levels with decreasing oil contents except for Uganda local red from Kisii. In the continuity of the foregoing study, Menza and Muturi [49] reported the occurrence of five causative Aspergillus fungi: A. flavus (L- and S-strains), A. parasiticus, A. niger, and A. tamari. Overall, the occurrence of A. flavus (both strains) was significantly higher than other aflatoxigenic spp identified in the nuts. A. flavus L-strain was the most common isolate $(58.8 \%)$ in samples from Busia while the S-strain dominated (60.2\%) in peanuts from Kisii Central. All in all, A. flavus S-strain was the most dominant with a mean prevalence of $45.1 \%$.

From the prevenient reports, it is notable that relatively higher AF concentrations have been detected and quantified in Kenyan peanuts. A plausible explanation advanced has been that aflatoxigenic fungi infect the shells, testa, and seeds as the pods in the soil grow. Further, mechanical damage while harvesting, drying, and storing aggravates the risk of invasion by the toxigenic fungi and aflatoxin biosynthesis.
This is corroborated by a Tanzanian report which unveiled that grains and oilseeds borne on aerial generative structures had comparatively lower AF levels vis-à-vis those borne in geocarpic structures of Bambara and peanuts [122].

2.2.3. Cassava (Manihot esculenta Crantz). Cassava is a revered food crop with edible carbohydrate-rich tuberous roots and proteinaceous young leaves $[123,124]$. However, it houses 2 cyanogenic glucosides: linamarin and lotaustralin (methyl linamarin) inherently synthesized for protection against predation. These cyanogens are spread in the whole plant but occur in higher quantities in the leaves and root cortex [125]. Cyanide is an inhibitor of aerobic respiration through blockage of mitochondrial electron transport and oxygen uptake. In addition, cassava is also prone to mycotoxins, particularly AFs.

In a study, dried cassava chips $(n=13)$ and cassava flour $(n=26)$ sourced from Nairobi and Mombasa markets were assessed for hydrogen cyanide, AF, and moisture contents [126]. Hydrogen cyanide ranged from 27.20 to $42.92 \mathrm{mg} / \mathrm{kg}$ and $21.45-37.77 \mathrm{mg} / \mathrm{kg}$ in cassava chips and 21.53 to $64.63 \mathrm{mg} / \mathrm{kg}$ and 21.70 to $70.03 \mathrm{mg} / \mathrm{kg}$ in flour from Nairobi and Mombasa, respectively. These were all above $10 \mathrm{mg} / \mathrm{kg}$ recommended by the East African standards (EAS 739: 2010 and EAS 740: 2010, respectively). AFs were detected in 2 flour samples from Nairobi (mean levels of 6.60 and $8.89 \mu \mathrm{g} /$ $\mathrm{kg}$ ) and a sample from Mombasa (mean level of $2.84 \mu \mathrm{g} / \mathrm{kg}$ ). Moisture content ranged from 8.62 to $9.98 \%$ and 8.85 to $11.57 \%$ in cassava chips and 8.50 to $12.51 \%$ and 7.30 to $11.0 \%$ in flour samples from Nairobi and Mombasa, respectively. The study revealed that marketed cassava flour though of good aesthetic quality could be mycotoxigenically unsafe for consumption.

There are no reports in the open literature on plant products such as sugarcane, spices, beans, wheat, and barley in Kenya. A. flavus was not identified in soils with sugarcane grown which reportedly had Phanerochaete chrysosporium, A. niger, Trichoderme viride, and Fusarium equiseti [46]. Sugarcane is one of the daily consumables in the form of sugar and has been previously reported to house AFs [127]. In addition, no recent studies have reported on the AF content of commercial beers consumed by Kenyans despite it being one of the widely consumed foods that evidently utilize cassava and cereal food crops (sorghum, barley, and maize). Beers are essentially continuous mixed-culture fermentation products. As such, brewing could be the innocuous route for $\mathrm{AF}$ exposure as it offers auspicious conditions in which toxigenic fungi thrive and may be an excellent avenue for use of aflatoxin-contaminated raw materials as the end-users cannot directly notice [16]. Similarly, no reports exist on AFs in beans. In the neighbouring Uganda where sometimes Kenya imports beans, AFs were earlier recorded in excess of $1,000 \mu \mathrm{g} / \mathrm{kg}$ [128].

\subsubsection{Animal Products. Aflatoxin-contaminated animal} products such as blood, eggs, ghee, meat, milk, and dairy products present food safety concerns [129]. In Kenya, $\mathrm{AFM}_{1}$ in bovine milk is the most studied. A list was 
TABle 3: AF content of peanuts and peanut butter from market outlets in Nairobi and Nyanza Provinces, Kenya.

\begin{tabular}{|c|c|c|c|c|c|c|c|}
\hline \multirow{2}{*}{ Source } & \multirow{2}{*}{ Sample } & \multirow{2}{*}{ Sample type } & \multicolumn{2}{|c|}{ AF level $(\mu \mathrm{g} / \mathrm{kg})$} & \multicolumn{3}{|c|}{ Aflatoxin-positive samples (\%) } \\
\hline & & & Range & Mean & $\leq 4.0 \mu \mathrm{g} / \mathrm{kg}$ & $\leq 10.0 \mu \mathrm{g} / \mathrm{kg}$ & $\geq 10.0 \mu \mathrm{g} / \mathrm{kg}$ \\
\hline \multirow{5}{*}{ Cottage industry } & \multirow{3}{*}{ Raw peanuts } & Pink regular $(n=3)$ & BDL-52.4 & 18.3 & 60 & 80 & 20 \\
\hline & & Red regular $(n=1)$ & NA & 5.0 & & & \\
\hline & & Red small $(n=1)$ & $\mathrm{NA}$ & $\mathrm{BDL}$ & & & \\
\hline & \multirow{2}{*}{$\begin{array}{l}\text { Roasted peanuts } \\
\text { Peanut butter }\end{array}$} & Red regular $(n=8)$ & $2.4-297.7$ & 54.8 & 25 & 50 & 50 \\
\hline & & Paste $(n=11)$ & BDL-2,377.1 & 318.3 & 18 & 27 & 73 \\
\hline \multirow{5}{*}{ Nairobi wholesale outlets } & \multirow{2}{*}{ Unsorted peanuts } & Pink regular $(n=11)$ & BDL-364.7 & 111.2 & 22 & 26 & 74 \\
\hline & & Red regular $(n=12)$ & BDL-276.1 & 89.1 & & & \\
\hline & \multirow{3}{*}{ Sorted peanuts } & Pink regular $(n=4)$ & BDL-82.4 & 24.0 & 36 & 82 & 18 \\
\hline & & Red regular $(n=5)$ & $2.0-9.2$ & 5.3 & & & \\
\hline & & Red small $(n=2)$ & $6.0-7.8$ & 6.9 & & & \\
\hline \multirow{4}{*}{ Nyanza retail outlets } & \multirow{4}{*}{ Unsorted nuts } & Pink large $(n=3)$ & $3.7-128.8$ & 71.6 & 71 & 75 & 25 \\
\hline & & Pink regular $(n=9)$ & BDL-229.8 & 44.9 & & & \\
\hline & & Red regular $(n=9)$ & BDL-14.0 & 1.9 & & & \\
\hline & & Red mixed $(n=3)$ & NA & BDL & & & \\
\hline
\end{tabular}

Adapted from [53]. BDL: below method detection limit of $0.5 \mu \mathrm{g} / \mathrm{kg}$; NA: not applicable.

TABLE 4: Oil content and total aflatoxins of peanuts from Busia and Kisii Central districts of Kenya.

\begin{tabular}{lccc}
\hline District & Variety & Mean oil content $(\%)$ & Mean total AFs $(\mu \mathrm{g} / \mathrm{kg})$ \\
\hline \multirow{4}{*}{ Busia } & Valencia red & 47.2 & 2.3 \\
& Uganda local red & 46.7 & 2.4 \\
& Homa Bay local & 43.2 & 2.8 \\
Kisii Central & Local red & 42.7 & $\mathbf{2 6 7 . 0}$ \\
& Valencia red & 46.6 & $\mathbf{9 3 . 0}$ \\
& Uganda local & 45.7 & $\mathbf{4 0 5 . 0}$ \\
\hline
\end{tabular}

Adapted from [121]. Values in bold indicate exceedance of the permissible limit of $10 \mu \mathrm{g} / \mathrm{kg}$.

developed [58] of the regions in Kenya that are at risk of AF outbreaks from milk consumption, and this encompassed all the milk production areas of Kenya. The dairy industry in Kenya is dominated by crosses between dairy and zebu breeds with more than $70 \%$ contribution to total national milk production. The feeds used are natural forage, cultivated fodder, and crop byproducts such as maize stalks and stover. Supplements such as dairy meal, maize germ, maize bran, cottonseed cake, wheat pollard, and wheat bran are also sometimes used [74].

A correlative study conducted in four urban centers by Kang'ethe and Lang'a [89] analyzed 613 milk and 830 feed samples for $\mathrm{AFM}_{1}$ and $\mathrm{AFB}_{1}$. About 86\% (353/412) of the feed samples from farmers were positive for $\mathrm{AFB}_{1}$ and $67 \%$ $(235 / 353)$ of these exceeded the FAO/WHO limit of $5 \mu \mathrm{g} / \mathrm{kg}$. About $81 \%$ (197/243) of the feeds from feed millers and $87 \%$ $(153 / 175)$ from agrochemical shops were AF positive, with $58 \%(115 / 197)$ and $66 \%(92 / 153)$ of these samples exceeding permissible limits, respectively. Approximately 72\% (315/ $439)$ of the milk from dairy farmers, $84 \%$ (71/85) from largeand medium-scale farmers, and 99\% (88/89) of the pasteurized marketed milk were positive for $\mathrm{AFM}_{1}$, and $20 \%$, $35 \%$, and $31 \%$ of positive milk from dairy farmers, mediumand large-scale farmers, and market outlets, respectively, exceeded the WHO/FAO limits of $0.05 \mu \mathrm{g} / \mathrm{kg}$. On the one hand, $67 \%$ of the urban smallholder dairy farmers had knowledge that milk could be contaminated with $\mathrm{AFM}_{1}$ but did not know the possible exposure mitigation strategies. Feed millers, on the other hand, knew about $\mathrm{AFB}_{1}$ in grains and its excretion as $\mathrm{AFM}_{1}$ in milk but were not alleviating exposure to animals [89] (Table 5). Similarly, Sirma et al. [130] surveyed 286 households in 37 villages representing four agroecological zones (semiarid, temperate, subhumid, and humid). They drew 280 samples of bovine milk which were subjected to $\mathrm{AFM}_{1}$ analysis. AF levels were from 0 to $0.359 \mu \mathrm{g} / \mathrm{kg}$. Generally, $58.9 \%$ of the milk sampled had $\mathrm{AFM}_{1}$ levels BDL though 9.3\% exceeded the WHO/FAO limit of $0.05 \mu \mathrm{g} / \mathrm{kg}$ (Table 6).

Aflatoxins were detected and quantified in fresh and sundried Rastrineobola argentea (Dagaa fish) collected from various markets in Luanda, Rongo, Kisumu, Ahero, and Maseno of the Winam Gulf of Lake Victoria [85]. Fresh samples had no detectable AFs, but the dried samples had mean total AF levels of $0.34 \pm 0.09,0.21 \pm 0.00,0.25 \pm 0.06$, $0.53 \pm 0.11$, and $0.11 \pm 0.00 \mu \mathrm{g} / \mathrm{kg}$ wet weight, respectively. It was asserted that the occurrence of AFs in processed Dagaa fish (omena) could have been due to the fact that the samples were collected from the markets in July 2010 when there were rains and drying was incomplete, and thus, the sundried Dagaa fish were packed in sacks when they were incompletely dried which favoured the growth of moulds.

In a bid to assess the AF status of marketed raw milk and associated risk factors in periurban Nairobi, raw milk retailers in Dagoretti division were interviewed and milk 
TABLE 5: Synopsis of aflatoxins in animal feeds and bovine milk in some Kenyan municipalities (from [89]).

\begin{tabular}{|c|c|c|c|c|c|}
\hline & Source/municipality & $\%$ AF positive & $>5.0 \mu \mathrm{g} / \mathrm{kg}(\%)$ & Mean & Range \\
\hline \multirow{16}{*}{ Aflatoxin $B_{1}$ (feed samples) } & \multicolumn{5}{|c|}{ Urban smallholder dairy farmers } \\
\hline & Nyeri $(n=118)$ & 68.6 & 49.2 & $136.0 \pm 10.0$ & $4.0-63.0$ \\
\hline & Eldoret $(n=108)$ & 98.1 & 61.1 & $23.2 \pm 23.2$ & $4.2-178.2$ \\
\hline & Machakos $(n=99)$ & 94.9 & 73.3 & $27.7 \pm 74.9$ & $3.6-595.0$ \\
\hline & Nakuru $(n=87)$ & 80.5 & 58.6 & $17.4 \pm 11.1$ & $1.8-58.0$ \\
\hline & \multicolumn{5}{|c|}{ Feed manufacturers } \\
\hline & Nyeri $(n=14)$ & 100.0 & 42.9 & $6.4 \pm 4.9$ & $1.9-15.8$ \\
\hline & Eldoret $(n=18)$ & 88.9 & 66.7 & $13.9 \pm 12.8$ & $1.9-49.0$ \\
\hline & Machakos $(n=1)$ & 100.0 & 100.0 & $43.8 \pm 0.0$ & 43.8 \\
\hline & Nakuru $(n=171)$ & 77.8 & 43.3 & $26.0 \pm 44.5$ & $0.9-280.0$ \\
\hline & Nairobi $(n=390)$ & 84.6 & 56.4 & $13.0 \pm 15.9$ & $0.9-280.0$ \\
\hline & \multicolumn{5}{|c|}{ Agrochemical shops } \\
\hline & Nyeri $(n=19)$ & 89.5 & 31.6 & $8.9 \pm 8.5$ & $1.9-28.7$ \\
\hline & Eldoret $(n=58)$ & 93.1 & 72.4 & $17.0 \pm 34.6$ & $1.8-238.0$ \\
\hline & Machakos $(n=29)$ & 79.3 & 43.3 & $17.6 \pm 19.6$ & $2.0-64.4$ \\
\hline & Nakuru $(n=69)$ & 84.1 & 43.5 & $46.0 \pm 8.4$ & $2.0-46.2$ \\
\hline \multicolumn{6}{|c|}{ Urban smallholder dairy farmers } \\
\hline \multirow{16}{*}{ Aflatoxin $\mathrm{M}_{1}$ (milk samples) } & Nyeri $(n=120)$ & 60.8 & 3.3 & $33.8 \pm 68.7$ & $5.0-46.0$ \\
\hline & Eldoret $(n=107)$ & 68.2 & 10.3 & $39.9 \pm 39.7$ & $5.4-228.0$ \\
\hline & Machakos $(n=99)$ & 82.8 & 24.2 & $99.7 \pm 168.9$ & $5.1-780.0$ \\
\hline & Nakuru $(n=110)$ & 77.3 & 20.9 & $83.3 \pm 129.3$ & $5.2-550.0$ \\
\hline & \multicolumn{5}{|c|}{ Medium- and large-scale farmers } \\
\hline & Nyeri $(n=25)$ & 76.0 & 0.0 & $20.2 \pm 29.0$ & $5.2-50.0$ \\
\hline & Eldoret $(n=16)$ & 68.8 & 12.5 & $115.6 \pm 202.7$ & $5.5-560.0$ \\
\hline & Machakos $(n=7)$ & 100.0 & 50.0 & $52.2 \pm 34.7$ & $10.9-102.5$ \\
\hline & Nakuru $(n=27)$ & 89.9 & 55.6 & $65.1 \pm 36.7$ & $5.3-165.0$ \\
\hline & Nairobi $(n=10)$ & 100.0 & 50.0 & $99.8 \pm 97.3$ & $10.0-245.0$ \\
\hline & \multicolumn{5}{|c|}{ Marketed milk } \\
\hline & Nyeri $(n=10)$ & 100.0 & 30.0 & $129.3 \pm 198.8$ & $16.5-600.0$ \\
\hline & Eldoret $(n=18)$ & 100.0 & 22.2 & $36.4 \pm 24.5$ & $5.8-74.0$ \\
\hline & Machakos $(n=18)$ & 94.4 & 16.7 & $33.1 \pm 17.0$ & $11.0-67.0$ \\
\hline & Nakuru $(n=19)$ & 100.0 & 36.8 & $36.1 \pm 22.9$ & $8.0-71.0$ \\
\hline & Nairobi $(n=24)$ & 100.0 & 41.7 & $64.9 \pm 76.4$ & $7.9-300.0$ \\
\hline
\end{tabular}

$n=$ number of samples. Means were presented with errors as standard deviations.

TABLE 6: $\mathrm{AFM}_{1}$ contamination of bovine milk in some selected agroecological zones of Kenya (from [130]).

\begin{tabular}{|c|c|c|c|c|c|}
\hline \multirow{2}{*}{ County } & \multirow{2}{*}{ Agroecological zone } & \multirow{2}{*}{ Number of samples } & \multicolumn{3}{|c|}{$\mathrm{AFM}_{1}$-positive samples (\%) } \\
\hline & & & $<0.002 \mu \mathrm{g} / \mathrm{kg}$ & $\leq 0.002-0.05 \mu \mathrm{g} / \mathrm{kg}$ & $\geq 0.05 \mu \mathrm{g} / \mathrm{kg}$ \\
\hline Tharaka-Nithi & Humid & 64 & 34 & 41 & 25 \\
\hline Kwale & Subhumid & 29 & 76 & 17 & 7 \\
\hline Bungoma & Temperate & 64 & 53 & 41 & 6 \\
\hline Kisii & Temperate & 63 & 65 & 30 & 5 \\
\hline Isiolo & Semiarid & 60 & 77 & 22 & 2 \\
\hline
\end{tabular}

samples were drawn and tested for $\mathrm{AFM}_{1}[131]$. The business types encountered were dairy shops, kiosks, street or mobile vendors, and grocery stands. Milk was primarily from dairy farms (59\%) or intermediate distributors (35\%). Although $58 \%$ of the retailers had known of AFs and many were in agreement that AFs could occur in milk, only $29 \%$ supported that "milk safety cannot be solely judged by sight or taste" and only $6 \%$ supported that "milk is not completely safe even after boiling". Analysis of the milk samples recorded mean $\mathrm{AFM}_{1}$ of $0.1287 \mu \mathrm{g} / \mathrm{kg}$ (median $=0.0499 \mu \mathrm{g} / \mathrm{kg}$; maximum of $1.675 \mu \mathrm{g} / \mathrm{kg}$ ). In entirety, $55 \%$ of the samples exceeded the EU maximum level of $0.05 \mu \mathrm{g} / \mathrm{kg}$ and $6 \%$ exceeded the recommended maximum level of the US FDA of $0.5 \mu \mathrm{g} / \mathrm{kg}$.
Vis-à-vis milk from street vendors, a significantly higher $\mathrm{AFM}_{1}$ concentration was detected in milk from kiosks and dairy shops, especially when the milk was sourced from farms without an intermediate distributor. Similarly, it was reported that 156 samples out of 185 (150 raw milk and 35 processed milk and milk products) from Bomet County were positive for $\mathrm{AFM}_{1}$ with an overall prevalence of $84.32 \%$ [132]. About $43.8 \%$ of these were above $0.05 \mu \mathrm{g} / \mathrm{kg}$, with raw milk compared to processed milk (52\% vs. $8.6 \%$ ) having more contamination.

In the same manner, $\mathrm{AFM}_{1}$ was detected in 291 samples of raw, pasteurized, and UHT milk, yoghurt, and Lala [90]. Monthly samples were drawn over a period of 1 year, just as 
a consumer would purchase them from retailers and traders in a low-income area (Dagoretti) and a major supermarket in a middle/high-income area (Nairobi). More than $50 \%$ of the samples had AFs exceeding $0.05 \mu \mathrm{g} / \mathrm{kg}$, though only 3 exceeded $0.5 \mu \mathrm{g} / \mathrm{kg}$ and the geometric mean $\mathrm{AFM}_{1}$ level was $0.0619 \mu \mathrm{g} / \mathrm{kg}$ in the 135 samples from Dagoretti while it was $0.0361 \mu \mathrm{g} / \mathrm{kg}$ in 156 samples from Nairobi. The levels varied significantly depending on the time of year, with the lowest levels reported in January. UHT milk had the lowest AF levels, and more expensive milk had lower $\mathrm{AFM}_{1}$ levels [90].

In a recent study [129], it was pointed that exposure to $\mathrm{AFM}_{1}$ in milk and the health risks associated with it are not clearly understood and monitored in Kenya. Thus, the team assessed the awareness, knowledge, and practices of urban and periurban farmers about AFs and evaluated the levels of AFs in on-farm milk in Kasarani subcounty, Nairobi County. In total, 84 milk samples were analyzed, and $90 \%$ $(83 / 84)$ were analytically declared to be contaminated with $\mathrm{AFM}_{1}$ (mean value of $0.084 \mu \mathrm{g} / \mathrm{kg}$ ). About $64 \%$ of the samples had $\mathrm{AFM}_{1}$ levels well above the EU limit of $0.05 \mu \mathrm{g} /$ $\mathrm{kg}$. Though $80 \%$ of the farmers had knowledge of AFs, no correlation existed between the farmers' knowledge and gender with $\mathrm{AFM}_{1}$ prevalence.

Kang'ethe et al. [87] reported that $45.5 \%$ and $98.6 \%$ of bovine milk and animal feeds in Kenya were positive for AFs. About $49 \%$ and $83 \%$ of these had $\mathrm{AFM}_{1}$ above $0.05 \mu \mathrm{g} / \mathrm{kg}$ and $\mathrm{AFB}_{1}$ above $10 \mu \mathrm{g} / \mathrm{kg}$, respectively. Similarly, an AF risk mapping study from milk consumption using biophysical and socioeconomic data [58] reported a mean $\mathrm{AFB}_{1}$ content of $9.25 \mu \mathrm{g} / \mathrm{kg}$ in animal feeds and a mean $\mathrm{AFM}_{1}$ content of $0.0265 \mu \mathrm{g} / \mathrm{kg}$ in bovine milk. Higher mean of the logarithmic $\mathrm{AFB}_{1}$ concentrations was reported in areas with historical aflatoxicosis outbreaks compared to those without outbreak history, a phenomenon that was not true for the mean logarithm of $\mathrm{AFM}_{1}$ when compared between areas with and those without a history of aflatoxicosis outbreaks. Analogously, a cross-sectional study of aflatoxigenic contamination of bovine milk and dairy concentrates was done in five counties of Kenya representing the agroecological zones: Kwale, Isiolo, Tharaka-Nithi, Kisii, and Bungoma [133]. Concentrates and milk were collected twice (during the dry season and rainy season) from 285 farmers in the five counties and analyzed for $\mathrm{AFB}_{1}$ and $\mathrm{AFM}_{1}$. Between 0 and $68 \%$ used concentrates, which had $\mathrm{AFB}_{1}$ ranging from $<1 \mu \mathrm{g} / \mathrm{kg}$ to $9,661 \mu \mathrm{g} / \mathrm{kg}$ with 47.8 to $90.3 \%$ positive samples. About $33.3 \%$ to $87.5 \%$ of the concentrates had more than $5 \mu \mathrm{g} / \mathrm{kg} \mathrm{AFB}_{1}$ ( $83.3 \%$ to $100 \%$ from retailers and $28.6 \%$ to $100 \%$ from manufacturers). $\mathrm{AFM}_{1}$ prevalence in milk was lowest in Kwale (13.6\%) and highest in Tharaka-Nithi (65.1\%). About $3.4 \%$ (Kwale) to $26.2 \%$ (Tharaka-Nithi) of milk samples had $\mathrm{AFM}_{1}$ above the WHO/FAO threshold of $0.05 \mu \mathrm{g} / \mathrm{kg}$, with the highest contamination of $6.999 \mu \mathrm{g} / \mathrm{kg}$. The study was in consonance with preceding studies which indicated that AFs are prevalent in Kenyan dairy rations and milk.

In Kisumu, Anyango et al. [134] reported that 97 randomly selected dairy farmers primarily fed cows on forage and concentrates. $\mathrm{AFM}_{1}$ levels in milk collected from these farms ranged from BDL to $0.151 \mu \mathrm{g} / \mathrm{kg}$ (mean of $0.02967 \mu \mathrm{g} /$ $\mathrm{kg}$ ) and $26.4 \%$ of these exceeded the EU limit. Concentrate feeding was associated with higher $\mathrm{AFM}_{1}$ levels so that farms feeding concentrates were more likely to record milk AF levels above $0.05 \mu \mathrm{g} / \mathrm{kg}$ [134]. Further, the prevalence of $\mathrm{AFM}_{1}$ in 96 samples of informally marketed milk from Nairobi, the knowledge of milk traders on AFs, and the effects of boiling and fermentation on $\mathrm{AFM}_{1}$ were assessed [135]. By and large, all samples had detectable AFM $_{1}$ (limit of detection $=0.005 \mu \mathrm{g} / \mathrm{kg}$ ) with a mean of $290.3 \pm 0.663 \mu \mathrm{g} / \mathrm{kg}$. About $64 \%$ of the samples had $\mathrm{AFM}_{1}$ above $0.05 \mu \mathrm{g} / \mathrm{kg}$ while $7.5 \%$ exceeded $0.5 \mu \mathrm{g} / \mathrm{kg}$. Majority of the traders had low $(69.8 \%)$ or medium $(30.2 \%)$ knowledge of AFs. The educated and female traders were more knowledgeable, and fermentation of milk to Lala (a traditional fermented drink) or yoghurt significantly reduced $\mathrm{AFM}_{1}$ levels by $71.8 \%$ (in Lala after 15 -hour room temperature incubation) and $73.6 \%$ in yoghurt after incubation at $45^{\circ} \mathrm{C}$ for 4 hours. Boiling, however, had no appreciable effect on $\mathrm{AFM}_{1}$ levels [135].

According to Sirma et al. [9] using a quantitative risk model, an equivalent of 5 hepatocellular cancer cases and deaths and the disability-adjusted life years of 255 for Kenya in 2016 were estimated as due to exposure to AFs in milk. Other than milk, there are no reports in the open literature on AF content of other products of animal origin such as blood, eggs, ghee, and meat in Kenya.

2.2.5. Animal Feeds. As pointed earlier, farming is one possible exposure route to AFs. For example, maize which is known to be highly susceptible to AF contamination in Kenya is also a major component of livestock and poultry feeds, and therefore, regular indirect human exposure through the consumption of animal products that contain $\mathrm{AF}$ residues cannot be underrated. Elevated levels of $\mathrm{AFB}_{1}$ have been recorded in Kenyan animal feeds [88, 89]. The situation is exacerbated by dairy farmers' habit of utilizing spoilt (pest- or mould-damaged and rotten) grains for the formulation of dairy rations [74, 92]. A study carried out on animal feeds in Nairobi Province revealed that AFs ranged from $5.13 \mu \mathrm{g} / \mathrm{kg}$ to $1,123 \mu \mathrm{g} / \mathrm{kg}$, with the largest proportion lying between $11 \mu \mathrm{g} / \mathrm{kg}$ and $99 \mu \mathrm{g} / \mathrm{kg}$ [78].

Further, 81 fish feeds sourced from 70 farms and 8 feed manufacturing establishments located in Nyeri, Kenya, were subjected to AF analysis by Mwihia et al. [73]. Fish were also sampled from 12 farms for gross and microscopic pathological investigation. About $84 \%$ of the feeds were AFpositive (range $1.8-39.7 \mu \mathrm{g} / \mathrm{kg}$, mean of $7.0-8.3 \mu \mathrm{g} / \mathrm{kg}$, and median of $3.6 \mu \mathrm{g} / \mathrm{kg}$ ). About $18.5 \%$ of the feeds sampled registered total AFs above the statutory limit of $10 \mu \mathrm{g} / \mathrm{kg}$. Meanwhile, homemade and tilapia feeds had evidently higher AF levels than commercial and trout feeds. Maize bran-based feeds and fish meal recorded higher AF levels than those devoid of these constituents. Microscopy revealed that five trout farms (41.7\%) had fish with swollen abdomens, enlarged livers with white or yellow nodules, and large dark basophilic hepatic cells with hyperchromatic nuclei in irregular cords. As such, the authors inferred that aflatoxigenic contamination of fish feeds is a scourge in Nyeri which if left unchecked may cause detrimental health effects in edible fish in the area. 
2.3. Co-Occurrence of Aflatoxins with Other Mycotoxins. It is now established that mycotoxins can coexist in foods [136]. In 1995, Muriuki and Siboe [45] analyzed 40 samples of flour packed in $90 \mathrm{~kg}$ bags, 58 samples of Ugali brand, and 74 samples of Jogoo brand drawn from Nairobi, Kenya. The samples were analyzed for resident mycoflora, and some mycotoxins associated with key fungal spp. Aspergillus flavus, A. sulphureus, Fusarium moniliforme, Penicillium stoloniferum, and P. cyclopium were the reported fungal spp in the samples. Ochratoxin A was the most prevalent mycotoxin, and all the flour brands had $\mathrm{AFB}_{1}$ and $\mathrm{AFB}_{2}$ $(0.4-20 \mu \mathrm{g} / \mathrm{kg})$, ochratoxin A $(50-1,500 \mu \mathrm{g} / \mathrm{kg})$, and ZEA $(2,500-5,000 \mu \mathrm{g} / \mathrm{kg})$. The authors recommended the need for rigorous countrywide monitoring of mycotoxins in maize at both farm and market levels. The foregoing was substantiated by a report by Kedera et al. [137] who reported the presence of Fusarium fungi and fumonisin $\mathrm{B}_{1}\left(\mathrm{FB}_{1}\right)$ in maize kernel samples from smallholder farm storages in Bomet, Bungoma, Kakamega, Kericho, Kisii, Nandi, Siaya, TransNzoia, and Vihiga districts in the tropical highlands of Western Kenya. Later, Mbugua and Gathumbi [138] affirmed the occurrence of $\mathrm{AFB}_{1}, \mathrm{FB}_{1}, \mathrm{ZEA}$, and $\mathrm{DON}$ in 36 Pilsner and 39 Tusker beer samples sourced from Nairobi and the surrounding satellite towns. All the samples were negative for $\mathrm{AFB}_{1}$; the prevalence of $\mathrm{DON}$ and ZEA were $100 \%$ in both brands while $\mathrm{FB}_{1}$ incidence was $72 \%$, with incidences in Tusker (76.9\%) being markedly higher than in Pilsner (66.7\%). The mean values of contamination were 3.29 and $3.57 \mathrm{ng} / \mathrm{mL}$ for DON, $0.28 \mathrm{ng} / \mathrm{mL}$ and $0.32 \mathrm{ng} / \mathrm{mL}$ for $\mathrm{FB}_{1}$, and 7.84 and $8.50 \mathrm{pg} / \mathrm{ml}$ for ZEA in Tusker and Pilsner brands, respectively. A positive correlation was reported between DON and $\mathrm{FB}_{1}$, and DON and ZEA, affirming their co-occurrence to be from Fusarium spp. This communication suggested that there were some but safe exposure to Fusarium mycotoxins by lager beer consumers of Kenya.

Fumonisin $\mathrm{B}_{1}$ and $\mathrm{AFB}_{1}$ in symptomless and rotten maize harvested at different harvest time points after physiological maturity (HTPAPM) from Malava and Tongaren were evaluated [139]. Fusarium verticillioides dominated at all HTPAPM though $F$. graminearum, F. subglutinans, A. flavus, A. parasiticus, and Stenocarpella maydis were also encountered. $\mathrm{FB}_{1}$ concentrations in symptomless maize ranged between 22 and $1,348 \mu \mathrm{g} / \mathrm{kg}$ with mean levels of 56,80 , and $317 \mu \mathrm{g} / \mathrm{kg}$, respectively, at 4,8 , and 12 weeks HTPAPM for Malava in the year 2001. In Tongaren during the same year, mean $\mathrm{FB}_{1}$ levels of 41,179 , and $590 \mu \mathrm{g} /$ $\mathrm{kg}$ were recorded at 4,8 , and 12 weeks HTPAPM, respectively. The concentration of $\mathrm{FB}_{1}$ in rotten maize ranged from 39 to $>5,000 \mu \mathrm{g} / \mathrm{kg}$ and increased with HTPAPM. The highest $\mathrm{AFB}_{1}$ level was $17.0 \mu \mathrm{g} / \mathrm{kg}$ in rotten maize. The authors hinted that the isolation of $F$. subglutinans and F. graminearum was an indication that other mycotoxins (DON, ZEA, and moniliformin) associated with infertility and hypoestrogenism could be inevitable in the samples.

In a study scrutinizing commodities, feeds, and feed ingredients from Middle East and Africa [140], 48\% (12/25) samples from Kenya were positive for B-trichothecenes (mean: $422 \mu \mathrm{g} / \mathrm{kg}$; maximum: $3859 \mu \mathrm{g} / \mathrm{kg}$ ), none had
A-trichothecenes, 76\% (19/25) had FUM (mean: $956 \mu \mathrm{g} / \mathrm{kg}$; maximum $10,485 \mu \mathrm{g} / \mathrm{kg}$ ), 56\% (14/25) had ZEA (mean: $67 \mu \mathrm{g} / \mathrm{kg}$; maximum: $167 \mu \mathrm{g} / \mathrm{kg}), 78 \%(21 / 27)$ had AFs (mean: $52 \mu \mathrm{g} / \mathrm{kg}$; maximum: $556 \mu \mathrm{g} / \mathrm{kg}$ ), while $50 \%(1 / 2)$ had ochratoxin A (mean: $2 \mu \mathrm{g} / \mathrm{kg}$ ). A gluten sample from Kenya presented the highest level of FUM found in the whole survey $(10,485 \mu \mathrm{g} / \mathrm{kg})$.

Similarly, maize samples were collected from 30 markets in diverse agroecological zones of Meru, Machakos, and Kitui counties during the 2013 harvest [54]. Fusarium and Aspergillus spp were isolated from the samples. Total AFs in Meru, Kitui, and Machakos samples were beyond the threshold of $10 \mu \mathrm{g} / \mathrm{kg}$. Meru had both the highest and lowest levels of AFs detected $(115.7 \mu \mathrm{g} / \mathrm{kg}$ and $0.3 \mu \mathrm{g} / \mathrm{kg}$, respectively). FUMs were reported in levels above the acceptable limits in Meru, and though detected in Kitui and Machakos, the contamination levels were within acceptable limits. Utilizing a near-infrared single kernel sorting machine, removal of $\mathrm{AF}$ and $\mathrm{FUM}$-contaminated kernels was perfected with up to $97.8 \%$ efficacy for AFs and $60.8 \%$ for FUM. The accepted fractions had statistically lower mycotoxin levels than the rejected maize [54].

The prevalence of AFs and FUM was investigated in maize intended for immediate human consumption in Eastern Kenya. Samples were collected from people who brought their maize for processing at local commercial mills [75]. Interviews and sampling of maize flours were done for 1,500 people who processed maize at 143 mills in 10 administrative districts. Mycotoxin analysis revealed that 39\% and $37 \%$ of the samples, respectively, had AFs and FUM in levels above tolerable limits. Samples with AFs above $10 \mu \mathrm{g} /$ $\mathrm{kg}$ were $22-60 \%$ across the districts. A higher occurrence of AFs was associated with smaller maize farms, lower grain yield, and monocropping systems. A larger magnitude of the toxin was observed in the subhumid agroecological zone, in samples with more broken kernels and less maize ear damage at harvest. Further scrutiny of paired grain samples (visually sorted and unsorted) showed that sorting reduced FUM by $65 \%$ to below the advisory threshold of $1,000 \mu \mathrm{g} / \mathrm{kg}$. Sorting did not, in essence, have any effect on AF concentration [75].

Besides, the presence of AFs, FUM, and DON in Busaa (a maize-based traditional beer) in Bomet County, Kenya, was reported [141]. Of the 61 samples obtained from homesteads involved in brewing in the northeastern part of Bomet East constituency, $93 \%, 9.8 \%$, and $23 \%$, respectively, were contaminated with AFs (mean: $5.2 \pm 0.2 \mu \mathrm{g} / \mathrm{kg}$; range: $2.8-11 \mu \mathrm{g} /$ $\mathrm{kg}$ ), FUM (mean $1460 \pm 188 \mu \mathrm{g} / \mathrm{kg}$; range: 280 to $4000 \mu \mathrm{g} /$ $\mathrm{kg}$ ), and DON (mean: $259 \pm 5.2 \mu \mathrm{g} / \mathrm{kg}$; range: $200-360 \mu \mathrm{g} /$ $\mathrm{kg}$ ). About $65.6 \%$ of these had AFs above the EU limit of $4 \mu \mathrm{g} / \mathrm{kg}$, but FUM and DON concentrations were all within the tolerable limits of $4,000 \mu \mathrm{g} / \mathrm{kg}$ and $1,750 \mu \mathrm{g} / \mathrm{kg}$, respectively. AFs \& FUM, AFs \& DON, and AFs, FUM, \& DON cooccurred in $9.8 \%, 23 \%$, and $3.3 \%$ of the samples, respectively [141].

Comparably, Mutiga et al. [72] evaluated AFs and FUM in maize from Western Kenya. The study covered 3 agroecological zones, taking samples of milled maize from 985 patrons of 26 hammer mills. AFs were detected in $49 \%$ of the 
samples, with $15 \%$ of these being above $10 \mu \mathrm{g} / \mathrm{kg}$. An estimated $65 \%$ of the samples from a drought-prone area were above acceptable limits. In Bungoma County, the authors assessed both AFs and FUM in four maize varieties at harvest and after 2 and 4 months of storage. For this, storage shed grain and milled samples were solicited. Mean AFs were identical for storage sheds and mills at $2.3 \mu \mathrm{g} / \mathrm{kg}$. About $41 \%$ of the samples from mills had detectable AFs, $4 \%$ of which were above $10 \mu \mathrm{g} / \mathrm{kg}$, while $87 \%$ had detectable FUM, with $50 \%$ above $1,000 \mu \mathrm{g} / \mathrm{kg}$ limit permitted in Kenya. Mean contamination levels did not vary during storage. As such, maize varieties reportedly differed in FUM contamination, with the most popular varieties spotted to be vulnerable to AFs, FUM, and weevils. It was concluded that thorough mycotoxin surveillance is vital for all parts of Kenya, irrespective of the past history of mycotoxin poisoning [72].

Samples of 74 animal feeds and 120 milk samples were simultaneously collected from individual cows and actors in the informal subvalue chains of rural and periurban dairy systems in Nakuru County, Kenya [142]. $\mathrm{AFB}_{1}$ was detected in $56 \%(41 / 74)$ of the feeds in levels above the EU limit of $5 \mu \mathrm{g} / \mathrm{kg}$ (range: BDL to $147.86 \mu \mathrm{g} / \mathrm{kg}$ ) while DON was identified in $63 \%(27 / 43)$ of the feeds (range: BDL to $179.89 \mu \mathrm{g} / \mathrm{kg})$. In the periurban dairy system, $48.5 \%(33 / 68)$ of the milk samples were contaminated with $\mathrm{AFM}_{1}$ in levels exceeding EU threshold of $0.05 \mu \mathrm{g} / \mathrm{kg}$ (range: 0.017 to $0.083 \mu \mathrm{g} / \mathrm{kg}$ ). Surprisingly, all milk samples from the rural dairy system had $\mathrm{AFM}_{1}$ in levels below the EU limit of $0.05 \mu \mathrm{g} / \mathrm{kg}$ (range: BDL to $0.041 \mu \mathrm{g} / \mathrm{kg}$ ). Linear regression depicted that there was a correlation between abiotic factors, viz., $\mathrm{pH}$, water activity, and moisture content of feeds with $\mathrm{AFB}_{1}$ and DON contamination.

Herbal preparations were sampled from Eldoret (14 liquid, 2 oil, and 34 powder samples) and Mombasa (12 liquid, 1 capsule, 3 oil, 6 tablets, and 28 powder samples) towns and analyzed for total AFs and FUMs [91]. Reported $32 \%$ of herbal products from Eldoret had AF levels less than $0.25 \mu \mathrm{g} / \mathrm{kg}$, while $34 \%$ had AFs between 0.38 and $24 \mu \mathrm{g} / \mathrm{kg}$. FUM occurred in very low concentrations in more than half of the samples. Samples drawn from Mombasa had AFs in levels lower than those from Eldoret, but the number of AFcontaminated samples was higher. About $32 \%$ of the samples had $<0.25 \mu \mathrm{g} / \mathrm{kg}$ with $14 \mu \mathrm{g} / \mathrm{kg}$ being the highest. About $80 \%$ had $<0.25 \mu \mathrm{g} / \mathrm{kg}$, and the highest was $>20 \mu \mathrm{g} / \mathrm{kg}$. Six out of 14 $(42.9 \%)$ liquid herbal samples from Eldoret were contaminated with AFs and 3 of the 6 were also contaminated with FUMs. All the 12 (100\%) liquid samples taken from Mombasa were contaminated with both AFs and FUMs. A total of 27 out of 34 (79.4\%) powders from Eldoret were contaminated, 23 with both mycotoxins and 4 with AFs only, while all the tablets (15 samples) and powders (19 samples) from Mombasa were contaminated with both mycotoxins; however, all capsules were free of mycotoxin contamination. All oily herbal samples $(n=3)$ from Mombasa were contaminated with both AFs and FUM, while only 1 oil sample from Eldoret was contaminated with FUM [91].
Into the bargain, a survey covering 116 push-pull and 139 non-push-pull cropping systems was conducted to determine the socioeconomic and agronomic factors that influence farmers' knowledge on incidence and contamination of maize by ear rots and associated mycotoxins in Siaya, Kakamega, Kisumu, Migori, and Vihiga counties of Western Kenya [143]. Data from smallholder farmers (23-80 years, $50 \%$ being female) were collected using questionnaires, and 10-20 maize cobs, depending on the size of cob, were collected from the standing crop in the field of each interviewed farmer and analyzed for AFs and FUMs. The authors reported that few farmers had knowledge of AFs and ear rots in maize. Overall, less than $20 \%$ of maize samples had AFs co-occurring with FUM, but more samples were contaminated with FUMs (range: $145.3-50,769.2 \mu \mathrm{g} / \mathrm{kg}$ ) than AFs (range: BDL-242.3 $\mu \mathrm{g} / \mathrm{kg}$ ) with maize containing the mycotoxins in levels above permissible limits $(10 \mu \mathrm{g} / \mathrm{kg}$ for AFs and $1,000 \mu \mathrm{g} / \mathrm{kg}$ for FUMs) being lower in samples from push-pull cropping system. Age of farmer and county of residence were significantly and positively associated with knowledge of AFs on the one hand. On the other hand, cropping system, county of residence, and level of education were positively associated with knowledge of maize ear rots. In addition, a strong correlation between knowledge of maize ear rots and knowledge of AFs was witnessed. The concentration of the mycotoxins was significantly and positively associated with the use of diammonium phosphate fertilizer at planting. AF levels were also positively associated with stem borer pest damage, though agronomic practices were not ideally different between push-pull and non-pushpull farmers [143].

2.4. Geographical Distribution of Aflatoxins in Kenya. Kenya was one of the hotspots of AFs first recorded [15, 144] with countries such as Uganda and Brazil [26, 145]. Kenya is partitioned into about 7 agroecological zones: humid, subhumid, transitional, temperate, semiarid, arid, and perarid [146]. AFs tend to be detected in samples from all the different zones $[105,110,130]$. This can be attributed to the similarity in the agronomic and pre-, peri-, and postharvest handling practices and the interregional marketing of foods $[61,92,111,147]$. However, the eastern part of the country is more aflatoxin-prone, possesses the most toxigenic Aspergillus spp, and has been the epicenter of aflatoxicoses recorded in Kenya [46]. Eastern Kenya experiences hotter and drier climatic conditions in comparison with Western Kenya. For this reason, it received characterization as semihumid to semiarid while Western Kenya is classified as subhumid to semihumid agroecological zone [110]. Environmental conditions have been demonstrated to influence the ability of Aspergillus fungi to infect, colonize, and survive on crops as well as produce mycotoxins. Further, fluctuations in these conditions also affect the quantities as well as community compositions of aflatoxin-producing fungi [148]. The prevalence of AFs in Eastern Kenya therefore is in 
congruence with a previous emphasis that mycotoxin infectivity is always multifactorial, but climate is the most important [149].

\section{Capacity for Detection and Quantification}

Detection and quantification of AFs are key to their mitigation because their distribution in samples is often skewed [150]. The first step for accurate detection and quantification of AFs is sampling, i.e., sampling/subsampling is the largest source of error in AFs analysis [151]. For this reason, a representative sample ought to be drawn from the sample lot. For the over 50 KEBS listed laboratories for monitoring mycotoxins in foods, Gafta methods (No. 130, 24:1) and EAS 79 are used as the sampling protocols. However, some clients do the sampling themselves, in which case the testing laboratories do not question the actual reason for sampling, or where and how the samples were taken. In addition, data from such analyses are always confidential, which do not enhance evidence-based decision making by policymakers [97].

Another emerging challenge in analyses of food toxins in Africa, Asia, America, and Europe is "masked mycotoxins" as they are not often identified and detected by the usual analytical techniques [152]. Masked (matrix-associated) mycotoxins are those that are biosynthesized by the toxigenic fungi and later undergo biomodification by plant enzymes during the infection stages. They may be housed in the vacuoles in the soluble form or bound to macromolecules and thus remain undetectable [153]. Unfortunately, these modified toxins can hydrolyze and revert back into their toxic forms during processing or digestion [154-156]. A way to circumvent this analytical problem has been to hydrolyze the modified forms (using enzymes, alkaline, or acidic pretreatments) [157-159] into their free forms which can then be detected $[157,160]$. For this reason, there is a paucity of data on masked AFs as usually detection and quantification are done for free AFs in matrices.

The methods for the detection of AFs used by studies in Kenya are outlined in Table 7. On the whole, AF research in Kenya used laboratory-based enzyme-linked immunosorbent assays (ELISAs), high-performance liquid chromatography (HPLC), thin-layer chromatography (TLC), fluorimetry, liquid chromatography-tandem mass spectrometry (LC-MS/MS), tandem quadrupole mass spectrometry (TQMS), and ultra-high-pressure liquid chromatography (UHPLC). Lateral flow immunochromatography (LFI) has also been used. There has been a shift in instrumentation for AF analysis, as evidenced by advancement from nondifferential TLC in 1973 to relatively fast and differential UHPLC, hyphenated with triple quadruple mass spectrometry (UHPLC-TTQS) in 2017-2020. Overall, the most employed method has been ELISA, which itself has undergone several advancements in the past few years. This could be because it is practically inexpensive, easy to use, is highly sensitive for routine analysis of food products, demands minimum sample clean up, and poses no inherent health hazards as it uses enzyme labels. In addition, concurrent analysis of several samples on a 96-well assay platform is possible, and thus, it has a high sample throughput with low sample volume requirement which offers obvious advantages [28]. In addition, ELISA has lower detection limits than most instrumental techniques which are used for AF determination [28].

However, the drawbacks of the foregoing standard methods are that they are unsuitable for rapid and real-time applications in food and feed sample analyses as they are relatively tedious and require technical know-how to operate. Rapid and robust methods such as polymerase chain reaction (PCR) and nondestructive methods based on fluorescence/near-infrared spectroscopy (FS/NIRS) and hyperspectral imaging (HSI) have emerged for quick and easy detection of AFs [161]. Some studies in Kenya [41-43, 46, 47, 110, 162] have utilized PCR in their analyses. It is of interest to note that, at industrial level, agroprocessing entities monitor grain total AFs utilizing single-step lateral flow immunoassays utilizing Reveal Q+ test strips that are developed and read on AccuScan Gold readers [163]. The bright greenish-yellow fluorescence (BGYF) or the black light test, which can aptly identify commodities presumed to be contaminated with AFs, has been reported in Kenya [54]. This test is relatively cheap and simple especially for detecting AFs in maize where kernels are viewed under an ultraviolet lamp at $365 \mathrm{~nm}$ for characteristic bright greenishyellow fluorescence which indicates a possible presence of aflatoxigenic fungi or the mycotoxin itself [164]. This could be adopted by regulatory agencies for the purpose of AFs surveillance.

\section{Exposure Assessment}

4.1. Exposure to Aflatoxins in Kenya. Exposure to AFs occurs via periodic ingestion of contaminated plant or animal products such as meat, eggs, blood, and milk of livestock previously served AF-contaminated rations [20]. Farmers and their workers may also inhale dust generated during the processing of contaminated crops and feeds or the toxins may permeate through their skin $[165,166]$. Exposure to AFs such as $\mathrm{AFM}_{1}$ may also be through their endogenous production [32]. In point of fact, AFs are known to cross the placenta, so that exposure to them may start in utero and continues in the postnatal period through breastfeeding [92, 167-169].

It is now established that detecting and quantifying food AF levels are not always adequately reflective of the extent of exposure because the quantities in foods are not directly the same as those ingested. For this reason, epidemiological biomarkers are often used to assess exposure. Biomarkers are quite exact in evaluating the magnitude of AF exposure because of their nonsubjectivity and faculty that allows the estimation of internal and biologically effective doses. Popular AF biomarkers are urinary AF- $\mathrm{N}^{7}$-guanine (for assessing previous day's exposure) and breast milk $\mathrm{AFM}_{1}$ which indicate exposure levels in the past 24 hours and plasma/serum aflatoxin-albumin (AF-alb) adduct with a half-life of about 2 months enhancing the evaluation of chronic and routine exposure [170]. Albumin is the sole serum protein that can get bound to $\mathrm{AFB}_{1}$, yielding 
TABLE 7: Analytical methods used by aflatoxin investigations in Kenya.

\begin{tabular}{|c|c|c|c|c|}
\hline Methods of analysis & Samples/matrices & Mycotoxins analyzed & Years & Authors \\
\hline ELISA & Maize grain & Total AFs & 2020 & Marete et al. [178] \\
\hline Fluorimetry, PCR & Soil & Total AFs & 2020 & Monda et al. [46] \\
\hline UHPLC & Maize grain (fresh), maize flour & $\mathrm{AFB}_{1}, \mathrm{AFG}_{1}, \mathrm{AFB}_{2}, \mathrm{AFG}_{2}$ & 2020 & Nabwire et al. [77] \\
\hline UPLC, PCR & Maize grain & $\mathrm{AFB}_{1}, \mathrm{AFG}_{1}, \mathrm{AFB}_{2}, \mathrm{AFG}_{2}$ & 2019 & Oloo et al. [42] \\
\hline $\begin{array}{l}\text { Quantitative PCR } \\
\text { (qPCR), TLC, HPLC }\end{array}$ & Maize tissues/grain & $\begin{array}{l}\text { A. flavus biomass, } \mathrm{AFB}_{1}, \mathrm{AFG}_{1} \\
\qquad \mathrm{AFB}_{2}, \mathrm{AFG}_{2}\end{array}$ & 2019 & Mitema et al, [43] \\
\hline ELISA & Bovine milk & $\mathrm{AFM}_{1}$ & 2019 & Kagera et al. [129] \\
\hline ELISA & Maize & $\mathrm{AFB}_{1}$ & 2019 & Mahuku et al. [94] \\
\hline ELISA & Maize & Total AFs, FUM & 2019 & Njeru et al. [143] \\
\hline ELISA & Bovine milk & $\mathrm{AFM}_{1}$ & 2019 & Kuboka et al. [135] \\
\hline PCR & Soils & A. flavus genotyping & 2018 & Islam et al. [47] \\
\hline $\begin{array}{l}\text { LC-MS/MS, UHPLC- } \\
\text { TTQS, PCR }\end{array}$ & Maize samples & $\begin{array}{l}\mathrm{AFB}_{1}, \mathrm{AFG}_{1}, \mathrm{AFB}_{2}, \mathrm{AFG}_{2}, \\
\text { Aspergillus spp genotyping }\end{array}$ & 2018 & Okoth et al. [48] \\
\hline PCR, HPLC & Kimere (a fermented milk product) & $\mathrm{AFB}_{1}$ & 2018 & Nduti [179] \\
\hline LFI & Maize grain, human sera (children) & Total AFs, $\mathrm{AFB}_{1}$ (lysine adducts) & 2018 & Hoffmann et al. [180] \\
\hline ELISA & $\begin{array}{c}\text { Raw, pasteurized and UHT milk, yoghurt, } \\
\text { Lala }\end{array}$ & $\mathrm{AFM}_{1}$ & 2018 & Lindahl et al. [90] \\
\hline ELISA, TLC, HPLC & Maize grain & Total AFs, $\mathrm{AFB}_{1}$ & 2018 & $\begin{array}{l}\text { Obonyo and Salano } \\
{[63]}\end{array}$ \\
\hline ELISA, PCR & Maize kernels & Total AFs & 2018 & Gachara et al. [110] \\
\hline ELISA, LC-HRMS/MS & Fish feeds & Total AFs & 2018 & Mwihia et al. [73] \\
\hline ELISA, HPLC & $\begin{array}{l}\text { Urine, breast milk, maize flour, sorghum, } \\
\text { millet }\end{array}$ & $\mathrm{AFM}_{1}$ & 2017 & Kang'ethe et al. [169] \\
\hline LFI & Maize grain and maize flour & Total AFs & 2017 & Nduti et al. [95] \\
\hline ELISA & Herbal products & Total AFs, FUMs & 2017 & Keter et al. [91] \\
\hline $\begin{array}{l}\text { HPLC, UPLC-MS/MS, } \\
\text { LC-MS/MS }\end{array}$ & Human urine, human blood & $\mathrm{AFM}_{1}, \mathrm{AFB}_{1}$ (lysine adducts) & 2017 & Awuor et al. [181] \\
\hline ELISA & Dairy cattle feeds, bovine milk & $\mathrm{AFB}_{1}, \mathrm{AFM}_{1}$ & 2016 & Ochungo et al. [58] \\
\hline ELISA & Bovine milk & $\mathrm{AFM}_{1}$ & 2016 & Kirino et al. [131] \\
\hline ELISA & Animal feeds and bovine milk & $\mathrm{AFB}_{1}, \mathrm{DON}$, and $\mathrm{AFM}_{1}$ & 2016 & Makau et al. [142] \\
\hline ELISA, HPLC, LC/MS & Maize grain, urine & $\mathrm{AFB}_{1}, \mathrm{AFM}_{1}$ & 2016 & Nduti et al. [182] \\
\hline ELISA & Dairy cattle concentrates, bovine milk & $\mathrm{AFB}_{1}, \mathrm{AFM}_{1}$ & 2016 & Senerwa et al. [133] \\
\hline ELISA & $\begin{array}{l}\text { Bovine milk (raw and processed), dairy } \\
\text { products }\end{array}$ & $\mathrm{AFM}_{1}$ & 2016 & Langat et al. [132] \\
\hline ELISA & Maize, sorghum, and milk & Total AFs and $\mathrm{AFM}_{1}$ & 2016 & Kiarie et al. [66] \\
\hline HPLC & Peanuts & Total AFs & 2016 & Menza et al. [121] \\
\hline ELISA & Maize grain & Total AFs & 2016 & Kirui [183] \\
\hline ELISA & Cassava (chips and flour) & Total AFs & 2015 & Gacheru et al. [126] \\
\hline ELISA & $\begin{array}{c}\text { Omena, maize, sorghum, rice, peanuts, } \\
\text { cassava }\end{array}$ & $\mathrm{AFB}_{1}, \mathrm{AFM}_{1}$ & 2015 & Obade et al. [80] \\
\hline ELISA & Maize (grain and flour) & Total AFs, FUM & 2015 & Mutiga et al. [72] \\
\hline ELISA & Maize, sorghum, millet & Total AFs & 2015 & Sirma et al. [76] \\
\hline HPLC & Human sera (women) & $\mathrm{AFB}_{1}$ (lysine adducts) & 2015 & Leroy et al. [60] \\
\hline ELISA, qPCR & Human sera (children) & $\mathrm{AFB}_{1}$ (albumin adducts) & 2015 & Castelino et al. [162] \\
\hline TLC, HPLC & $\begin{array}{c}\text { Fresh and sun-dried fish (Rastrineobola } \\
\text { argentea) }\end{array}$ & Total AFs & 2015 & Orony et al. [85] \\
\hline ELISA & Cattle feeds, rice, maize, peanuts & Total AFs & 2014 & Nyangaga [86] \\
\hline ELISA & Maize grain & Total AFs, FUM & 2014 & Mutiga et al. [75] \\
\hline TLC, HPLC & Maize grains, githeri, muthokoi & Total AFs & 2014 & Kilonzo et al. [109] \\
\hline ELISA & Bovine milk & $\mathrm{AFM}_{1}$ & 2014 & Sirma et al. [130] \\
\hline ELISA, BGYF & Maize grain & Total AFs, FUM & 2014 & Murithi [54] \\
\hline LFI & Busaa (a local brew) & Total AFs, FUM, DON & 2014 & Kirui et al. [141] \\
\hline ELISA & Peanuts (raw and roasted) & Total AFs & 2013 & $\begin{array}{c}\text { Nyirahakizimana et al. } \\
{[115]}\end{array}$ \\
\hline ELISA & Peanuts & Total AFs & 2013 & Mutegi et al. [64] \\
\hline ELISA & Peanuts and peanut products & Total AFs & 2013 & Mutegi et al. [62] \\
\hline ELISA & Peanuts (raw and roasted), peanut butter & Total AFs & 2013 & Ndung'u et al. [53] \\
\hline TQMS & Human sera & $\mathrm{AFB}_{1}$ (lysine adducts) & 2013 & Yard et al. [184] \\
\hline ELISA & Peanuts & Total AFs & 2012 & Mutegi et al. [44] \\
\hline LC-MS/MS, PCR & Maize kernels & $\mathrm{AFB}_{1}, \mathrm{AFG}_{1}, \mathrm{AFB}_{2}, \mathrm{AFG}_{2}$ & 2012 & Okoth et al. [41] \\
\hline
\end{tabular}


TABLE 7: Continued.

\begin{tabular}{|c|c|c|c|c|}
\hline Methods of analysis & Samples/matrices & Mycotoxins analyzed & Years & Authors \\
\hline TLC & $\begin{array}{l}\text { Maize (grains, flour), milled maize-cereal } \\
\text { products, dairy cattle feed, oil seed cake }\end{array}$ & Total AFs & 2012 & Okoth and Kola [78] \\
\hline ELISA & Human plasma (children) & $\mathrm{AFB}_{1}$ (albumin adducts) & 2012 & Gong et al. [185] \\
\hline ELISA & $\begin{array}{l}\text { Maize (grains, flour, semiprocessed), soil, } \\
\text { mill dust }\end{array}$ & Total AFs & 2012 & Muthomi et al. [107] \\
\hline Fluorimetry & Maize grain & Total AFs & 2011 & Daniel et al. [70] \\
\hline LC-MS, HPLC & Commodities, feeds, and feed ingredients & $\begin{array}{c}\text { Total AFs, FUM, ZEA, } \\
\text { trichothecenes (A\&B), ochratoxin } \\
\text { A }\end{array}$ & 2011 & Rodrigues et al. [140] \\
\hline ELISA & Ground maize, soil & Total AFs & 2010 & Probst et al. [55] \\
\hline ELISA & Milk, animal feeds & $\mathrm{AFM}_{1}, \mathrm{AFB}_{1}$ & 2009 & $\begin{array}{c}\text { Kang'ethe and Lang'a } \\
\text { [89] }\end{array}$ \\
\hline ELISA & Maize, soils, mill dust & $\mathrm{AFB}_{1}$ & 2009 & Muthomi et al. [40] \\
\hline ELISA & Peanuts & Total AFs & 2009 & Mutegi et al. [61] \\
\hline ELISA & Maize grain & $\mathrm{AFB}_{1}, \mathrm{FB}_{1}$ & 2009 & Alakonya et al. [139] \\
\hline HPLC/fluorimetry & Maize grain & $\mathrm{AFB}_{1}$ & 2007 & Probst et al. [39] \\
\hline ELISA & Peanuts & Total AFs & 2007 & Mutegi et al. [65] \\
\hline HPLC & Maize kernels, maize flour, muthokoi & Total AFs & 2005 & Lewis et al. [71] \\
\hline Fluorimetry & Maize grain & Total AFs & 2005 & $\begin{array}{l}\text { Azziz-Baumgartner } \\
\text { et al. [69] }\end{array}$ \\
\hline Fluorimetry & Maize grain and maize products & Total AFs & 2005 & $\begin{array}{l}\text { Muture and Ogana } \\
{[103]}\end{array}$ \\
\hline ELISA & Pilsner and Tusker beers & $\mathrm{AFB}_{1}, \mathrm{FB}_{1}, \mathrm{DON}, \mathrm{ZEA}$ & 2004 & $\begin{array}{l}\text { Mbugua and } \\
\text { Gathumbi [138] }\end{array}$ \\
\hline TLC & Peanuts & Total AFs & 2004 & Gachomo et al. [84] \\
\hline TLC & Weaning foods & Total AFs & 2004 & $\begin{array}{l}\text { Okoth and Ohingo } \\
{[118]}\end{array}$ \\
\hline TLC, HPLC & Malted millet, maize flour & $\mathrm{AFB}_{1}, \mathrm{AFB}_{2}$ & 2000 & Kenji et al. [81] \\
\hline ELISA, HPLC-FS & Human sera & $\mathrm{AFB}_{1}$ (lysine adducts) & 1990 & Wild et al. [186] \\
\hline HPLC & $\begin{array}{l}\text { Breast milk, human sera, neonatal cord } \\
\text { blood, blood (pregnant women) }\end{array}$ & $\begin{array}{c}\mathrm{AFB}_{1}, \mathrm{AFB}_{2}, \mathrm{AFG}_{1}, \mathrm{AFG}_{2}, \mathrm{AFM}_{1} \\
\mathrm{AFM}_{2} \text {, aflatoxicol }\end{array}$ & 1989 & Maxwell et al. [187] \\
\hline HPLC & Human urine & $\mathrm{AFB}_{1}$ (guanine adduct) & 1987 & Autrup et al. [188] \\
\hline TLC & $\begin{array}{l}\text { Local beer, food (maize, millet, sorghum, } \\
\text { pigeon peas, and yam components) }\end{array}$ & Total AFs & 1973 & Peers and Linsell [82] \\
\hline
\end{tabular}

Years are those in which the data joined scientific literature with most data gathered and analyzed in more than 3 months before publication. Muthokoi are maize kernels with the outer hull removed. Lala also called Maziwa Lala or Mala is a locally fermented milk product. Busaa is a sociocultural maize-based traditional brew mostly consumed during events such as male circumcisions, weddings, and funerals, made from raw maize flour and semiground finger millet malt [141]. LC-HRMS/MS: liquid chromatography high-resolution mass spectrometry. LFI: Hoffmann et al. [180] used Romer AgraStrip rapid test; Kirui et al. [141] used Envirologix Quick Tox kits.

biomarker adducts [171]. Human blood and urine AF-alb can be used to determine the biologically effective dose of ingested $\mathrm{AFB}_{1}$. Though both $\mathrm{AFG}_{1}$ and $\mathrm{AFB}_{1}$ can covalently interact with albumin to form AF-8, 9-epoxide [98], the adduct levels are taken to reflect the amount of the latter as the former is infrequently encountered in foods [172]. The AF-alb adduct is the most frequently utilized AF biomarker because it is easily detectable using ELISA (Table 7) [173]. Additionally, the determination of $\mathrm{AFB}_{1}$-Lys levels in proteolytic digests of serum with LC-MS/MS and HPLC-FS has recently been appraised [174, 175].

Biopsy material was first utilized in 1967 to illustrate that the Kamba ethnic community of Kenya had a frequency of liver cancer that was doubling that of the Kikuyus [176]. This is partly supported by the fact that subsequent aflatoxicoses were witnessed in Eastern Kenya where the Kamba are the main inhabitants [71, 177]. A dietary AF-liver cancer study in Murang'a district of Kenya reassessed the correlation between $\mathrm{AF}$ and the disease incidence rates based on a total of 7 years of cancer registration [82]. The results of the study were however interpreted in combination with a study later done in Swaziland. With consideration of males and females separately, the pooled results of the studies hinted that there was a high degree of positive correlation between the calculated ingestion levels of AFs $(X)$ and the adult incidences of hepatocellular carcinoma $(Y)$ for the two studied populations and for both males and females. With the assumption of a wet intake diet of $2 \mathrm{~kg} /$ day and a mean body weight of $70 \mathrm{~kg}$, the relationship for adult females was $Y=4.14 \log _{10} X-0.80$. With a further assumption of a daily intake of native beer of 2 liters/day, the regression equation for adult males was $Y=21.96 \log _{10} X-11.17$. The regression data were reported to corroborate those reported by previous researchers [82].

To validate the assertion, another team [188] evaluated if there were any synergistic effects of hepatitis $B$ virus and $\mathrm{AFB}_{1}$ on the incidences of hepatocellular cancer. The study encompassed various parts of Kenya with different liver 
cancer incidences so as to establish the rate of exposure to AFs and the prevalence of hepatitis infections. It turned out that of all the tested participants, $12.6 \%$ were positive for AF exposure as shown by urinary excretion of $\mathrm{AF}^{-\mathrm{N}^{7}}$-guanine adduct and the highest exposure to the toxins was in the Western Highlands and Central Province. The incidence of hepatitis infection nationwide as measured by the presence of the surface antigens was $10.6 \%$ with a marked regional variation. Execution of multiplicative and additive regression analysis suggested that the two were not a synergetic combination in the etiology of liver cancer, though a moderate degree of correlation between AF exposure and liver cancer was observed when the study was limited to certain ethnic groups [188].

Further, Maxwell et al. [187] undertook a study in Kenya, Sudan, Ghana, and Nigeria to evaluate the extent of AF exposure by breastfed infants and to investigate the possibility that AFs cross the human placental membrane. In this study, breast milk, cord blood, and maternal blood were analyzed for AFs which were detected in $28 \%$ of 191 Kenyan, $37 \%$ of 99 Sudanese, and $34 \%$ of 510 Ghanaian breast milk samples (Table 8). Blood drawn from 101 babies in Kenya, 282 babies in Ghana, and 78 babies in Nigeria had AFs in $37 \%, 31 \%$, and $12 \%$ of the samples, respectively. In Kenya, the rate of detection was higher in the wet season (52\%) than in the dry season (23\%). Maternal blood sampled at delivery in 83 Kenyan cases and 77 Nigerian cases recorded AFs in both maternal and cord blood specimens in 14 Kenyan and 7 Nigerian instances. These confirmed that infantile exposure to AFs occurs and demonstrated the ability of AFs to cross the human placental membrane [187].

Differently, a survey which recruited adults from Kenya, Thailand, The Gambia, and France was used to validate the measurement of AF-albumin adducts by three methods [186]. Levels of 7 to $338 \mathrm{pg} \mathrm{AF} / \mathrm{mg}$ alb were observed in the first three countries while no adducts were detected in samples from France. Another cross-sectional serosurvey in Kenya confirmed regional influence on AF exposure patterns [184]. Randomly selected 600 serum specimens stratified by province from a 2007 Kenya AIDS Indicator Survey were analyzed for AFs. About $78 \%$ of the sampled group had exposure to AFs and this varied by province. The highest were in Eastern (median $=7.87 \mathrm{pg} / \mathrm{mg}$ alb) and Coast (median $=3.70 \mathrm{pg} / \mathrm{mg}$ alb) provinces, while Nyanza (median $\leq$ limit of detection) and Rift Valley (median $=0.70 \mathrm{pg} / \mathrm{mg}$ alb) provinces recorded the lowest exposures. According to the authors, age group, sex, marital status, religion, and socioeconomic characteristics did not influence exposure.

In another study, random samples of weaning flours were obtained from 242 households with 3- to 36-month-old children (43.6\% males and 53.4\% females) in Kisumu district, Kenya, and analyzed for AFs [118]. The types of weaning foods, handling, and storage of the foods were captured. The nutritional status of the children was also determined along with heights and lengths. About 29\% (70/ 242) of the samples were positive for total AFs (range: $2-82 \mu \mathrm{g} / \mathrm{kg}$ ). Malnutrition was $34 \%$ for stunting, 30\% for underweight, and $6 \%$ for wasting. About $53.8 \%$ of the wasted children were being fed on AF-contaminated weaner flour vis-à-vis $27.7 \%$ of the normal children. The contaminated flours $(n=70)$ were being stored in plastic containers $(63 \%)$, polyethylene bags (20.4\%), metal buckets (3.7\%), manila sacks (1.9\%), earthen pots (1.9\%), and reed baskets (7.4\%) for 1 day to 2-3 weeks. These all had effects on aflatoxigenic contamination as those with AFs had higher mean moisture content (13.6\%) than those devoid of AFs (12.5\%). Aspergillus spp (including A. flavus and A. parasiticus), Fusarium, Mucor, Rhizopus nigricans, Trichoderma viride, and Candida spp were isolated from the flour samples [118].

Agreeably, Leroy et al. [60] collected socioeconomic data to quantify the extent to which socioeconomic characteristics could explain the differences in serum $A_{F B}$-lysine adduct levels in 100 women from the Eastern province of Kenya. The correlation between serum $\mathrm{AFB}_{1}$ level and a number of households, farm, and individual characteristics was assessed for 884 mothers (pregnant or with a child under 24 months). AF was detected in all women with a median level of $7.47 \mathrm{pg} / \mathrm{mg}$ alb. Higher exposure levels were correlated with poverty: predicted serum AF levels in women living in the worst socioeconomic conditions were 4.7-7.1 times higher than those with the best socioeconomic status.

Further, samples of Rastrineobola argentea $(n=50)$, polished rice $(n=31)$, peanuts $(n=22)$, cassava $(n=37)$, maize $(n=41)$, and sorghum $(n=28)$ were collected from Kibuye wholesale, Kibuye open-air, Ahero, Oile, and Mamboleo markets in Kisumu County and analyzed for AFs [80]. Processed bovine milk samples $(n=50)$ were collected from supermarkets along with raw bovine milk samples $(n=30)$ from 3 market milk bazaars in the same markets. Analytical results indicated that AFs ranged from 0 to $34.5 \mu \mathrm{g} / \mathrm{kg} \mathrm{AFB}_{1}$ in the solid foods, 0.012 to $0.127 \mu \mathrm{g} / \mathrm{kg}$ $\mathrm{AFM}_{1}$ in processed milk, and 0.0002 to $0.013 \mu \mathrm{g} / \mathrm{kg} \mathrm{AFM}$ in raw milk. Only cassava among the scrutinized food items had detectable AFs below the regulatory limit of $10 \mu \mathrm{g} / \mathrm{kg}$ $\mathrm{AFB}_{1}$ by then. Daily AF consumption ranged from $4.43 \mathrm{ng} /$ $\mathrm{kg}$ bw/day in a combination of maize flour and milk to $110.4 \mathrm{ng} / \mathrm{kg}$ bw/day in a combination of sorghum and raw milk for 6-month-old children (average weight: $7.9 \mathrm{~kg}$ ) with a daily consumption of $60 \mathrm{~g}$ of mixed cereal flour and $500 \mathrm{ml}$ of milk per day. These results emphasized that weaning children in Kisumu County are chronically exposed to high $\mathrm{AF}$ levels for the fact that the analyzed food items are common ingredients of weaning foods in the area [80]. In addition, the calculated AF consumption of $0.6 \mathrm{ng} / \mathrm{kg} \mathrm{bw} /$ day for a child at 6 months weighing $7.9 \mathrm{~kg}$ was higher than that indicated by the Codex Alimentarius Committee (0.1 ng/person/day) $\mathrm{AFM}_{1}$ through milk for the Africa region. The weighted mean concentration of $0.05 \mu \mathrm{g} \mathrm{AFM}_{1}$ in milk and a consumption of $0.25 \mathrm{ng} / \mathrm{kg}$ bw/day have been associated with a prevalence of between 3.2 and 20 cancer cases/year $/ 10^{6}$ [189]. The exposure was much higher than estimated because most children in Kenya are breastfed until at least the latter part of the second year and yet they begin to receive cereal-based gruel before the age of 3 months [190]. Further, the results of the study corroborated a previous report which estimated that about $40 \%$ of foods from farmers in the Nyanza province had AF levels above the statutory limit of $10 \mu \mathrm{g} / \mathrm{kg}$ [65]. 
TABle 8: AF content of breast milk and cord blood from Kenya, Sudan, Ghana, and Nigeria.

\begin{tabular}{lcccc}
\hline Sample & Country & Number of samples & Number of AF-positive samples & Positive samples (\%) \\
\hline \multirow{3}{*}{ Breast milk } & Kenya & 191 & 53 & 28 \\
& Sudan & 99 & 37 & 37 \\
& Ghana & 510 & 163 & 32 \\
\hline \multirow{3}{*}{ Cord blood } & Kenya & 101 & 37 & 37 \\
& Nigeria & 78 & 9 & 12 \\
& Ghana & 282 & 86 & 30.5 \\
\hline
\end{tabular}

Adapted from [187]. $\mathrm{AFM}_{1}$ was detected in 121 milk samples (range: 5-1379 ng/L), $\mathrm{AFM}_{2}$ in 103 (range: 3-6368 ng/L), $\mathrm{AFB}_{1}$ in 41 (range: 150-55,792 ng/L), $\mathrm{AFB}_{2}$ in 10 (range: $49-623 \mathrm{ng} / \mathrm{L}$ ), $\mathrm{AFG}_{1}$ in 4 (range: $1890-5180 \mathrm{ng} / \mathrm{L}$ ), $\mathrm{AFG}_{2}$ in 3 (range: $10-87 \mathrm{ng} / \mathrm{L}$ ), and aflatoxicol in 6 (range: $14-270 \mathrm{ng} / \mathrm{L}$ ). In cord blood, $\mathrm{AFM}_{1}$ (range: $25-8942 \mathrm{ng} / \mathrm{L}$ ) and $\mathrm{AFM}_{2}$ (range: $15-732 \mathrm{ng} / \mathrm{L}$ ) were detected frequently in 63 and 47 samples; $\mathrm{AFB}_{1}(\mathrm{range}: 185-43822 \mathrm{ng} / \mathrm{L})$ and $\mathrm{AFB}{ }_{2}(\mathrm{range}$ : $10-925 \mathrm{ng} / \mathrm{L}$ ) were detected in 20 and 19 samples. $\mathrm{AFG}_{1}$ was detected 4 times (range: 611-2086 ng/L), $\mathrm{AFG}_{2}$ once (37 ng/L) and aflatoxicol thrice (177, 214, \& $280 \mathrm{ng} / \mathrm{L})$.

Another cross-sectional study was undertaken involving 204 low-income households randomly selected in two lowincome areas (Korogocho and Dagoretti), Nairobi, Kenya [66]. Demographics, a 24-hour dietary recall, and anthropometric measurements were conducted in children aged 1-3 years. Height-for-age Z-scores (HAZ), weight-for-age Z-scores (WAZ), and weight-for-height Z-scores (WHZ) were calculated for each child using the WHO growth standard reference data. Maize $(n=99$ and 87), sorghum ( $n=53$ and 36), and milk ( $n=76$ and 52) samples from the households or retailers from Korogocho and Dagoretti, respectively, were analyzed for total $\mathrm{AFs}$ and $\mathrm{AFM}_{1}$. As a whole, $98 \%$ of food samples collected were AF positive (maize: mean: 6.7, range: 0.0-88.83; sorghum: mean: 8.07, range: $0.1-194.41$; milk: mean: 0.132 , range: $0.007-2.56$ for samples from Korogocho; maize: mean: 2.97, range: 0.0-20.0; sorghum: mean: 2.59, range: 0.2-14.47; milk: mean: 0.093, range: 0.002-0.64 for samples from Dagoretti). About $41 \%$ of the children had stunted growth; boys were more stunted than girls $(p=0.057)$, and Korogocho had more stunted children than Dagoretti $(p=0.041)$. The average $\mathrm{AF}$ exposure was $21.3 \mathrm{ng} / \mathrm{kg}$ bw/day. Exposure to $\mathrm{AFM}_{1}$, location, and sex was significantly associated with HAZ, with boys and children from Korogocho having lower $\mathrm{HAZ}$, and $\mathrm{AFM}_{1}$ was negatively associated with HAZ ( $p=0.047)$, suggesting that $\mathrm{AFM}_{1}$ was associated with stunting. No correlation was statistically found between total AFs and HAZ, WAZ, and WHZ. The authors reiterated that there was a high prevalence of malnutrition (stunting) in the studied low-income urban sites, and this was most pronounced in the high-density area. It was stressed that the association between $\mathrm{AFM}_{1}$ and growth impairment warranted further investigations [66].

Kang'ethe et al. [169] reported that, with a maize consumption of 0.1 to $0.25 \mathrm{~kg} / \mathrm{person} /$ day in Nandi and Makueni counties, an AF exposure rate of 0.011 and $0.49 \mu \mathrm{g} /$ $\mathrm{kg}$ bw/day, respectively, was recorded in children younger than 5 years. Exposure to $\mathrm{AFM}_{1}$ through milk consumption in this study was $4 \times 10^{-4}$ and $1 \times 10^{-4} \mu \mathrm{g} / \mathrm{kg}$ bw/day, respectively. Breast milk nursed children on the other hand had exposure of $6 \times 10^{-3}$ and $1 \times 10^{-6} \mu \mathrm{g} / \mathrm{kg}$ bw/day in Makueni and Nandi, respectively. Children younger than 30 months in Makueni had 1.4 times higher levels of $\mathrm{AFM}_{1}$ in urine than those of the same age in Nandi. The stunting and severe stunting rates in Makueni and Nandi were 28.7\% and $18.5 \%$, and $30.7 \%$ and $16.5 \%$, respectively.

In a recent study [180] which enrolled 1230 unborn children, 881 (72\%) were included in LAZ and 798 (65\%) in the serum $\mathrm{AFB}_{1}$ analysis. A cluster randomised controlled design was used (28 intervention and 28 control clusters). The intervention arm received a swapping (contaminated maize was replaced with safe maize) and a stockist intervention (households were encouraged to purchase from a stockist supplied with clean maize). Women in the fifth to the final month of pregnancy were invited to enroll in the study. Outcomes were child LAZ, the prevalence of stunting, and child serum $\mathrm{AFB}_{1}$-lysine adduct level 24 (end-line, primary outcomes) and 11 to 19 months (midline, secondary outcomes) after trial commencement, respectively. The intervention was reported to considerably reduce end-line $\ln$ serum $\mathrm{AFB}_{1}$-lysine adduct levels (intervention effect was $0.273,95 \%$ CI 0.547 to 0.001 ; one-sided $p=0.025$ ) but had no effect on end-line LAZ or stunting (mean LAZ at end-line was -1.64). At midline, the intervention increased LAZ by 0.16 (95\% CI -0.009 to 0.33 ; one-sided $p=0.032$ ) and reduced stunting by $7 \%$ points $(95 \% \mathrm{CI}-0.125$ to -0.007 ; onesided $p=0.015$ ) but had no effect on serum $\mathrm{AFB}_{1}$ levels [180]. It was inferred that the midline analysis suggested that AFs may affect linear growth at younger ages.

Overall average estimation of exposure rates based on annual consumption, as is appropriate for cancer risk because of the cumulative nature of this response, indicates that AF exposure was 3.5 to $14.8 \mathrm{ng} / \mathrm{kg} /$ day in Kenya for about $67 \%$ of the population $[92,191]$. No study in Kenya has examined the relationship between $\mathrm{AFM}_{1}$ in breast milk samples and growth impairment in infants.

4.2. Coexposure to Aflatoxins with Other Mycotoxins. Aflatoxin poisoning could be compounded by the occurrence of AFs in combination with other mycotoxins such as FUM, trichothecenes, ochratoxins, ZEA, and DON $[16,192,193]$. This is supported by the occurrence of mycotoxin producing fungi simultaneously in the same batch of food/matrix and the faculty of some toxigenic fungi to produce more than one mycotoxin in a given matrix. For example, Fusarium (F. verticillioides, $F$. proliferatum, and F. oxysporum) [54] and Penicillium spp were reported with 
Aspergillus fungi in Kenya [41, 45, 53, 84, 115, 194, 195], sometimes in soils and mill dust around maize stores [40]. Fusarium spp are known for the production of FUMs [196].

The current review did not identify any reports evaluating coexposure to AFs in combination with other mycotoxins and the potential adverse health outcomes. There have been developments in both mycotoxin-specific and multimycotoxin methods developed for biological matrices [197]. For example, mycotoxin-specific biomarkers for FUM in maize and DON in wheat have been developed and validated [198, 199], though none has been applied in Kenya. In neighbouring Tanzania, coexposure to AFs with other mycotoxins utilizing individual biomarkers was recently investigated. Children (6-14 months old) were recruited at a maize harvest season and followed up twice at 6-month intervals. The children were reported to be chronically exposed to $\mathrm{AFB}_{1}, \mathrm{FB}_{1}$, and DON [200, 201]. Blood AF-alb [200] and urinary DON levels [201] steadily increased over the 12 months, which likely corresponded to increased food intake that is possible as the child grows. A linear trend was not apparent for urinary $\mathrm{FB}_{1}$ as the mean level at 6 months was significantly lower than mean levels at recruitment and at 12 months [200]. It was deduced that the lower exposure levels observed 6 months postharvest could be reflective of reduced maize stocks, resulting in lower maize consumption [200]. Though no significant correlation was appreciated between AF exposure and stunted child growth, increased FUM exposure was evidently associated with reduced length-for-age Z-scores [200].

In addition, coexposure to mycotoxins in utero is also wanting, as observations elsewhere reported AF-alb in 36\% of the blood samples with urinary $\mathrm{AFM}_{1}$ and DON present in $47 \%$ and $68 \%$ of samples from pregnant women in their third trimester coexposed to AFs and DON [202]. About $41 \%$ of the pregnant women were concurrently exposed to both AFs and DON. Thus, assessment of coexposure to AFs in Kenya with other mycotoxins is warranted.

\section{Infantile Stunting due to Aflatoxin Exposure in Kenya}

The first 1,000 days of life (from conception to about 36 months) is a critical window for healthy growth and development. Dietary intake of AFs during pregnancy plays a fundamental role in the child's future health status [187, 197]. In sub-Saharan Africa, and particularly Kenya, malnutrition and child growth impairment are major public health burdens $[80,118,180]$. Intake of low, daily doses of AFs over long periods result in chronic aflatoxicosis expressed as impaired food conversion, stunting in children, immunosuppression, cancer, and reduced life expectancy $[6,203-205]$. The WHO defined stunting as a height-for-age Z-score (HAZ), of $<-2$, being underweight as a weight-forage $Z$-score (WAZ), of $<-2$, and wasting as a weight-forheight Z-score (WHZ), of $<-2$ [206]. Stunting of infants in some aflatoxin-prone areas of Kenya is shown in Table 9.

It was advanced that AF exposure may disrupt the insulin-like growth factor (IGF) pathway through liver toxicity. In a study in Kenya [162], AF-alb concentrations were inversely associated with IGF1 levels $(p=0.039)$ and IGF binding protein 3 levels $(p=0.046)$ in a sample of 199 school children from Yumbuni in the west and Matangini (Lower Mangalete) in the east. A path analysis showed that lower IGF1 levels explained about $16 \%$ of the effect of AFs on child height $(p=0.052)$. Both IGF1 and IGFBP3 were significantly associated with child height and weight $(p<0.01)$. Children in the highest tertile of AF-alb exposure $(>198.5 \mathrm{pg} / \mathrm{mg}$ ) were shorter than those in the lowest tertile $(<74.5 \mathrm{pg} / \mathrm{mg})$, after adjusting for confounders $(p=0.043)$. To further investigate this putative mechanistic pathway, human hepatocyte line 16 (HHL-16) cells were treated with $\mathrm{AFB}_{1}$ at $0.5,5.0$, and $20.0 \mu \mathrm{g} / \mathrm{mL}$ for $24-48$ hours. IGF1 and IGFBP3 gene expression measured by quantitative PCR and protein in culture media showed a significant downregulation of IGF genes and reduced IGF protein levels. The study concluded that AF-induced changes in IGF protein levels could contribute to growth impairment where AF exposure is high [162].

Aflatoxin-child growth impairment may be explained by the immunosuppressive effect of AFs that aggravates neonatal infection susceptibility, thereby impairing nutritional status through inappetence and diminished nutrient absorption [207]. It is also argued that exposure to AFs may initiate intestinal damages by dysregulation of protein synthesis culminating in diminished nutrient absorption and impaired growth [208]. AFs have also been implicated in the etiology of other liver diseases including jaundice, cirrhosis, and hepatomegaly $[185,209,210]$. A study in Kenya by Gong et al. [185] reported that the prevalence of hepatomegaly, a firm form of liver enlargement, increased in children with higher AF exposure. This is in complete agreement with the knowledge that the liver is the target metabolic organ for AFs.

\section{Aflatoxicoses in Kenya}

Since the discovery of AFs, Kenya has been one of the countries with devastatingly severe human exposure to AFs $[109,211,212]$. Exposure to AFs is chiefly via intake of contaminated food. Ingestion, however at concentrations greater than $6000 \mathrm{mg} / \mathrm{kg}$ in food, degenerates into liver failure and can be lethal after 1-2 weeks of exposure (acute aflatoxicosis) [213]. Aflatoxicosis is typified by oedema, convulsions, vomiting, jaundice, abdominal pain, sudden liver failure, and lastly death [214]. In practice, acute toxicities associated with exposure to elevated AF levels are not very common globally; cases occur and are concentrated in high-risk regions such as the Makueni County of Kenya [77] (Table 10). In humans, acute toxicity due to exposure to high dietary doses of AFs (2,000-6,000 $\mu \mathrm{g} /$ day) in contaminated maize was reported in Western India in 1974 with a case fatality rate of $10 \%[215,216]$. In Taiwan, 26 members of 3 families were victims of consumption of about $200 \mu \mathrm{g} / \mathrm{kg}$ of AFs in mouldy rice. Three of the victims died [217]. In neighbouring Uganda, a 15-year-old boy also succumbed to death following ingestion of cassava containing $1,700 \mu \mathrm{g} / \mathrm{kg}$ of AFs, leaving behind a brother and a sister who survived very narrowly [218]. Recently, consumption of AF- 
TABLE 9: Aflatoxin levels in foods and stunting in some aflatoxin hotspots of Kenya.

\begin{tabular}{lccc}
\hline County & Stunting (\%) & Highest reported AF levels in foods $(\mu \mathrm{g} / \mathrm{kg})$ & Authors \\
\hline Urban Nairobi & 22.7 & $4,593.93$ (maize and maize products), total AFs & Okoth and Kola [78] \\
Nairobi (Korogocho and Dagoretti) & 41.0 & 88.83 (maize), 194.41 (sorghum), total AFs & Kiarie et al. [66] \\
Kisumu & 33.1 & 82.0 (cereal-based weaning foods), total AFs & Okoth and Ohingo [118] \\
Homa Bay & 37.0 & 1,000 (peanuts), total AFs & Mutegi et al. [65] \\
Makueni & 33.5 & 5,400 (maize), total AFs & Lewis et al. [71] \\
Kitui & 47.4 & 25,000 (maize), total AFs & Lewis et al. [71] \\
Machakos & 31.3 & 3,800 (maize), total AFs & Lewis et al. [71] \\
Embu & 23.7 & 21.0, total AFs & Collins et al. [106] \\
Kakamega (Malava) & 34.2 & 17.0 (rotten maize), AFB FB $_{1}>5,000 \mu \mathrm{g} / \mathrm{kg}$ & Alakonya et al. [139] \\
Tongaren (Bungoma) & 52.1 & 17.0 (rotten maize), AFB FB $_{1}$ was $>5,000 \mu \mathrm{g} / \mathrm{kg}$ & Alakonya et al. [139] \\
Kisii South & 35.3 & 3,442; total AFs & Collins et al. [106] \\
\hline
\end{tabular}

Adapted from Obade et al. [80].

TABle 10: Aflatoxicosis outbreaks reported in Kenya since the discovery of aflatoxins in 1960.

\begin{tabular}{|c|c|c|c|c|c|c|}
\hline $\begin{array}{l}\text { Affected } \\
\text { group }\end{array}$ & $\begin{array}{l}\text { Case-patients/ } \\
\text { number } \\
\text { affected }\end{array}$ & Area & Toxin source & Recorded effects & Years & Authors \\
\hline $\begin{array}{l}\text { Humans, } \\
\text { dogs }\end{array}$ & $\begin{array}{l}\text { None } \\
\text { confirmed }\end{array}$ & $\begin{array}{c}\text { Eastern Kenya (29 } \\
\text { districts) }\end{array}$ & $\begin{array}{c}\text { Suspected } \\
\text { contaminated maize }\end{array}$ & $\begin{array}{l}\text { Price spiral down, grain trade } \\
\text { breakdown, unconfirmed dog } \\
\text { deaths in Nairobi }\end{array}$ & 2010 & $\begin{array}{l}\text { Muthomi et al. } \\
\text { [236] }\end{array}$ \\
\hline Humans & 5 & $\begin{array}{l}\text { Kibwezi, Kajiado, } \\
\text { Mutomo }\end{array}$ & Maize & 3 hospitalized, 2 deaths & 2008 & $\begin{array}{l}\text { Muthomi et al. } \\
{[40]}\end{array}$ \\
\hline Humans & 4 & Kibwezi, Makueni & Maize & $\begin{array}{l}2 \text { deaths in Makindu town of } \\
\text { Mukueni County }\end{array}$ & 2007 & $\begin{array}{l}\text { Wagacha and } \\
\text { Muthomi }\end{array}$ \\
\hline Humans & 20 & $\begin{array}{l}\text { Makueni, Kitui, } \\
\text { Machakos, Mutomo }\end{array}$ & $\begin{array}{l}\text { Contaminated } \\
\text { maize }\end{array}$ & $\begin{array}{l}\text { Acute poisoning, } 10 \text { deaths in } \\
\text { Mutomo and } 9 \text { in Makueni }\end{array}$ & 2006 & $\begin{array}{l}\text { Daniel et al. } \\
{[70,103]}\end{array}$ \\
\hline Humans & 75 & $\begin{array}{l}\text { Machakos, Makueni, } \\
\text { Kitui }\end{array}$ & Maize & $\begin{array}{c}\text { Acute poisoning, } 75 \text { cases, } 32 \\
\text { deaths }\end{array}$ & 2005 & $\begin{array}{c}\text { Azziz- }^{-} \\
\text {Baumgartner et al. } \\
{[69,70]}\end{array}$ \\
\hline Humans & 331 & $\begin{array}{c}\text { Eastern/Central } \\
\text { Machakos, Kitui, and } \\
\text { Makueni areas }\end{array}$ & $\begin{array}{l}\text { Contaminated } \\
\text { maize }\end{array}$ & Acute poisoning, 125 deaths & 2004 & Lewis et al. [237] \\
\hline Humans & 6 & Thika & Mouldy & 6 deaths & 2003 & Onsongo [238] \\
\hline $\begin{array}{l}\text { Poultry/ } \\
\text { dogs }\end{array}$ & Large numbers & Coast & Contaminated feed & 150 deaths & 2002 & $\begin{array}{c}\text { Njapau and Probst } \\
{[239]}\end{array}$ \\
\hline Humans & 3,26 & Meru North, Maua & $\begin{array}{l}\text { Mouldy maize, } \\
\text { contaminated maize }\end{array}$ & Severe liver damage, 16 deaths & 2001 & Probst et al. [39] \\
\hline Humans & 3 & Meru North & Maize & Acute effects, 3 deaths & 1998 & Mutegi et al. [38] \\
\hline Poultry & Large numbers & Kenya & Imported maize & Deaths & $\begin{array}{c}1984 / \\
1985\end{array}$ & {$[240,241]$} \\
\hline Humans & 12 & Machakos & Poorly stored maize & Deaths & 1981 & Ngindu et al. [177] \\
\hline $\begin{array}{l}\text { Poultry/ } \\
\text { dogs }\end{array}$ & Large numbers & $\begin{array}{l}\text { Nairobi, Mombasa, } \\
\text { Eldoret }\end{array}$ & Poorly stored feed & Deaths & $\begin{array}{c}1977 / \\
1978\end{array}$ & $\begin{array}{l}\text { Muraguri et al. } \\
{[241,242]}\end{array}$ \\
\hline Ducklings & 16,000 & Rift Valley & Peanut ration & Deaths & 1960 & $\begin{array}{l}\text { Peers and Linsell } \\
{[82]}\end{array}$ \\
\hline
\end{tabular}

Years are those in which the aflatoxicoses occurred rather than the years the data were published. Data are from [38, 92, 97]. A case report is also filed of a possible aflatoxicosis of a 17-year-old schoolboy [214].

contaminated maize triggered aflatoxicosis in humans with a case fatality rate of $50 \%$ in Tanzania [219].

In Kenya, aflatoxicosis was first witnessed in 1960 which recorded the death of at least 16,000 ducklings [82]. In 1981, Kenya witnessed its first serious recorded outbreak of human aflatoxicosis [177]. It was found that after 7 days of consumption of maize grain containing $3.2-12 \mathrm{mg} / \mathrm{kg}$ of $\mathrm{AFB}_{1}$, symptoms of abdominal discomfort, anorexia, general malaise, and low-grade fever were exhibited in 20 cases of patients between 2.5 and 45 years of age. Hepatic failure developed in 12 of the 20 patients, all of whom eventually died 1-12 days following hospital admission. The most unprecedented episode of human aflatoxicosis in history was witnessed in Kenya in 2004 with 317 reported cases of which 125 were fatal [39]. This outbreak, which occurred in the Eastern Province, recorded a case fatality rate of $39 \%$, and out of the 308 patients for whom age data were available, 68 (22\%) were $<5$ years, $90(29 \%)$ were $5-14$ years, and 150 (49\%) were $>15$ years. Children younger than 14 years, representing $51 \%$ of the children population, were thus 
presumed to have had a greater predisposition to aflatoxicosis risk. The case fatality rate was significantly higher in Makueni district than in Kitui district [69, 70, 177, 220, 221].

Since 2004, outbreaks among subsistence farmers have recurred annually in Eastern Province and it is right to assert that the magnitude of exposure to AFs could be higher than reported due to the dearth of robust monitoring systems $[63,109]$. Table 10 summarizes some of the fatal aflatoxicoses recorded in the history of Kenya since the discovery of AFs. It is worth noting that several studies on AF poisoning in humans have shown that low-level chronic intake may be more devastating than one-time high-level intake (that leads to aflatoxicosis) as it is linked to the development of hepatocellular carcinoma [30, 82, 128, 222-231]. During the aflatoxicosis outbreak that occurred in 2010, the levels of $\mathrm{AFB}_{1}$ sera reported in Kenya were among the highest ever recorded in the world [232]. As can be traced from Table 10, most areas that have been hit by aflatoxicosis in Kenya are in the Eastern and some Central parts of the country.

\section{Prevention and Control}

7.1. International, Regional, and Statutory Efforts. Appreciable efforts have been advanced towards AF control in Kenya through countrywide awareness creation [97, 233]. The regional mycotoxin facility at the Kenya Agricultural and Livestock Research Institute (KALRO) in Katumani offers training to people from both the public and private sectors.

After the fatal aflatoxicosis in which dogs fed on contaminated rations died between 1970 and 1980s, KEBS came up with a standard for dog feeds in 1985. Standards for maize grain, other grains, and their products that have been in existence were also revised. For example, total AFs were initially at $20 \mu \mathrm{g} / \mathrm{kg}$; this has been revised to $10 \mu \mathrm{g} / \mathrm{kg}$, with $5 \mu \mathrm{g} / \mathrm{kg}$ as the threshold for $\mathrm{AFB}_{1}$ in 2007 [234]. At least 25 standards aimed at regulating AFs have been drafted and are in full use and encompass key parameters such as moisture, mouldy grains, pest damage, filth, broken kernels/seeds, foreign matter, and discoloured grains. Most of these standards have been harmonized with the East African Standards by the Eastern Africa Grain Council (EAGC) in collaboration with KEBS through the Eastern Africa Grain Institute with its Kenyan headquarters at Nairobi, Kenya [235]. Between 2015 and 2018, the duo has trained maize exporters, traders, farmer-based organizations, and warehouse handlers on understanding the integrated East African maize standard (EAS 2:2013), food standardization, comparison of East African standards with international standards, standard maize sampling methods, maize grading, mycotoxins, and the available methods for mycotoxin analysis [235].

Following its launch way back in 2006, EAGC has been among the lead in the fight against AFs in East Africa as a whole. It has advanced several interventions to reduce the incidence of AFs, including (1) harmonization of AF control measures and improving the regulatory environment, (2) launch of AF control training programs, (3) furnishing moisture meters and waterproof sheets for drying, fumigation, and storing grains, (4) outsourcing portable kits for detecting and quantifying AFs, (5) farmer-based assessment of AFs prevalence, (6) collaborating with East African Community to expand AF testing and surveillance in maize, and (7) laying strategies of the Partnership for Aflatoxin Control in Africa (PACA) strategy 2013-2022 and revising EAC AFs communication strategy [235]. In addition, AF surveillance and capacity has been enhanced through the PACA Curated Africa Aflatoxin Information Management System (Africa-AIMS) in seven member states: Kenya, Malawi, Nigeria, Senegal, Tanzania, The Gambia, and Uganda.

Kenya Agricultural and Livestock Research Organization in connection with the International Institute of Tropical Agriculture (IITA) in 2018 developed a farmercentered manual for the management of AFs in maize and peanuts [233]. The manual gives a general overview of AFs (structures, health, and economic effects), how to control AFs, drying, threshing, sorting, and some of the farming practices that favour AF growth. It was particularly drafted to provide ample guidance on the best practices for limiting AF contamination of maize and peanuts and to raise the value of these dietary staples.

Further, there are some projects running in the country to handle the plague of mycotoxins and these include the Aflacontrol Project and Purchasing for Progress (P4P) Programme. The Aflacontrol Project strives to minimize the ravage of AFs in maize and peanut value chains and is spearheaded by International Food Policy Research Institute (IFPRI). In addition, it seeks to increase the understanding of the economic and health impacts of AF contamination and identify and promote cost-effective methods and technologies available to reduce contamination of foods and feeds. The project, funded by Bill and Melinda Gates Foundation, has a partnership with the International Maize and Wheat Improvement Center (CIYMMT), University of Pennsylvania (USA), United States Uniformed Health Services, Kenya Agricultural Research Institute (KARI), and Agricultural Cooperative Development Initiative (ACDIVOCA). The project has been experimented in Mbere (Embu), Makueni, Homa Bay, Kisii, and Rongo at the household level [97]. So far, it has released policy briefs and held inceptions, and one-year national workshops to disseminate information on AFs. These are targeted at the Ministries of Agriculture and Public Health, who are the key players in mitigating AFs. On the other hand, the Purchasing for Progress Programme is led by the World Food Programme that purchases maize from local farmers, usually ensuring strict adherence to AF limits in the grains. The grains are procured at fairer prices, encouraging the farmers to adhere to good pre-, peri-, and postharvest practices [97]. Several partnerships are currently running in the country; some are with FAO and CDC to mitigate AFs in Kenya. These have been discussed in sufficient details in a previous review by Mutegi et al. [38].

7.2. Scholarly Efforts. Earlier reports on the fate of AFs during the processing of maize into muthokoi, a traditional Kenyan food, revealed that traditional maize preparation 
methods such as fermentation and dehulling in Eastern Kenya reduced AFs by up to $71 \%$ [83]. The findings of this study indicate that exposure to acute AF levels could be minimized during food processing and preparation. Generally, these processing techniques have been traditionally used for increasing the palatability of different food recipes but should also be promoted as strategies capable of reducing AF contamination of grains [97].

Intermediate processes such as sorting and dehusking were shown to reduce AF in peanuts [243]. Soaking peanuts in water, magadi, sodium hypochlorite, and ammonium persulphate significantly reduced AF levels by $27.7 \%, 18.4 \%$, $18.3 \%$, and $1.6 \%$, respectively, while boiling in magadi, local ash, baking powder, and water reduced AF levels by $43.8 \%$, $41.8 \%, 28.9 \%$, and $11.7 \%$, respectively. Similarly, Kirui [183] while assessing the levels of residual AFs following various treatments using physicochemical and traditional cooking methods for maize and maize products reported that boiling maize reduced total AFs from $83.1 \pm 0.3$ to $7.0 \pm 3.9 \mu \mathrm{g} / \mathrm{kg}$, dry decortication reduced the level from $51.3 \pm 15.3$ to $9.6 \pm 0.8 \mu \mathrm{g} / \mathrm{kg}$, while boiling with magadi soda (or maize wood ash) reduced the level from $59.5 \pm 3.82$ to $13.4 \pm 0.42 \mu \mathrm{g} / \mathrm{kg}$. Solar irradiation (for 18 hours) reduced the levels from $60.8 \pm 1.8$ to $13.7 \pm 0.1 \mu \mathrm{g} / \mathrm{kg}$ while ultraviolet irradiation (for 18 hours) reduced the levels from $81.7 \pm 0.5$ to $61.4 \pm 4.5 \mu \mathrm{g} / \mathrm{kg}$. The author reiterated that only the dry decortication method and boiling with magadi soda followed by washing with water and boiling reduced AFs significantly to below the maximum advisory limit of $10 \mu \mathrm{g} / \mathrm{kg}$.

In the same struggle, a probiotic yoghurt was formulated with $\mathrm{AFB}_{1}$ binding Streptococcus thermophilus, Lactobacillus rhamnosus GR-1, and Weissella cibaria NN20 isolated from fermented Kimere, a dough food product made from millet $[179,182]$. Forty primary school children, with maize being a regular part of their diet, were randomly assigned to consume $200 \mathrm{ml}$ of yoghurt or control milk daily for 7 days, followed by a 7-day washout and another 7-day treatment. After both 7-day treatment periods, AF concentration in urine samples was significantly lower than baseline in the probiotic group $(p>0.01)$ but increased in the milk group. This suggested that locally produced probiotic yoghurt could reduce AF poisoning in Kenyan children, corroborating previous observations in our laboratory [244, 245]. Similarly, fermentation of milk into Lala, a traditional fermented drink, and yoghurt significantly reduced $\mathrm{AFM}_{1}$ levels by $71.8 \%$ (in Lala after 15-hour room temperature incubation) and $73.6 \%$ in yoghurt after incubation at $45 \mathrm{C}$ for 4 hours [135].

In another intervention survey, the use of a calcium montmorillonite clay (calcium silicate 100 , popularized as ACCS100) in food reduced the bioavailability of AFs [181]. It was reported to be palatable, effective, and acceptable, though further evaluation in the AF-endemic parts of Eastern Kenya as well as its efficacy to ameliorate AFs to levels incapable of triggering poisoning yet remains to be established.

Another study [43] screened maize lines resistant to A. flavus infection, together with a biocontrol strategy. Two African maize lines (GAF4 and KDV1) were reported to have different fungal loads for the aflatoxigenic isolate (KSM014), fourteen days after infection, with no significant variation in A. flavus biomass between diseased and nondiseased maize tissues for GAF4. Meanwhile, KDV1 had a significantly higher A. flavus biomass $(p<0.05)$ in infected shoots and roots compared to the control. The biocontrol strategy using an atoxigenic isolate (KSM012) against the toxigenic isolate (KSM014) showed aflatoxin production inhibition at the coinfection ratio, 50:50 for both maize lines (KDV1 $>99.7 \%$ and GAF 69.4\%), as confirmed by bioanalytical techniques. It was indicated that the maize lines, which exhibited resistance to A. flavus with the appropriate biocontrol strategy, could reduce aflatoxicosis outbreaks.

In a 2020 report [46], the possibility of using Pseudomonas and Bacillus bacterial spp was explored in soils from Eastern Kenya (semiarid) and Western Kenya (subhumidsemihumid) [110]. Pseudomonas $(n=7)$ and Bacillus $(n=5)$ were identified in the two regions, though Western Kenya recorded a higher occurrence of Bacillus. Because these bacterial spp have been frequently associated with biological control of several plant pathogens including Aspergillus spp, a regression analysis was done to ascertain if there were any associations between the occurrence of Aspergillus spp and these bacterial spp in the studied regions. Weak relationships between the occurrence of $A$. flavus and Pseudomonas spp in the western region $\left(R^{2}=0.03693\right)$ and the eastern region $\left(R^{2}=0.06126\right)$ as well as occurrence of Bacillus spp in the western region $\left(R^{2}=0.196\right)$ and in the eastern region of Kenya $\left(R^{2}=0.03693\right)$. The same observation was made for the relationship between the occurrence of Trichoderma viride in both eastern $\left(R^{2}=003406\right)$ and western $\left(R^{2}=0.2266\right)$ regions of the country. As a consequence, the authors deduced that the occurrence of the bacterial spp had little influence on the occurrence of A. flavus in the two regions. To ascertain their assertion, an in vitro preliminary assay to determine the inhibitory potential of both Pseudomonas and Bacillus spp against A. flavus proliferation was done. Unfortunately, none of the bacterial strains from either spp had an inhibitory effect on A. flavus proliferation [46].

\section{Suggested Management Strategies}

8.1. Preharvest Management. Staple food crop varieties that are disease-, drought-, and pest-tolerant or less susceptible to fungal growth could be adopted. This approach is so far the best for the reduction of effects of AFs-producing fungi [246]. Valencia red (a peanut variety) was reported to be the least contaminated with AFs and had higher oil content than Uganda local, Homa Bay local, and Local red [121]. Food oils and microorganisms are viable inhibitors of AF biosynthesis [6] through interference with signal transduction regulatory chains in AF gene expression, inhibiting AF biosynthetic cytosolic enzymes and downregulating fungal genes of the oxidative stress defence system [247]. Further, host and parasite macro- and micromolecular trafficking which targets circumvention of AF scourge through the utilization of cross species RNA interference have been attempted in maize and peanuts $[248,249]$. Particularly, UBI, COH, 26s, 
ATP, PPK, IMP, ABC, and aflM were recommended as the suitable genes for RNAi silencing of A. flavus in vivo [248, 249]. This may, however, be impeded by the current policy on genetically modified organisms in the country.

Prompt harvest of mature food crops as well as selective disposal of broken kernels or cobs is a recommended AF mitigation measure [250]. Sorting, winnowing, and dehulling can lower AF levels in grains by $40-80 \%$ [151, 251]. Sorting is more practical in groundnuts [250, 252-254] and cassava chips mechanically or utilizing clean water. Soaking or cooking in magadi soda, malting, and roasting are other strategies reported to lower food AF levels [83, 251, 255, 256]. Magadi soda and wood ash are used by the Kalenjin of the Rift Valley region and Nyanza and Western provinces to increase food palatability and offer convenience as it reduces cooking time but also reduces phytates and increases the availability of niacin [257].

Pest control is another measure of AF management. This may be affected using ash for maize $[258,259]$ and essential oils which are broad-spectrum bioinsecticides [260-263]. Competitive exclusion is another underexplored AF control measure. A shift of strain profile from toxigenic to atoxigenic is possible and Kenya already approved a potential biocontrol product (Aflasafe KE01) [8,233]. A typical example is a product constituted by a rhizosphere-competent nonaflatoxigenic Aspergillus strain possessing competitive saprophytic potential [264, 265]. For peanuts, an atoxigenic A. flavus strain (NRRL 21882) is commercialized as AflaGuard ${ }^{\circledR}$ in the US [266]. Additionally, pseudomonads and Trichoderma spp inhabiting rhizospheres of various plants have been targeted against toxigenic A. flavus. Recently, various Streptomyces, Pseudomonas, and Trichoderma spp have been isolated, evaluated, and validated to possess antagonism towards A. flavus [267]. However, their efficacy is a theme that could be further explored under Kenyan conditions as was done in some African and Asian countries with up to $79 \%$ reduction of AFs reported [268].

8.2. Postharvest Management. Proper drying of produce to moisture contents between 12 and $14 \%$, preferably $12.5 \%$ or below, is recommended. Fresh harvests should be shelled and cleaned prior to storage to minimize pest infestation that may initiate mould growth [269]. Further, proper ventilation of storage facilities is a requisite to avoid attaining temperatures between $25^{\circ} \mathrm{C}$ and $32^{\circ} \mathrm{C}$ and sustained relative humidity of $65 \%$ favourable for mould growth [11]. Moisture of $12-13 \%$ and temperatures below $18^{\circ} \mathrm{C}$ do not favour the growth of Aspergillus fungi [270].

Following good agricultural, good storage, and good manufacturing practices as well as the use of advanced agricultural technologies can reduce AF contamination [152]. Novel food processing techniques such as use of ozone, pulsed light, electrolyzed water, electron beam, microwave, cold plasma, and gamma and ultraviolet irradiation can reduce AF concentrations in agricultural foods. Food additives such as citric acid have been reported to sequester AFs in combination with moisture at high pressures and temperatures [271].
Clays notably Novasil Plus can ably bind AFs [272], reducing their available concentration. Other compounds like curcumin can afford alteration of $\mathrm{AFB}_{1}$ microsomal activation, thereby augmenting its detoxification. Chemoprotection from ingested AFs is also feasible [273]. It makes use of compounds such as esterified glucomanoses and other yeast extracts that accelerate the detoxification process or otherwise block bioactivation of AFs to AF-epoxide, inhibiting $\mathrm{AFB}_{1}$-induced hepatocarcinogenesis. Oltipraz and chlorophyll have reported use in this regard [273].

The management strategies suggested each have their advantages and limitations. Thus, biocontrol measures in tandem with physicochemical approaches could be adopted to manage the plague of AFs in Kenya.

\section{Conclusion}

Aflatoxin exposure is ubiquitous in Kenya, and the different commodities have relatively high levels of AFs, usually above statutory compliance limits by several folds. Maize, peanuts, and their products are the most contaminated food crops in Kenya. Variations in AF exposure are evident between the different regions of the country and are fundamentally a function of diet and economic status. Large-scale, evidencebased interventions are required to reduce exposure. More exposure assessments including coexposure with other mycotoxins alongside routine monitoring of AFs should be adopted.

\section{Data Availability}

This article is a review article and no raw data were collected. Any data used and/or analyzed are within this article.

\section{Conflicts of Interest}

The authors declare that there are no conflicts of interest regarding the publication of this paper.

\section{Acknowledgments}

TO, PN, MPO, CKN, and SBO are grateful to the World Bank and the Inter-University Council of East Africa (IUCEA) for the scholarship awarded to them through the Africa Center of Excellence II in Phytochemicals, Textiles and Renewable Energy (ACE II PTRE) at Moi University which prompted this review. TO is grateful to the Directors of AgroWays Uganda Limited, Uganda, for the leave granted which made this study a success. The authors commend preceding authors for their efforts in mycotoxin studies done in Kenya, the results of which were recapitulated in this study.

\section{References}

[1] K. Reddy, B. Salleh, B. Saad, H. Abbas, C. Abel, and W. Shier, "An overview of mycotoxin contamination in foods and its implications for human health," Toxin Reviews, vol. 29, no. 1, pp. 3-26, 2010. 
[2] J. W. Bennett and M. Klich, "Mycotoxins," Clinical Microbiology Reviews, vol. 16, no. 3, pp. 497-516, 2003.

[3] J. M. Wagacha and J. W. Muthomi, "Mycotoxin problem in Africa: current status, implications to food safety and health and possible management strategies," International Journal of Food Microbiology, vol. 124, no. 1, pp. 1-12, 2008.

[4] D. C. Kemboi, G. Antonissen, P. E. Ochieng et al., "A review of the impact of mycotoxins on dairy cattle health: challenges for food safety and dairy production in Sub-Saharan Africa," Toxins, vol. 12, no. 4, p. 222, 2020.

[5] V. Kumar, M. S. Basu, and T. P. Rajendran, "Mycotoxin research and mycoflora in some commercially important agricultural commodities," Crop Protection, vol. 27, no. 6, pp. 891-905, 2008.

[6] J. H. Williams, T. D. Phillips, P. E. Jolly, J. K. Stiles, C. M. Jolly, and D. Aggarwal, "Human aflatoxicosis in developing countries: a review of toxicology, exposure, potential health consequences, and interventions," The American Journal of Clinical Nutrition, vol. 80, no. 5, pp. 1106-1122, 2004.

[7] Y. Gebrehiwet, S. Ngqangweni, and J. F. Kirsten, "Quantifying the trade effect of sanitary and phytosanitary regulations of OECD countries on South African food exports," Agrekon, vol. 46, no. 1, pp. 1-17, 2007.

[8] B. Mutahi, "Kenya's ugali scare: how safe is your maize flour?” 2019, https://www.bbc.com/news/world-africa50407159.

[9] A. J. Sirma, J. F. Lindahl, K. Makita et al., "The impacts of aflatoxin standards on health and nutrition in sub-Saharan Africa: the case of Kenya," Global Food Security, vol. 18, pp. 57-61, 2018.

[10] N. Baranyi, S. Kocsube, C. Vagvolgyi, and J. Varga, "Current trends in aflatoxin research," Acta Biologica Szegediensis, vol. 57, pp. 95-107, 2013.

[11] P. Villers, "Aflatoxins and safe storage," Frontiers in Microbiology, vol. 5, no. 158, pp. 1-6, 2014.

[12] W. P. Blount, “Turkey X disease," Journal of British Turkey Federation, vol. 9, no. 52, pp. 52-61, 1961.

[13] J. L. Richard, "Discovery of aflatoxins and significant historical features," Toxin Reviews, vol. 27, no. 3-4, pp. 171-201, 2008.

[14] K. Sargeant, A. Sheridan, J. O’kelly, and R. B. A. Carnaghan, "Toxicity associated with certain samples of groundnuts," Nature, vol. 192, no. 4807, pp. 1096-1097, 1961.

[15] F. D. Asplin and R. B. A. Carnaghan, "The toxicity of certain groundnut meals for poultry with special reference to their effect on ducklings and chickens," Veterinary Records, vol. 73, pp. 1215-1219, 1961.

[16] T. Omara, W. Nassazi, T. Omute et al., "Aflatoxins in Uganda: an encyclopedic review of the etiology, epidemiology, detection, quantification, exposure assessment, reduction, and control," International Journal of Microbiology, vol. 2020, Article ID 4723612, 18 pages, 2020.

[17] Q. Wu, A. Jezkova, Z. Yuan, L. Pavlikova, V. Dohnal, and K. Kuca, "Biological degradation of aflatoxins," Drug Metabolism Reviews, vol. 41, no. 1, pp. 1-7, 2009.

[18] INCHEM, Principles of Evaluating Chemical Effects on the Aged Population: International Programme on Chemical Safety-Environmental Health Criteria 144, World Health Organization, Geneva, Switzerland, 1993.

[19] H. S. Chun, H. J. Kim, H. E. Ok, J.-B. Hwang, and D.-H. Chung, "Determination of aflatoxin levels in nuts and their products consumed in South Korea," Food Chemistry, vol. 102, no. 1, pp. 385-391, 2007.
[20] A. W. Yunus, E. Razzazi-Fazeli, and J. Bohm, “Aflatoxin B1 in affecting broiler's performance, immunity, and gastrointestinal tract: a review of history and contemporary issues," Toxins, vol. 3, no. 6, pp. 566-590, 2011.

[21] H. Strosnider, E. Azziz-Baumgartner, M. Banziger et al., "Workgroup report: public health strategies for reducing aflatoxin exposure in developing countries," Environmental Health Perspectives, vol. 114, no. 12, pp. 1898-1903, 2006.

[22] K. D. Raney, D. J. Meyer, B. Ketterer, T. M. Harris, and F. P. Guengerich, "Glutathione conjugation of aflatoxin B1 exo- and endo-epoxides by rat and human glutathione S-transferases," Chemical Research in Toxicology, vol. 5, no. 4, pp. 470-478, 1992.

[23] J. K. Jewers, Mycotoxins and Their Effect on Poultry Production, Tropical Development and Research Institute (TDRI), London, UK, 2015.

[24] D. M. Dereszynski, S. A. Center, J. F. Randolph et al., "Clinical and clinicopathologic features of dogs that consumed foodborne hepatotoxic aflatoxins: 72 cases (20052006)," Journal of the American Veterinary Medical Association, vol. 232, no. 9, pp. 1329-1337, 2008

[25] G. C. Dors, S. S. Caldas, V. Feddern et al., "Aflatoxins: contamination, analysis and control," in Aflatoxins-Biochemistry and Molecular Biology, pp. 415-438, InTechOpen, Shanghai, China, 2011.

[26] N. Benkerroum, "Retrospective and prospective look at aflatoxin research and development from a practical standpoint," International Journal of Environmental Research and Public Health, vol. 16, no. 19, p. 3633, 2019.

[27] M. Klvana and U. Bren, "Aflatoxin B1-formamidopyrimidine DNA adducts: relationships between structures, free energies, and melting temperatures," Molecules, vol. 24, no. 1, p. 150, 2019.

[28] A. P. Wacoo, D. Wendiro, P. C. Vuzi, and J. F. Hawumba, "Methods for detection of aflatoxins in agricultural food crops," Journal of Applied Chemistry, vol. 2014, Article ID 706291, 15 pages, 2014.

[29] J. Mehrzad, A. M. Malvandi, M. Alipour, and S. Hosseinkhani, "Environmentally relevant level of aflatoxin B1 elicits toxic pro-inflammatory response in murine CNSderived cells," Toxicology Letters, vol. 279, pp. 96-106, 2017.

[30] M. E. Smela, S. S. Currier, E. A. Bailey, and J. M. Essigmann, "The chemistry and biology of aflatoxin B1: from mutational spectrometry to carcinogenesis," Carcinogenesis, vol. 22, no. 4 , pp. $535-545,2001$.

[31] L. Wojnowski, P. C. Turner, B. Pedersen et al., "Increased levels of aflatoxin-albumin adducts are associated with CYP3A5 polymorphisms in the Gambia, West Africa," Pharmacogenetics, vol. 14, no. 10, pp. 691-700, 2004.

[32] G. E. Neal, D. L. Eaton, D. J. Judah, and A. Verma, "Metabolism and toxicity of aflatoxins M1 and B1 in humanderived in vitro systems," Toxicology and Applied Pharmacology, vol. 151, no. 1, pp. 152-158, 1998.

[33] L. L. Bedard and T. E. Massey, "Aflatoxin B1-induced DNA damage and its repair," Cancer Letters, vol. 241, no. 2, pp. 174-183, 2006.

[34] Z. Zhuang, Y. Huang, Y. Yang, and S. Wang, "Identification of AFB1-interacting proteins and interactions between RPSA and AFB1," Journal of Hazardous Materials, vol. 301, pp. 297-303, 2016.

[35] C. A. F. D. Oliveira and P. M. L. Germano, "Aflatoxinas: conceitos sobre mecanismos de toxicidade e seu envolvimento na etiologia do câncer hepático celular," Revista de Saúde Pública, vol. 31, no. 4, pp. 417-424, 1997. 
[36] G. S. Bbosa, D. Kitya, A. Lubega et al., "Review of the biological and health effects of aflatoxins on body organs and body systems," in Aflatoxins-Recent Advances and Future Prospects, pp. 239-265, InTech Open, Shanghai, China, 2013.

[37] D. Dhanasekaran, S. Shanmugapriya, N. Thajuddin, and A. Panneerselvam, "Aflatoxins and aflatoxicosis in human and animals," in Aflatoxins-Biochemistry and Molecular Biology, R. G. Guevara-Gonzalez, Ed., pp. 221-254, InTech Open, Shanghai, China, 2011.

[38] C. K. Mutegi, P. J. Cotty, and R. Bandyopadhyay, "Prevalence and mitigation of aflatoxins in Kenya (1960-to date)," World Mycotoxin Journal, vol. 11, no. 3, pp. 341-357, 2018.

[39] C. Probst, H. Njapau, and P. J. Cotty, "Outbreak of an acute aflatoxicosis in Kenya in 2004: identification of the causal agent," Applied and Environmental Microbiology, vol. 73, no. 8, pp. 2762-2764, 2007.

[40] J. W. Muthomi, L. N. Njenga, J. K. Gathumbi, and G. N. Chemining, "The occurrence of aflatoxins in maize and distribution of mycotoxin-producing fungi in Eastern Kenya," Plant Pathology Journal, vol. 8, no. 3, pp. 113-119, 2009.

[41] S. Okoth, B. Nyongesa, V. Ayugi, E. Kang'ethe, H. Korhonen, and V. Joutsjoki, “Toxigenic potential of Aspergillus species occurring on maize kernels from two agro-ecological zones in Kenya," Toxins, vol. 4, no. 11, pp. 991-1007, 2012.

[42] D. R. Oloo, S. Okoth, P. Wachira et al., "Genetic profiling of Aspergillus isolates with varying aflatoxin production potential from different maize-growing regions of Kenya," Toxins, vol. 11, no. 8, p. 467, 2019.

[43] A. Mitema, S. Okoth, and S. Rafudeen, "The development of a qPCR assay to measure Aspergillus flavus biomass in maize and the use of a biocontrol strategy to limit aflatoxin production," Toxins, vol. 11, no. 3, p. 179, 2019.

[44] C. K. Mutegi, H. K. Ngugi, S. L. Hendriks, and R. B. Jones, "Factors associated with the incidence of aspergillus section flavi and aflatoxin contamination of peanuts in the Busia and Homa bay districts of western Kenya," Plant Pathology, vol. 61, no. 6, pp. 1143-1153, 2012.

[45] G. K. Muriuki and G. M. Siboe, "Maize flour contaminated with toxigenic fungi and mycotoxins in Kenya," African Journal of Health Sciences, vol. 2, no. 1, pp. 236-241, 1995.

[46] E. Monda, J. Masanga, and A. Alakonya, "Variation in occurrence and aflatoxigenicity of Aspergillus flavus from two climatically varied regions in Kenya," Toxins, vol. 12, no. 34, 2020.

[47] M.-S. Islam, K. A. Callicott, C. Mutegi, R. Bandyopadhyay, and P. J. Cotty, "Aspergillus flavus resident in Kenya: high genetic diversity in an ancient population primarily shaped by clonal reproduction and mutation-driven evolution," Fungal Ecology, vol. 35, pp. 20-33, 2018.

[48] S. Okoth, M. De Boevre, A. Vidal et al., "Genetic and toxigenic variability within Aspergillus flavus population isolated from maize in two diverse environments in Kenya," Frontiers in Microbiology, vol. 9, p. 57, 2018.

[49] C. N. Menza and W. M. Muturi, "Occurrence of aflatoxigenic Aspergillus species in peanut varieties in Busia and Kisii central districts, Kenya," Open Journal of Medical Microbiology, vol. 8, no. 4, pp. 98-108, 2018.

[50] J. Varga, J. Frisvad, and R. Samson, "A reappraisal of fungi producing aflatoxins," World Mycotoxin Journal, vol. 2, no. 3, pp. 263-277, 2009.

[51] C. Soares, P. Rodrigues, S. W. Peterson, N. Lima, and A. Venâncio, "Three new species of Aspergillus section flavi isolated from almonds and maize in Portugal," Mycologia, vol. 104, no. 3, pp. 682-697, 2012.

[52] A. C. Baquião, M. M. M. de Oliveira, T. A. Reis, P. Zorzete, D. Diniz Atayde, and B. Correa, "Polyphasic approach to the identification of Aspergillus section flavi isolated from Brazil nuts," Food Chemistry, vol. 139, no. 1-4, pp. 1127-1132, 2013.

[53] J. W. Ndung'u, A. O. Makokha, C. A. Onyango et al., "Prevalence and potential for aflatoxin contamination in groundnuts and peanut butter from farmers and traders in Nairobi and Nyanza provinces of Kenya," Journal of Applied Biosciences, vol. 65, pp. 4922-4934, 2013.

[54] M. E. Murithi, "Prevalence of Fusarium and Aspergillus species in maize grain from Kitui, Machakos and Meru and use of near infra-red-light sorting to remove fumonisins and aflatoxin contaminated grain in Kenya," MSc thesis, University of Nairobi, Nairobi, Kenya, 2014.

[55] C. Probst, F. Schulthess, and P. J. Cotty, "Impact of Aspergillus section flavi community structure on the development of lethal levels of aflatoxins in Kenyan maize (Zea mays)," Journal of Applied Microbiology, vol. 108, no. 2, pp. 600-610, 2010.

[56] C. Probst, K. A. Callicott, and P. J. Cotty, "Deadly strains of Kenyan Aspergillus are distinct from other aflatoxin producers," European Journal of Plant Pathology, vol. 132, no. 3, pp. 419-429, 2012.

[57] E. G. Lizárraga-Paulin, E. Moreno-Martinez, and S. P. Miranda-Castro, "Aflatoxins and their impact on human and animal health: an emerging problem,", in Aflatoxins-Biochemistry and Molecular Biology, Rijeka (Croatia), R. G. Guevara-González, Ed., pp. 255-282, InTech Open, Shanghai, China, 2011.

[58] P. Ochungo, J. F. Lindahl, T. Kayano et al., "Mapping aflatoxin risk from milk consumption using biophysical and socio-economic data: a case study of Kenya," African Journal of Food, Agriculture, Nutrition and Development, vol. 16, no. 3, pp. 11066-11085, 2016.

[59] H. S. Nzioki, "Review of aflatoxin research in Kenya: NARS (KARI) perspective, Nairobi, Kenya," 2008.

[60] J. L. Leroy, J.-S. Wang, and K. Jones, "Serum aflatoxin B1lysine adduct level in adult women from Eastern Province in Kenya depends on household socio-economic status: a cross sectional study," Social Science \& Medicine, vol. 146, pp. 104-110, 2015.

[61] C. K. Mutegi, H. K. Ngugi, S. L. Hendriks, and R. B. Jones, "Prevalence and factors associated with aflatoxin contamination of peanuts from Western Kenya," International Journal of Food Microbiology, vol. 130, no. 1, pp. 27-34, 2009.

[62] C. Mutegi, M. Wagacha, J. Kimani et al., "Incidence of aflatoxin in peanuts (Arachis hypogaea Linnaeus) from markets in Western, Nyanza and Nairobi Provinces of Kenya and related market traits," Journal of Stored Products Research, vol. 52, pp. 118-127, 2013.

[63] M. A. Obonyo and E. N. Salano, "Perennial and seasonal contamination of maize by aflatoxins in Eastern Kenya," International Journal of Food Contamination, vol. 5, no. 1, 2018.

[64] C. K. Mutegi, J. M. Wagacha, M. E. Christie, J. Kimani, and L. Karanja, "Effect of storage conditions on quality and aflatoxin contamination of peanuts (Arachis hypogaea L.)," International Journal of AgriScience, vol. 3, no. 10, pp. 746-758, 2013.

[65] C. K. Mutegi, S. L. Hendricks, R. B. Jones, J. J. Okello, and H. K. Ngugi, "Role of collective action and handling practices on aflatoxin contamination of groundnuts," in Proceedings of 
the African Crop Science Conference, El-Minia, Egypt, October 2007.

[66] G. Kiarie, P. Dominguez-Salas, S. Kang'ethe, D. Grace, and J. Lindahl, "Aflatoxin exposure among young children in urban low-income areas of Nairobi and association with child growth," African Journal of Food, Agriculture, Nutrition and Development, vol. 16, no. 3, pp. 10967-10990, 2016.

[67] W. Moturi, "Factors likely to enhance mycotoxin introduction into the human diet through maize in Kenya," African Journal of Food, Agriculture, Nutrition and Development, vol. 8, no. 3, pp. 291-303, 2008.

[68] P. Koskei, C. C. Bii, P. Musotsi, and S. M. Karanja, "Postharvest storage practices of maize in rift valley and lower eastern regions of Kenya: a cross-sectional study," International Journal of Microbiology, vol. 2020, Article ID 6109214, 10 pages, 2020.

[69] E. Azziz-Baumgartner, K. Lindblade, K. Gieseker et al., "Case-control study of an acute aflatoxicosis outbreak, Kenya, 2004,” Environmental Health Perspectives, vol. 113, no. 12, pp. 1779-1783, 2005.

[70] J. H. Daniel, L. W. Lewis, Y. A. Redwood et al., "Comprehensive assessment of maize aflatoxin levels in eastern Kenya, 2005-2007," Environmental Health Perspectives, vol. 119, no. 12, p. 1794, 2011.

[71] L. Lewis, M. Onsongo, H. Njapau et al., "Aflatoxin contamination of commercial maize products during an outbreak of acute aflatoxicosis in Eastern and Central Kenya," Environmental Health Perspectives, vol. 113, no. 12, pp. 1763-1767, 2005.

[72] S. K. Mutiga, V. Hoffmann, J. W. Harvey, M. G. Milgroom, and R. J. Nelson, "Assessment of aflatoxin and fumonisin contamination of maize in western Kenya," Phytopathology, vol. 105, no. 9, pp. 1250-1261, 2015.

[73] E. Mwihia, P. Mbuthia, G. Eriksen et al., "Occurrence and levels of aflatoxins in fish feeds and their potential effects on fish in Nyeri, Kenya," Toxins, vol. 10, no. 12, p. 543, 2018.

[74] T. Kiama, J. Lindahl, A. J. Sirma et al., "Kenya dairy farmer perception of moulds and mycotoxins and implications for exposure to aflatoxins: a gendered analysis," African Journal of Food, Agriculture, Nutrition and Development, vol. 16, no. 3, pp. 11106-11125, 2016.

[75] S. K. Mutiga, V. Were, V. Hoffmann, J. W. Harvey, M. G. Milgroom, and R. J. Nelson, "Extent and drivers of mycotoxin contamination: inferences from a survey of Kenyan maize mills," Phytopathology, vol. 104, no. 11, pp. 1221-1231, 2014.

[76] A. J. Sirma, E. O. Ouko, G. Murithi et al., "Prevalence of aflatoxin contamination in cereals from Nandi county, Kenya," International Journal of Agricultural Sciences and Veterinary Medicine, vol. 3, no. 3, pp. 55-63, 2015.

[77] W. R. Nabwire, J. Ombaka, C. P. Dick et al., "Aflatoxin in household maize for human consumption in Kenya, East Africa," Food Additives \& Contaminants: Part B, vol. 13, no. 1, pp. 45-51, 2020.

[78] S. A. Okoth and M. A. Kola, "Market samples as a source of chronic aflatoxin exposure in Kenya," African Journal of Health Sciences, vol. 20, no. 1, pp. 56-61, 2012.

[79] J. K. Kibugu, D. Mburu, L. K. Munga et al., "Food-borne mycotoxin hazards in the Kenyan market-a retrospective study," , 2019.

[80] M. I. Obade, P. Andang'O, C. Obonyo, and F. Lusweti, "Exposure of children 4 to 6 months of age to aflatoxin in Kisumu County, Kenya," African Journal of Food,
Agriculture, Nutrition and Development, vol. 15, no. 2, pp. 9949-9963, 2015.

[81] G. M. Kenji, A. M. Mvula, H. Koaze, and N. Baba, "Aflatoxin contamination of Kenyan maize flour and malted Kenyan and Malawian grains," Scientific Reports of the Faculty of Agriculture, vol. 89, pp. 5-7, Okayama University, Okayama, Japan, 2000.

[82] F. G. Peers and C. A. Linsell, "Dietary aflatoxins and liver cancer - a population based study in Kenya," British Journal of Cancer, vol. 27, no. 6, pp. 473-484, 1973.

[83] C. Mutungi, P. Lamuka, S. Arimi, J. Gathumbi, and C. Onyango, "The fate of aflatoxins during processing of maize into muthokoi-a traditional Kenyan food," Food Control, vol. 19, no. 7, pp. 714-721, 2008.

[84] E. W. Gachomo, E. W. Mutitu, and O. S. Kotchoni, "Diversity of fungal species associated with peanuts in storage and the levels of aflatoxins in infected samples," International Journal of Agricultural Biology, vol. 6, pp. 955-959, 2004.

[85] D. N. A. Orony, J. O. Lalah, and I. O. Jondiko, "Determination of carcinogenic polycyclic aromatic hydrocarbons (PAHs), aflatoxins, and nitrosamines in processed fish from the Winam gulf area of Kenya and estimated potential exposure in human," Polycyclic Aromatic Compounds, vol. 36, no. 4, pp. 295-317, 2015.

[86] D. K. Nyangaga, “Traders' awareness and level of aflatoxins in human foods and cattle feeds in selected markets and stores in Nairobi county, Kenya," MSc thesis, Kenyatta University, Nairobi, Kenya, 2014.

[87] E. K. Kang'ethe, G. M. M'ibui, T. F. Randolph, and A. K. Lang'a, "Prevalence of aflatoxin M1 and B1 in milk and animal feeds from urban smallholder dairy production in Dagoretti division, Nairobi, Kenya," East African Medical Journal, vol. 84, no. 11, pp. S83-S86, 2007.

[88] T. P. Lanyasunya, L. W. Wamae, H. H. Musa, O. Olowofeso, and I. K. Lokwaleput, "The risk of mycotoxins contamination of dairy feed and milk on smallholder dairy farms in Kenya," Pakistan Journal of Nutrition, vol. 4, no. 3, pp. 162-169, 2005.

[89] E. K. Kang'ethe and K. A. Lang'a, “Aflatoxin B1 and M1 contamination of animal feeds and milk from urban centers in Kenya," African Health Sciences, vol. 9, no. 4, pp. 218-226, 2009.

[90] J. F. Lindahl, I. N. Kagera, and D. Grace, "Aflatoxin M1 levels in different marketed milk products in Nairobi, Kenya," Mycotoxin Research, vol. 34, no. 4, pp. 289-295, 2018.

[91] L. Keter, R. Too, N. Mwikwabe et al., "Risk of fungi associated with aflatoxin and fumonisin in medicinal herbal products in the Kenyan market," The Scientific World Journal, vol. 2017, Article ID 1892972, 6 pages, 2017.

[92] S. Okoth, "Improving the evidence base on aflatoxin contamination and exposure, series: agriculture and nutrition, the technical centre for agricultural and rural cooperation," CTA Working Paper 16/13, Wageningen, The Netherlands, 2016.

[93] A. Medina, M. K. Gilbert, B. M. Mack et al., "Interactions between water activity and temperature on the Aspergillus flavus transcriptome and aflatoxin B1 production," International Journal of Food Microbiology, vol. 256, pp. 36-44, 2017.

[94] G. Mahuku, H. S. Nzioki, C. Mutegi, F. Kanampiu, C. Narrod, and D. Makumbi, "Pre-harvest management is a critical practice for minimizing aflatoxin contamination of maize," Food Control, vol. 96, pp. 219-226, 2019. 
[95] N. Nduti, P. N. Njeru, M. Mwaniki, and G. Reid, "Aflatoxin variations in maize flour and grains collected from various regions of Kenya," African Journal of Food, Agriculture, Nutrition and Development, vol. 17, no. 1, pp. 11743-11756, 2017.

[96] K. Hell and C. Mutegi, "Aflatoxin control and prevention strategies in key crops of Sub-Saharan Africa," African Journal of Microbiology Research, vol. 5, no. 5, pp. 459-466, 2011.

[97] E. Kang'ethe, Situational Analysis: Improving Food Safety in the Maize Value Chain in Kenya, University of Nairobi, Nairobi, Kenya, 2011.

[98] S. Egal, A. Hounsa, Y. Y. Gong et al., "Dietary exposure to aflatoxin from maize and groundnut in young children from Benin and Togo, West Africa," International Journal of Food Microbiology, vol. 104, no. 2, pp. 215-224, 2005.

[99] G. S. Shephard, "Risk assessment of aflatoxins in food in Africa," Food Additives and Contaminamination Part A, vol. 25, pp. 1246-1256, 2008.

[100] A. R. Abizari, H. A. Garti, G. Gajate-Garrido et al., Technological and Market Interventions for Aflatoxin Control in Ghana: Final Report, Global Alliance for Improved Nutrition, Geneva, Switzerland, 2016.

[101] ACDI/VOCA, Kenya Maize Development Program (KMDP), ACDI/VOCA, Washington, DC, USA, 2015.

[102] G. Kenji, "Aflatoxins in traditional beer (busaa) in Nairobi, Kenya," African Journal of Food \& Nutritional Sciences, vol. 3, pp. 7-8, 2003.

[103] B. Muture and G. Ogana, "Aflatoxin levels in maize and maize products during the 2004 food poisoning outbreak in Eastern Province of Kenya," East African Medical Journal, vol. 82, no. 6, pp. 275-279, 2005.

[104] A. Pietri, M. Zanetti, and T. Bertuzzi, "Distribution of aflatoxins and fumonisins in dry-milled maize fractions," Food Additives \& Contaminants: Part A, vol. 26, no. 3, pp. 372380, 2009.

[105] International Food Policy Research Institute (IFPRI), Aflacontrol Project Note 3, Prevalence of Aflatoxin in Kenya: Summary of Findings January-June 2010, International Food Policy Research Institute (IFPRI), Washington, DC, USA, 2010.

[106] S. Collins, G. Mahuku, H. S. Nzioki, C. Narrod, and P. Trench, Aflatoxin in Kenya: An Overview, Aflacontrol Project Note 1, International Food Policy Research Institute (IFPRI), Washington, DC, USA, 2010.

[107] J. W. Muthomi, B. K. Mureithi, G. N. Chemining'wa, J. K. Gathumbi, and E. W. Mutitu, "Aspergillus and aflatoxin B1 contamination of maize and maize products from semiarid and humid regions of Kenya," International Journal Agricultural Sciences, vol. 2, pp. 22-34, 2012.

[108] Building an Aflatoxin Safe East African Community, Technical Policy Paper 8, Aflatoxin Standards for Food Knowledge Platform 2015, Situational Analysis East Africa Region, 30 pages, http://aflasafe.com/wp-content/uploads/ pdf/TPP-8-Aflatoxin-Standards-for-Food.pdf.

[109] R. M. Kilonzo, J. K. Imungi, W. M. Muiru, P. O. Lamuka, and P. M. K. Njage, "Household dietary exposure to aflatoxins from maize and maize products in Kenya," Food Additives \& Contaminants: Part A, vol. 31, no. 12, pp. 2055-2062, 2014.

[110] G. W. Gachara, A. K. Nyamache, J. Harvey, G. J. B. Gnonlonfin, and J. Wainaina, "Genetic diversity of Aspergillus flavus and occurrence of aflatoxin contamination in stored maize across three agro-ecological zones in Kenya," Agriculture \& Food Security, vol. 7, no. 1, p. 52, 2018.

[111] A. K. Kipkoech, M. A. Okiror, J. R. Okalebo, and H. K. Maritim, "Production efficiency and economic potential of different soil fertility management strategies among groundnut farmers of Kenya," Science World Journal, vol. 2, pp. 15-21, 2007.

[112] T. L. Bucheyeki, E. M. Shenkalwa, T. X. Mapunda, and L. W. Matata, "On-farm evaluation of promising groundnut varieties for adaptation and adoption in Tanzania," African Journal of Agricultural Research, vol. 3, pp. 531-536, 2008.

[113] N. Okoko, N. Kidula, L. Wasilwa et al., "Participatory evaluation and dissemination of improved groundnut varieties and technologies for processing and utilization," in Proceedings of the 12th KARI Biennial Scientific Conference: Transforming Agriculture for Improved Livelihoods through Agricultural Product Value Chains, pp. 1403-1408, Nairobi, Kenya, November 2010.

[114] E. N. K. Okoko, D. J. Rees, J. K. Kwach, and P. Ochieng, "Participatory evaluation of groundnut production in Southwest Kenya," in Proceedings of the Towards Increased Use of Demand Driven Technology KARI/DFID NARP II PROJECT, End of Project Conference, pp. 305-307, Nairobi, Kenya, March 1999.

[115] H. Nyirahakizimana, L. Mwamburi, J. Wakhisi et al., "Occurrence of Aspergillus species and aflatoxin contamination in raw and roasted peanuts from formal and informal markets in Eldoret and Kericho towns, Kenya," Advances in Microbiology, vol. 3, pp. 333-342, 2013.

[116] FAOSTAT, Production: Crops, Food and Agriculture Organization of the United Nations, Rome, Italy, 2012.

[117] D. Nabuuma, D. Nakimbugwe, Y. B. Byaruhanga, F. K. Saalia, R. D. Phillips, and J. Chen, "Formulation of a drinkable peanut-based therapeutic food for malnourished children using plant sources," International Journal of Food Sciences and Nutrition, vol. 64, no. 4, pp. 467-475, 2012.

[118] S. A. Okoth and M. Ohingo, "Dietary aflatoxin exposure and impaired growth in young children from Kisumu district, Kenya: cross sectional study," African Journal of Health Sciences, vol. 11, no. 1-2, pp. 43-54, 2004.

[119] M. C. Nelson, M. W. Margaret, and K. M. Lucy, "Oil contents and aflatoxin levels in peanut varieties produced in Busia and Kisii Central Districts, Kenya," Tropical Medicine \& Surgery, vol. 4, p. 204, 2016.

[120] R. Nyaguthie, "6 foods that can be contaminated with aflatoxins if not well stored," 2020, https://www.tuko.co.ke/ 324051-6-foods-contaminated-aflatoxins-stored.html.

[121] C. N. Menza, W. M. Muturi, and M. L. Kamau, "Oil contents and aflatoxin levels in peanut varieties produced in Busia and Kisii Central Districts, Kenya," Tropical Medicine \& Surgery, vol. 4 , no. 204 , pp. 1-6, 2016

[122] A. Seetha, W. Munthali, H. W. Msere et al., "Occurrence of aflatoxins and its management in diverse cropping systems of Central Tanzania," Mycotoxin Research, vol. 33, no. 4, pp. 323-331, 2017.

[123] A. U. Achidi, O. A. Ajayi, M. Bokanga, and B. Maziya-Dixon, "The use of cassava leaves as food in Africa," Ecology and Food Nutrition, vol. 44, pp. 423-435, 2005.

[124] J. A. Montagnac, C. R. Davis, and S. A. Tanumihardjo, "Nutritional value of cassava for use as a staple food and recent advances for improvement," Comprehensive Reviews in Food Science and Food Safety, vol. 8, no. 3, pp. 181-194, 2009. 
[125] A. P. Cardoso, E. Mirione, M. Ernesto et al., "Processing of cassava roots to remove cyanogens," Journal of Food Composition and Analysis, vol. 18, no. 5, pp. 451-460, 2005.

[126] P. Gacheru, G. Abong, M. Okoth, P. Lamuka, S. Shibairo, and C. Katama, "Cyanogenic content, aflatoxin level and quality of dried cassava chips and flour sold in Nairobi and Coastal regions of Kenya," Current Research in Nutrition and Food Science Journal, vol. 3, no. 3, pp. 197-206, 2015.

[127] M. Abdallah, R. Krska, and M. Sulyok, "Mycotoxin contamination in sugarcane grass and juice: first report on detection of multiple mycotoxins and exposure assessment for aflatoxins B1 and G1 in humans," Toxins, vol. 8, no. 11, p. 343, 2016.

[128] M. E. Alpert, M. S. R. Hutt, G. N. Wogan, and C. S. Davidson, "Association between aflatoxin content of food and hepatoma frequency in Uganda," Cancer, vol. 28, no. 1, pp. 253-260, 1971.

[129] I. Kagera, P. Kahenya, F. Mutua et al., "Status of aflatoxin contamination in cow milk produced in smallholder dairy farms in urban and peri-urban areas of Nairobi County: a case study of Kasarani sub county, Kenya," Infection Ecology \& Epidemiology, vol. 9, no. 1, Article ID 1547095, 2019.

[130] A. Sirma, D. Senerwa, J. Lindahl et al., "Aflatoxin M1 survey in dairy households in Kenya," in Proceedings of the Food Africa Midterm Seminar, Helsinki, Finland, June 2014.

[131] Y. Kirino, K. Makita, D. Grace et al., "Survey of informal milk retailers in Nairobi, Kenya and prevalence of aflatoxin M1 in marketed milk," African Journal of Food, Agriculture, Nutrition and Development, vol. 16, no. 3, pp. 11022-11038, 2016.

[132] G. Langat, M. Tetsuhiro, T. Gonoi, V. Matiru, and C. Bii, "Aflatoxin M1 contamination of milk and its products in Bomet County, Kenya," Advances in Microbiology, vol. 6, no. 7, pp. 528-536, 2016.

[133] D. Senerwa, A. J. Sirma, N. Mtimet et al., "Prevalence of aflatoxin in feeds and cow milk from five counties in Kenya," African Journal of Food, Agriculture, Nutrition and Development, vol. 16, no. 3, pp. 11004-11021, 2016.

[134] G. Anyango, F. Mutua, I. Kagera, P. Andang'O, D. Grace, and J. F. Lindahl, "A survey of aflatoxin M1 contamination in raw milk produced in urban and peri-urban areas of Kisumu County, Kenya," Infection Ecology \& Epidemiology, vol. 8, no. 1, Article ID 1547094, 2018.

[135] M. M. Kuboka, J. K. Imungi, L. Njue, F. Mutua, D. Grace, and J. F. Lindahl, "Occurrence of aflatoxin M1 in raw milk traded in peri-urban Nairobi, and the effect of boiling and fermentation," Infection Ecology \& Epidemiology, vol. 9, no. 1, Article ID 1625703, 2019.

[136] G. J. A. Speijers and M. H. M. Speijers, "Combined toxic effects of mycotoxins," Toxicology Letters, vol. 153, no. 1, pp. 91-98, 2004.

[137] C. J. Kedera, R. D. Plattner, and A. E. Desjardins, "Incidence of Fusarium spp. and levels of fumonisin B1 in maize in western Kenya," Applied Environmental Microbiology, vol. 65, pp. 41-44, 1998.

[138] S. K. Mbugua and J. K. Gathumbi, "The contamination of Kenyan lager beers with fusarium mycotoxins," Journal of Institute of Brewing, vol. 110, pp. 227-229, 2004.

[139] A. E. Alakonya, E. O. Monda, and S. Ajanga, "Fumorism B1 and aflatoxin B1 levels in Kenyan maize," Journal of Plant Pathology, vol. 91, no. 2, pp. 459-464, 2009.

[140] I. Rodrigues, J. Handl, and E. M. Binder, "Mycotoxin occurrence in commodities, feeds and feed ingredients sourced in the Middle East and Africa," Food Additives and Contaminants: Part B, vol. 4, no. 3, pp. 168-179, 2011.

[141] M. C. Kirui, A. E. Alakonya, K. K. Talam, G. Tohru, and C. C. Bii, "Total aflatoxin, fumonisin and deoxynivalenol contamination of busaa in Bomet County, Kenya," African Journal of Biotechnology, vol. 13, pp. 2675-2678, 2014.

[142] C. M. Makau, J. W. Matofari, P. S. Muliro, and B. O. Bebe, "Aflatoxin B1 and Deoxynivalenol contamination of dairy feeds and presence of aflatoxin M1 contamination in milk from smallholder dairy systems in Nakuru, Kenya," International Journal of Food Contamination, vol. 3, no. 1, 2016.

[143] N. K. Njeru, C. A. O. Midega, J. W. Muthomi, J. M. Wagacha, and Z. R. Khan, "Influence of socio-economic and agronomic factors on aflatoxin and fumonisin contamination of maize in western Kenya," Food Science \& Nutrition, vol. 7, no. 7, pp. 2291-2301, 2019.

[144] A. Stevens, C. Saunders, J. Spence et al., "Investigations into "diseases" of Turkey poults," Veterinary Record, vol. 72, pp. 627-628, 1960.

[145] M. Ozturk, "P53 mutation in hepatocellular carcinoma after aflatoxin exposure," Lancet (London, England), vol. 338, no. 8779, pp. 1356-1359, 1991.

[146] R. Jaetzold and H. Schmidt, Farm Management Handbook of Kenya. Natural Condition and Farm Management Information, Ministry of Agriculture and German Agricultural Team (GTZ), Nairobi, Kenya, 2009.

[147] L. N. Kirimi, T. S. Sitko, F. Jayne et al., A Farm Gate to Consumer Value Chain Analysis of Kenya's Maize Marketing System, Egerton University Working Paper Series, Njoro, Kenya, 2011.

[148] R. Bandyopadhyay, A. Ortega-Beltran, A. Akande et al., "Biological control of aflatoxins in Africa: current status and potential challenges in the face of climate change," World Mycotoxin Journal, vol. 9, no. 5, pp. 771-789, 2016.

[149] J. Milani, "Ecological conditions affecting mycotoxin production in cereals: a review," Veterinární Medicína, vol. 58, no. 8, pp. 405-411, 2013.

[150] N. W. Turner, S. Subrahmanyam, and S. A. Piletsky, "Analytical methods for determination of mycotoxins: a review," Analytica Chimica Acta, vol. 632, no. 2, pp. 168-180, 2009.

[151] T. B. Whitaker, "Detecting mycotoxins in agricultural commodities," Molecular Biotechnology, vol. 23, no. 1, pp. 61-72, 2003.

[152] M. Kamle, D. K. Mahato, S. Devi, K. E. Lee, S. G. Kang, and P. Kumar, "Fumonisins: impact on agriculture, food, and human health and their management strategies," Toxins, vol. 11, no. 6, p. 328, 2019.

[153] F. Berthiller, C. Crews, C. Dall'Asta et al., "Masked mycotoxins: a review," Molecular Nutrition \& Food Research, vol. 57, no. 1, pp. 165-186, 2013.

[154] V. Nagl, B. Woechtl, H. E. Schwartz-Zimmermann et al., "Metabolism of the masked mycotoxin deoxynivalenol-3glucoside in pigs," Toxicology Letters, vol. 229, no. 1, pp. 190-197, 2014.

[155] M. Gareis, J. Bauer, J. Thiem, G. Plank, S. Grabley, and B. Gedek, "Cleavage of zearalenone-glycoside, a "masked" mycotoxin, during digestion in swine," Journal of Veterinary Medicine, Series B, vol. 37, no. 1-10, pp. 236-240, 1990.

[156] N. Broekaert, M. Devreese, T. De Mil et al., "Oral bioavailability, hydrolysis, and comparative toxicokinetics of 3acetyldeoxynivalenol and 15-acetyldeoxynivalenol in broiler chickens and pigs," Journal of Agricultural and Food Chemistry, vol. 63, no. 39, pp. 8734-8742, 2015. 
[157] C. Dall'Asta, M. Mangia, F. Berthiller et al., "Difficulties in fumonisin determination: the issue of hidden fumonisins," Analytical and Bioanalytical Chemistry, vol. 395, pp. 13351345, 2009.

[158] A. Vidal, S. Marín, V. Sanchis, S. De Saeger, and M. De Boevre, "Hydrolysers of modified mycotoxins in maize: $\alpha$-Amylase and cellulase induce an underestimation of the total aflatoxin content," Food Chemistry, vol. 248, pp. 86-92, 2018.

[159] N. V. Beloglazova, M. De Boevre, I. Y. Goryacheva, S. Werbrouck, Y. Guo, and S. De Saeger, "Immunochemical approach for zearalenone-4-glucoside determination," Talanta, vol. 106, pp. 422-430, 2013.

[160] C. Dall'Asta, G. Galaverna, G. Aureli, A. Dossena, and R. Marchelli, "A LC/MS/MS method for the simultaneous quantification of free and masked fumonisins in maize and maize-based products," World Mycotoxin Journal, vol. 1, pp. 237-246, 2008.

[161] F. Tao, H. Yao, Z. Hruska, L. W. Burger, K. Rajasekaran, and D. Bhatnagar, "Recent development of optical methods in rapid and non-destructive detection of aflatoxin and fungal contamination in agricultural products," TrAC Trends in Analytical Chemistry, vol. 100, pp. 65-81, 2018.

[162] J. M. Castelino, M. N. Routledge, S. Wilson et al., “Aflatoxin exposure is inversely associated with IGF1 and IGFBP3 levels in vitro and in Kenyan schoolchildren," Molecular Nutrition \& Food Research, vol. 59, no. 3, pp. 574-581, 2015.

[163] O. Guguyu, "american companies jostle for aflatoxin test kits deal,” 2017, https://www.standardmedia.co.ke/business/ article/2001243799/american-companies-jostle-for-aflatoxintest-kits-deal.

[164] H. Yao, Z. Hruska, R. Kincaid, R. Brown, T. Cleveland, and D. Bhatnagar, "Correlation and classification of single kernel fluorescence hyperspectral data with aflatoxin concentration in corn kernels inoculated withAspergillus flavusspores," Food Additives \& Contaminants: Part A, vol. 27, no. 5, pp. 701-709, 2010.

[165] J. Boonen, S. V. Malysheva, L. Taevernier, J. Diana Di Mavungu, S. De Saeger, and B. De Spiegeleer, "Human skin penetration of selected model mycotoxins," Toxicology, vol. 301, no. 1-3, pp. 21-32, 2012.

[166] P. Larsson and H. Tjalve, "Intranasal instillation of Aflatoxin $\mathrm{B} 1$ in rats: bioactivation in the nasal mucosa and neuronal transport to the olfactory bulb," Toxicological Sciences, vol. 55, no. 2, pp. 383-391, 2000.

[167] L. K. Kamdem, I. Meineke, U. Gödtel-Armbrust, J. Brockmöller, and L. Wojnowski, "Dominant contribution of P450 3A4 to the hepatic carcinogenic activation of aflatoxin B1," Chemical Research in Toxicology, vol. 19, no. 4, pp. 577-586, 2006.

[168] T. Kamataki, H. Hashimoto, M. Shimoji et al., "Expression of CYP3A7, a human fetus-specific cytochrome P450, in cultured cells and in the hepatocytes of p53-knockout mice," Toxicology Letters, vol. 82-83, pp. 879-882, 1995.

[169] E. K. Kang'ethe, M. Gatwiri, A. J. Sirma et al., "Exposure of Kenyan population to aflatoxins in foods with special reference to Nandi and Makueni counties," Food Quality and Safety, vol. 1, no. 2, pp. 131-137, 2017.

[170] M. N. Routledge and Y. Y. Gong, "Developing biomarkers of human exposure to mycotoxins," in Determining Mycotoxins and Mycotoxigenic Fungi in Food and Feed, S. De Saeger, Ed., pp. 225-244, Woodhead Publishing, Cambridge, UK, 2011.

[171] P. L. Skipper, D. H. Hutchins, R. J. Turesky et al., "Carcinogen binding to serum-albumin," in Proceedings of the
American Association for Cancer Research, American Association for Cancer Research, Houston, TX, USA, February 1985.

[172] B. I. Agag, "Mycotoxins in foods and feeds: aflatoxins," Assiut University Bulletin for Environmental Researches, vol. 7, pp. 173-206, 2004.

[173] B. Chapot and C. P. Wild, "ELISA for quantification of AFalb adducts and their application to human exposure assessment," in Techniques in Diagnostic Pathology, M. Warhol, D. van Velzen, and G. R. Bullock, Eds., pp. 1-13, Academic Press, San Diego, CA, USA, 1991.

[174] G. Sabbioni, S. Ambs, G. N. Wogan, and J. D. Groopman, "The aflatoxin-lysine adduct quantified by high-performance liquid chromatography from human serum albumin samples," Carcinogenesis, vol. 11, no. 11, pp. 2063-2066, 1990.

[175] P. F. Scholl, L. McCoy, T. W. Kensler, and J. D. Groopman, "Quantitative analysis and chronic dosimetry of the aflatoxin B1 plasma albumin adduct lys-AFB1 in rats by isotope dilution mass spectrometry," Chemical Research in Toxicology, vol. 19, no. 1, pp. 44-49, 2006.

[176] C. A. Linsell, "Cancer incidence in Kenya 1957-63," British Journal of Cancer, vol. 21, no. 3, pp. 465-473, 1967.

[177] A. Ngindu, P. Kenya, D. Ocheng et al., "Outbreak of acute hepatitis caused by aflatoxin poisoning in Kenya," The Lancet, vol. 319, no. 8285, pp. 1346-1348, 1982.

[178] G. N. Marete, L. W. Kanja, J. M. Mbaria et al., "Effects of the use of good agricultural practices on aflatoxin levels in maize grown in Nandi County, Kenya," Sci, vol. 2, no. 2, p. 26, 2020.

[179] N. Nduti, G. Reid, M. Sumarah et al., "Weissella cibaria Nn20 isolated from fermented Kimere shows ability to sequester AFB1 invitro and ferment milk with good viscosity and phin comparison to yogurt," Food Science \& Nutrition Technology, vol. 3, no. 1, Article ID 000137, 2018.

[180] V. Hoffmann, K. Jones, and J. L. Leroy, "The impact of reducing dietary aflatoxin exposure on child linear growth: a cluster randomised controlled trial in Kenya," BMJ Global Health, vol. 3, no. 6, Article ID e000983, 2018.

[181] A. O. Awuor, E. Yard, J. H. Daniel et al., "Evaluation of the efficacy, acceptability and palatability of calcium montmorillonite clay used to reduce aflatoxin B1 dietary exposure in a crossover study in Kenya," Food Additives \& Contaminants: Part A, vol. 34, no. 1, pp. 93-102, 2017.

[182] N. Nduti, A. McMillan, S. Seney et al., "Investigating probiotic yoghurt to reduce an aflatoxin B1 biomarker among school children in Eastern Kenya: preliminary study," International Dairy Journal, vol. 63, pp. 124-129, 2016.

[183] C. C. Kirui, "Assessment of the traditional and improved processing methods in the reduction of aflatoxin levels in maize and maize products," MSc thesis, University of Nairobi, Nairobi, Kenya, 2016.

[184] E. E. Yard, J. H. Daniel, L. S. Lewis et al., "Human aflatoxin exposure in Kenya, 2007: a cross-sectional study," Food Additives \& Contaminants: Part $A$, vol. 30 , no. 7 , pp. 1322-1331, 2013.

[185] Y. Y. Gong, S. Wilson, J. K. Mwatha et al., "Aflatoxin exposure may contribute to chronic hepatomegaly in Kenyan school children," Environmental Health Perspectives, vol. 120 , no. 6, pp. 893-896, 2012.

[186] C. P. Wild, Y. Z. Jiang, G. Sabbioni, B. Chapot, and R. Montesano, "Evaluation of methods for quantitation of aflatoxin-albumin adducts and their application to human exposure assessment," Cancer Research, vol. 50, no. 2, pp. 245-251, 1990. 
[187] S. M. Maxwell, F. Apeagyei, H. R. De Vries, D. D. Mwanmut, and R. G. Hendrickse, "Aflatoxins in breast milk, neonatal cord blood and sera of pregnant women," Journal of Toxicology: Toxin Reviews, vol. 8, no. 1-2, pp. 19-29, 1989.

[188] H. Autrup, T. Seremet, J. Wakhisi, and A. Wasunna, "Aflatoxin exposure measured by urinary excretion of aflatoxin $\mathrm{B} 1$-guanine adduct and hepatitis $\mathrm{B}$ virus infection in areas with different liver cancer incidence in Kenya," Cancer Research, vol. 47, no. 13, pp. 3430-3433, 1987.

[189] S. H. Henry, T. Whitaker, I. Rabbani et al., Aflatoxin M1, JECFA 47, Food and Drug Administration, Washington, DC, USA, 2001.

[190] A. W. Onyango, O. Receveur, and S. A. Esrey, "The contribution of breastmilk to toddlers diet in Western Kenya," Bulletin of the World Health Organization, vol. 80, pp. 292-299, 2002.

[191] D. Githang'a and A. Awuor, “Acute aflatoxin exposure and impacts: the Kenyan example, and response towards outbreaks," in Proceedings of the PACA Meeting on Engaging the Health and Nutrition Sector in Aflatoxin Control in Africa, African Union, pp. 23-24, Addis Ababa, Ethiopia, March 2016.

[192] R. Echodu, H. Edema, G. M. Malinga et al., "Is nodding syndrome in Northern Uganda linked to consumption of mycotoxin contaminated food grains?" BMC Research Notes, vol. 11, no. 1, p. 678, 2018.

[193] R. Echodu, G. Maxwell Malinga, J. Moriku Kaducu, E. Ovuga, and G. Haesaert, "Prevalence of aflatoxin, ochratoxin and deoxynivalenol in cereal grains in Northern Uganda: implication for food safety and health," Toxicology Reports, vol. 6, pp. 1012-1017, 2019.

[194] A. W. Kigotho, "Fungal problems in Kenya," The Lancet, vol. 350, no. 9079, p. 718, 1997.

[195] G. Njagi, "Isolation of fungal agents from formulated and commercial feeds in three fish farms in humid tropical environments of Kenya," in Proceedings of the 5th Annual National Biosafety Conference, National Biosafety Authority, Nairobi, Kenya, 2016.

[196] A. Atukwase, A. N. Kaaya, and C. Muyanja, "Factors associated with Fumonisin contamination of maize in Uganda," Journal of the Science of Food and Agriculture, vol. 89, no. 14, pp. 2393-2398, 2009.

[197] B. A. Al-Jaal, M. Jaganjac, A. Barcaru, P. Horvatovich, and A. Latiff, "Aflatoxin, fumonisin, ochratoxin, zearalenone and deoxynivalenol biomarkers in human biological fluids: a systematic literature review, 2001-2018," Food and Chemical Toxicology, vol. 129, pp. 211-228, 2019.

[198] Y. Y. Gong, L. Torres-Sanchez, L. Lopez-Carrillo et al., "Association between tortilla consumption and human urinary fumonisin B1 levels in a Mexican population," Cancer Epidemiology Biomarkers \& Prevention, vol. 17, no. 3, pp. 688-694, 2008.

[199] P. C. Turner, V. J. Burley, J. A. Rothwell, K. L. M. White, J. E. Cade, and C. P. Wild, "Dietary wheat reduction decreases the level of urinary deoxynivalenol in UK adults," Journal of Exposure Science \& Environmental Epidemiology, vol. 18, no. 4, pp. 392-399, 2008.

[200] C. P. Shirima, M. E. Kimanya, M. N. Routledge et al., "A prospective study of growth and biomarkers of exposure to aflatoxin and fumonisin during early childhood in Tanzania," Environmental Health Perspectives, vol. 123, no. 2, pp. 173-178, 2015.

[201] C. Srey, M. E. Kimanya, M. N. Routledge, C. P. Shirima, and Y. Y. Gong, "Deoxynivalenol exposure assessment in young children in Tanzania," Molecular Nutrition \& Food Research, vol. 58, no. 7, pp. 1574-1580, 2014.

[202] S. Piekkola, P. C. Turner, M. Abdel-Hamid et al., "Characterisation of aflatoxin and deoxynivalenol exposure among pregnant Egyptian women," Food Additives \& Contaminants: Part A, vol. 29, no. 6, pp. 962-971, 2012.

[203] Y. Gong, A. Hounsa, S. Egal et al., "Postweaning exposure to aflatoxin results in impaired child growth: a longitudinal study in Benin, West Africa," Environmental Health Perspectives, vol. 112, no. 13, pp. 1334-1338, 2004.

[204] K. F. Cardwell and S. H. Henry, "Risk of exposure to and mitigation of effect of aflatoxin on human health: a West African example," Journal of Toxicology: Toxin Reviews, vol. 23, no. 2-3, pp. 217-247, 2004.

[205] T. Omara, A. K. Kiprop, R. C. Ramkat et al., "Medicinal plants used in traditional management of cancer in Uganda: a review of ethnobotanical surveys, phytochemistry, and anticancer studies," Evidence-Based Complementary and Alternative Medicine, vol. 2020, Article ID 3529081, 26 pages, 2020.

[206] WHO, WHO Child Growth Standards: Length/Height-forAge, Weight-for-Age, Weight-for-Length, Weight-for-Height and Body Mass Index-for-Age: Methods and Development, World Health Organization, Geneva, Switzerland, 2006.

[207] Y. Y. Gong, P. C. Turner, A. J. Hall, and C. P. Wild, "Aflatoxin exposure and impaired child growth in West Africa: an unexplored international public health burden?" in Mycotoxins Detection Methods, Management, Public Health and Agricultural Trade, J. F. Leslie, R. Banerjee, and A. Visconti, Eds., pp. 53-66, Centre for Agriculture and Bioscience International, Oxfordshire, UK, 2008.

[208] L. E. Smith, R. J. Stoltzfus, and A. Prendergast, "Food chain mycotoxin exposure, gut health, and impaired growth: a conceptual framework," Advances in Nutrition, vol. 3, no. 4, pp. 526-531, 2012.

[209] International Agency for Research on Cancer, "IARC monographs on the evaluation of carcinogenic risks to humans," Chemical Agents and Related Occupations, vol. 56, pp. 1-599, IARC, Lyon, France, 2012.

[210] R. G. Hendrickse, "Of sick turkeys, kwashiorkor, malaria, perinatal mortality, heroin addicts and food poisoning: research on the Influence of aflatoxins on child health in the tropics," Annals of Tropical Medicine \& Parasitology, vol. 91, no. 7, pp. 787-793, 1997.

[211] H. L. Mehl and P. J. Cotty, "Variation in competitive ability among isolates of Aspergillus flavus from different vegetative compatibility groups during maize infection," Phytopathology, vol. 100, no. 2, pp. 150-159, 2010.

[212] M. N. Okioma, "The 2004 and 2005 aflatoxin tragedies in Kenya-a case study," in Mycotoxins: Detection Methods, Management, Public Health and Agricultural Trade, J. F. Leslie, R. Bandyopadhyay, and A. Visconti, Eds., pp. 127-131, Cromwell Press, Trowbridge, UK, 2008.

[213] J. D. Groopman, L. G. Cain, T. W. Kensler, and C. C. Harris, "Aflatoxin exposure in human populations: measurements and relationship to cancer," CRC Critical Reviews in Toxicology, vol. 19, no. 2, pp. 113-145, 1988.

[214] O. Mwanda, C. Otieno, and E. Omonge, "Acute aflatoxicosis: case report,” East African Medical Journal, vol. 82, no. 6, pp. 320-324, 2005.

[215] K. A. V. R. Krishnamachari, V. Nagarajan, R. Bhat, and T. B. G. Tilak, "Hepatitis due to aflatoxicosis," The Lancet, vol. 305, no. 7915, pp. 1061-1063, 1975. 
[216] B. N. Tandon, L. Krishnamurthy, A. Koshy et al., "Study of an epidemic of jaundice, presumably due to toxic hepatitis, in Northwest India," Gastroenterology, vol. 72, pp. 488-494, 1977.

[217] J. I. Pitt, “An introduction to mycotoxins, food and agriculture organization, Rome, Italy," in Mycotoxin Prevention and Control in Food Grains:, R. L. Semple, A. S. Frio, P. A. Hicks, and J. V. Lozare, Eds., Food and Agriculture Organization, Rome, Italy, 1989.

[218] A. Serck-Hanssen, "Aflatoxin-induced fatal hepatitis?" Archives of Environmental Health: An International Journal, vol. 20, no. 6, pp. 729-731, 1970.

[219] A. Kamala, C. Shirima, B. Jani et al., "Outbreak of an acute aflatoxicosis in Tanzania during 2016," World Mycotoxin Journal, vol. 11, no. 3, pp. 311-320, 2018.

[220] E. K. Kang'ethe, H. Korhonen, K. A. Marimba et al., "Management and mitigation of health risks associated with the occurrence of mycotoxins along the maize value chain in two counties in Kenya," Food Quality \& Safety, vol. 1, no. 4, pp. 268-274, 2017.

[221] Centers for Disease Control and Prevention (CDC), "Outbreak of aflatoxin poisoning: eastern and central provinces, Kenya, January-July 2004," Morbidity and Mortality Weekly Report, vol. 53, no. 34, pp. 790-793, 2004.

[222] R. C. Shank, N. Bhamarapravati, J. E. Gordon, G. N. Wogan, and B. Subhamani, "Dietary aflatoxins and human liver cancer. IV. Incidence of primary liver cancer in two municipal populations of Thailand," Food and Cosmetics Toxicology, vol. 10, no. 2, pp. 171-179, 1972.

[223] F. G. Peers and C. A. Linsell, "Dietary aflatoxins and human primary liver cancer," Annales de la Nutrition et de L'alimentation, vol. 31, no. 4-6, pp. 1005-1017, 1977.

[224] G. N. Wogan, "Dietary factors and special epidemiological situations of liver cancer in Thailand and Africa," Cancer Research, vol. 35, no. 11, pp. 3499-3502, 1975.

[225] N. D. McGlashan, "Primary liver cancer and food-based toxins. A Swaziland review," Ecology of Disease, vol. 1, no. 1, pp. 37-44, 1982.

[226] J. R. Barrett, "Liver cancer and aflatoxin: new information from the Kenyan outbreak," Environmental Health Perspectives, vol. 113, no. 12, pp. A837-A838, 2005.

[227] B. Kucukcakan and Z. Hayrulai-Musliu, "Challenging role of dietary aflatoxin B1 exposure and Hepatitis B infection on risk of hepatocellular carcinoma," Open Access Macedonian Journal of Medical Sciences, vol. 3, no. 2, pp. 363-369, 2015.

[228] S. Marin, A. J. Ramos, G. Cano-Sancho, and V. Sanchis, "Mycotoxins: occurrence, toxicology, and exposure assessment," Food and Chemical Toxicology, vol. 60, pp. 218-237, 2013.

[229] A. Petruzziello, "Epidemiology of hepatitis B virus (HBV) and hepatitis $\mathrm{C}$ virus (HCV) related hepatocellular carcinoma," The Open Virology Journal, vol. 12, no. 1, pp. 26-32, 2018.

[230] C. P. Wild and Y. Y. Gong, "Mycotoxins and human disease: a largely ignored global health issue," Carcinogenesis, vol. 31, no. 1, pp. 71-82, 2010.

[231] A. Magnussen and M. A. Parsi, "Aflatoxins, hepatocellular carcinoma and public health," World Journal of Gastroenterology, vol. 19, no. 10, pp. 1508-1512, 2013.

[232] International Food Policy Research Institute, "Aflatoxins finding solutions for improved food safety," in Focus 20, L. Unnevehr and D. Grace, Eds., pp. 1-62, International Food Policy Research Institute, Washington, DC, USA, 2013.
[233] J. Atehnkeng and C. Mutegi, Management of Aflatoxins in Maize and Groundnuts in Kenya: A Farmers' Training Manual, IITA, Ibadan, Nigeria, 2018.

[234] Kenya Bureau of Standards (KEBS), Kenya Standard KSEAS 2: 2017. Maize Grains Specifications, KEBS, Nairobi, Kenya, 2018.

[235] E. Stronger, "EAGC," 2018, http://eagc.org/wp-content/ uploads/2018/01/EAGC_@10_Milestone.pdf.

[236] J. W. Muthomi, B. K. Mureithi, G. N. Chemining, J. K. Gathumbi, and E. W. Mutitu, "Aspergillus and aflatoxin B1 contamination of maize and maize products from eastern and North Rift regions of Kenya," in Proceedings of the 12th KARI Biennial Conference, pp. 344-352, Nairobi, Kenya, November 2010.

[237] J. H. Lewis, L. W. Redwood, Y. A. Kieszak et al., "Comprehensive assessment of maize aflatoxin levels in eastern Kenya," Environmental Health Perspectives, vol. 119, no. 12, p. $1795,2011$.

[238] J. Onsongo, "Outbreak of aflatoxin poisoning in Kenya," IDS Bulletin, vol. 5, pp. 3-4, 2004.

[239] H. Njapau and P. J. C. Probst, "Outbreak of an acute aflatoxicosis in Kenya in 2004: identification of the causal agent," Applied Environmental Microbiology, vol. 73, pp. 2762-2764, 2007.

[240] International Maize and Wheat Improvement Center (CIMMYT), "United nations development programme (UNDP), and the United States agency for international development (USAID)," in Proceedings of the Workshop El Batan, Mexico: Aflatoxins in MaizeCIMMYT, Mexico City, Mexico, April 1986.

[241] Food and Agriculture Organization of the United Nations (FAO), Aflatoxin in Kenya, FAO, Rome, Italy, 1988, http:// agris.fao.org/aos/records/QY870004888.

[242] N. Muraguri, L. C. Omulkoola, G. M. Kenji, and G. A. Condier, "A survey of mycotoxins in human and animal foods: Part 1," East African Medical Journal, vol. 58, no. 7, pp. 484-488, 1981.

[243] C. K. Mutegi, The extent of aflatoxin and aspergillus section flavi, Penicillium spp and Rhizopus spp contamination of peanuts from households in western Kenya and the causative factors of contamination, $\mathrm{PhD}$ thesis, University of KwaZulu, KwaZulu-Natal, South Africa, 2010.

[244] A. Wacoo, I. Mukisa, R. Meeme et al., "Probiotic enrichment and reduction of aflatoxins in a traditional african maizebased fermented food," Nutrients, vol. 11, no. 2, p. 265, 2019.

[245] S. Byakika, I. M. Mukisa, A. P. Wacoo, R. Kort, Y. B. Byaruhanga, and C. Muyanja, "Potential application of lactic acid starters in the reduction of aflatoxin contamination in fermented sorghum-millet beverages," International Journal of Food Contamination, vol. 6, no. 1, 2019.

[246] R. L. Brown, D. Bhatnagar, T. E. Cleveland, Z. Chen, and A. Menkir, "Development of maize host resistance to aflatoxigenic fungi,", in Aflatoxins: Recent Advances and Future Prospects, M. R. Mehdi, Ed., InTech Open, Rijeka, Croatia, 2013.

[247] L. Ranasinghe, B. Jayawardena, and K. Abeywickrama, "Fungicidal activity of essential oils of Cinnamomum zeylanicum (L.) and Syzygium aromaticum (L.) Merr et L.M.Perry against crown rot and anthracnose pathogens isolated from banana," Letters in Applied Microbiology, vol. 35, no. 3, pp. 208-211, 2002.

[248] J. Ssekandi, "Identification of suitable genes for RNAi silencing of Aflatoxigenic Aspergillus flavus isolated from 
groundnuts in Uganda," MSc thesis, Makerere University, Kampala,Uganda, 2018.

[249] Y. Raruang, O. Omolehin, D. Hu et al., "Host induced gene silencing targeting Aspergillus flavus aflM reduced aflatoxin contamination in transgenic maize under field conditions," Frontiers in Microbiology, vol. 11, no. 754, 2020.

[250] K. Hell, P. Fandohan, R. Bandyopadhyay et al., "Pre- and post-harvest management of AF in maize,", in Mycotoxins: Detection Methods, Management, Public Health and Agricultural Trade, J. F. Leslie, R. Bandyopadhyay, and A. Visconti, Eds., CABI Publishing, Wallingford, UK, 2008.

[251] P. Fandohan, D. Zoumenou, D. J. Hounhouigan, W. F. O. Marasas, M. J. Wingfield, and K. Hell, "Fate of aflatoxins and fumonisins during the processing of maize into food products in Benin," International Journal of Food Microbiology, vol. 98, no. 3, pp. 249-259, 2005.

[252] D. L. Park, "Effect of processing on aflatoxin," in Mycotoxins and Food Safety. Advances in Experimental Medicine and Biology, J. W. DeVries and L. S. Jackson, Eds., vol. 504,Springer, Boston, MA, USA, 2002.

[253] P. Turner, A. Sylla, Y. Gong et al., "Reduction in exposure to carcinogenic aflatoxins by postharvest intervention measures in West Africa: a community-based intervention study," The Lancet, vol. 365, no. 9475, pp. 1950-1956, 2005.

[254] C. B. N'dede, C. M. Jolly, S. D. Vodouhe, and P. E. Jolly, "Economic risks of AF contamination in marketing of peanut in Benin," Economics Research International, vol. 2012, Article ID 230638, 12 pages, 2012.

[255] T. Omara, S. Karungi, R. Kalukusu et al., "Mercuric pollution of surface water, superficial sediments, Nile tilapia (Oreochromis nilotica Linnaeus 1758 [Cichlidae]) and yams (Dioscorea alata) in auriferous areas of Namukombe stream, Syanyonja, Busia, Uganda," PeerJ, vol. 7, 31 pages, Article ID e7179, 2019.

[256] A. O. Makokha, R. K. Oniang'o, S. M. Njoroge, and O. K. Kamar, "Effect of traditional fermentation and malting on phytic acid and mineral availability from sorghum (sorghum bicolor) and finger millet (eleusine coracana) grain varieties grown in Kenya," Food and Nutrition Bulletin, vol. 23, no. 3, pp. 241-245, 2002.

[257] P. J. Muindi, S. Thomke, and R. Ekman, "Effect of magadi soda treatment on the tannin content and in vitro nutritive value of sorghum grains," Journal of Science of Food and Agriculture, vol. 32, pp. 25-34, 2006.

[258] G. Avantaggiato, F. Quaranta, E. Desiderio, and A. Visconti, "Fumonisin contamination of maize hybrids visibly damaged by Sesamia," Journal of the Science of Food and Agriculture, vol. 83, no. 1, pp. 13-18, 2003.

[259] G. P. Munkvold, "Cultural and genetic approaches to managing mycotoxins in maize," Annual Review of Phytopathology, vol. 41, no. 1, pp. 99-116, 2003.

[260] T. Omara, K. F. Kateeba, B. Musau et al., "Bioinsecticidal activity of eucalyptol and 1R-alpha-pinene rich acetonic oils of Eucalyptus saligna on Sitophilus zeamais Motschulsky, 1855 (Coleoptera: Curculionidae)," Journal of Health and Environmental Research, vol. 4, no. 4, pp. 153-160, 2018.

[261] J. M. Kirima, M. Okuta, and T. Omara, "Chemical composition of essential oils from Pinus caribaea Morelet needles," French-Ukrainian Journal of Chemistry, vol. 8, no. 1, pp. 142-148, 2020.

[262] S. A. Bankole, "Effect of essential oils from two Nigerian medicinal plants (Azadirachta indica and Morinda lucida) on growth and aflatoxin B1 production in maize grain by a toxigenic Aspergillus flavus," Letters in Applied Microbiology, vol. 24, no. 3, pp. 190-192, 1997.

[263] G. O. Adegoke, H. Iwahashi, Y. Komatsu, K. Obuchi, and Y. Iwahashi, "Inhibition of food spoilage yeasts and aflatoxigenic moulds by monoterpenes of the spice Aframomum danielli," Flavour and Fragrance Journal, vol. 15, no. 3, pp. 147-150, 2000.

[264] H. K. Abbas, C. Accinelli, and W. T. Shier, "Biological control of aflatoxin contamination in U.S. crops and the use of bioplastic formulations of Aspergillus flavus biocontrol strains to optimize application strategies," Journal of Agricultural and Food Chemistry, vol. 65, no. 33, pp. 7081-7087, 2017.

[265] J. W. Dorner, "Biological control of aflatoxin contamination in corn using a nontoxigenic strain of Aspergillus flavus," Journal of Food Protection, vol. 72, no. 4, pp. 801-804, 2009.

[266] J. W. Dorner, "Biological control of aflatoxin contamination," in Aflatoxin and Food Safety, H. K. Abbas, Ed., pp. 333-352, Taylor \& Francis, New York, NY, USA, 2005.

[267] V. Anjaiah, R. P. Thakur, and N. Koedam, "Evaluation of bacteria and Trichoderma for biocontrol of pre-harvest seed infection by Aspergillus flavus in groundnut," Biocontrol Science and Technology, vol. 16, no. 4, pp. 431-436, 2006.

[268] G. N. Harini, N. Kumar, B. Hameeda et al., "Biological management of Aspergillus flavus infection and aflatoxin contamination in groundnut by Streptomyces sp. CDA 19," in Proceedings of the 64th Indian Phytopathological Society Annual Meeting and National Symposium, p. 133, Hyderabad, India, December 2011.

[269] A. N. Kaaya and W. Kyamuhangire, "The effect of storage time and agroecological zone on mould incidence and aflatoxin contamination of maize from traders in Uganda," International Journal of Food Microbiology, vol. 110, no. 3, pp. 217-223, 2006.

[270] P. E. Sumner and D. Lee, Reducing Aflatoxinin Corn during Harvest and Storage, The University of Georgia, Georgia College of Agriculture and Environmental Sciences, Atlanta, GA, USA, 2012.

[271] A. Méndez-Albores, J. Veles-Medina, E. Urbina-Álvarez, F. Martínez-Bustos, and E. Moreno-Martínez, "Effect of citric acid on aflatoxin degradation and on functional and textural properties of extruded sorghum," Animal Feed Science and Technology, vol. 150, no. 3-4, pp. 316-329, 2009.

[272] B. Kabak and A. D. W. Dobson, "Biological strategies to counteract the effects of mycotoxins," Journal of Food Protection, vol. 72, no. 9, pp. 2006-2016, 2009.

[273] T. W. Kensler, N. E. Davidson, P. A. Egner et al., "Mechanisms of chemoprotection against aflatoxin-induced hepatocarcinogenesis by oltipraz,", in Anticarcinogenesis and Radiation Protection 2, O. F. Nygaard and A. C. Upton, Eds., vol. 1, pp. 315-322, Springer, Boston, MA, USA, 1991. 